\title{
SECTOR

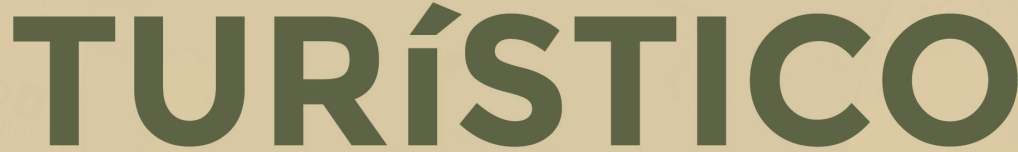 \\ y su Impacto en la Economía Ecuatoriana
}

Autores:

Eduardo Germán Zurita Moreano María Eugenia Borja Lombeida

\section{TOPAXI LATA}

María Gabriela González Bảuitista Diego Enrique Pinilla Rodríguez

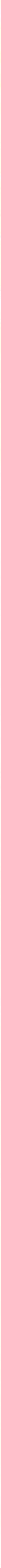




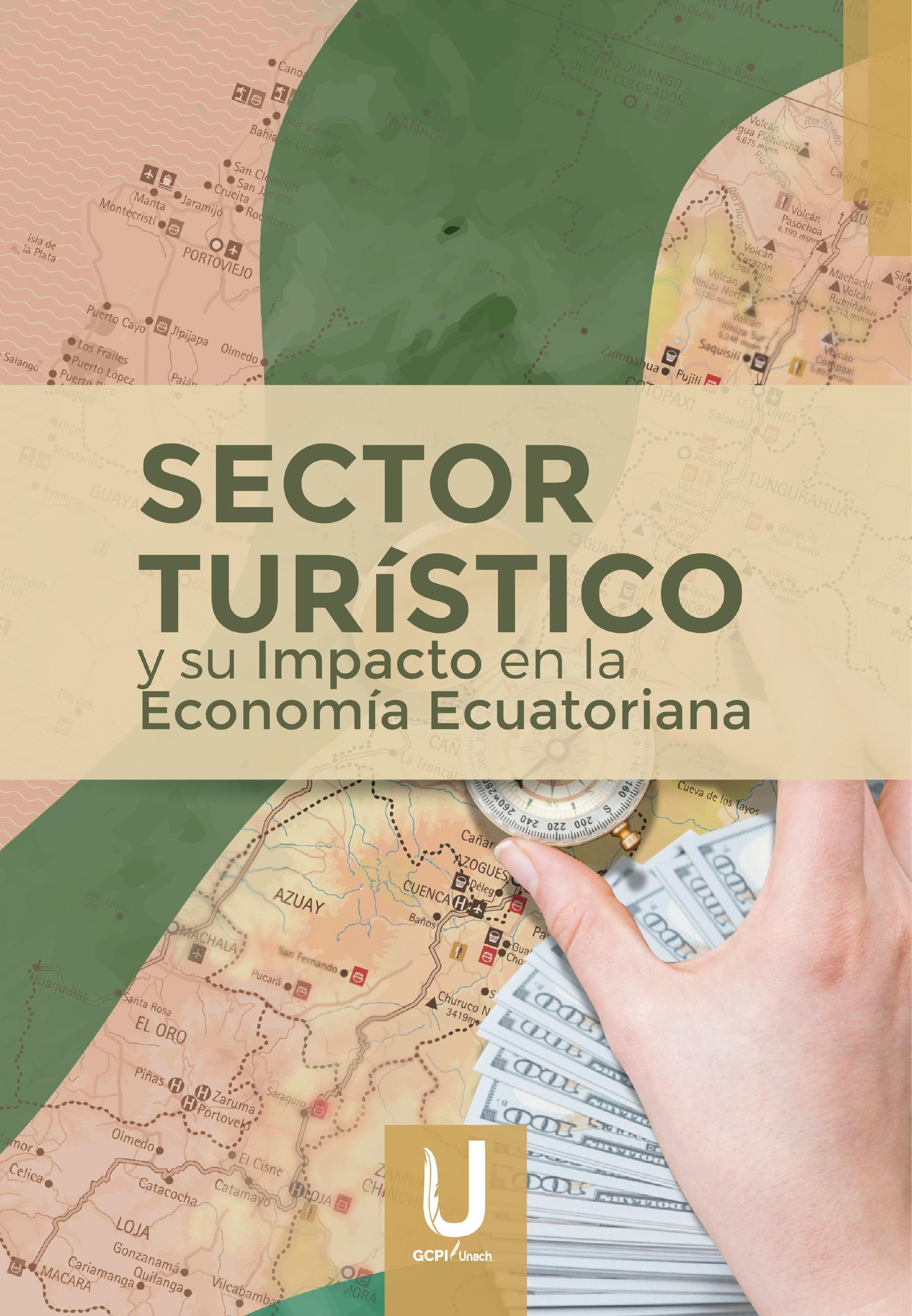


\section{UNIVERSIDAD NACIONAL DE CHIMBORAZO}

Rector

Ph.D. Gonzalo Nicolay Samaniego Erazo

Vicerrectora Académica

Ph.D. Lida Mercedes Barba Maggi

Vicerrector de Investigación, Vinculación y Posgrado

Ph.D. Luis Alberto Tuaza Castro

Vicerrectora Administrativa

Mag. Yolanda Elizabeth Salazar Granizo

\section{Comité Editorial:}

Presidente: Ph.D. Luis Alberto Tuaza Castro

Secretaria: Mg. Sandra Zúñiga Donoso

Miembros: Ph.D. Anita Ríos Rivera; Ph.D. Víctor Julio García; Ph.D. Gerardo Nieves Loja; Ph.D. Carmen Varguillas Carmona; Ph.D. Cristhy Jiménez Granizo; Ph.D. Pablo Djabayan Djibeyan; Ph.D. Magda Cejas Martínez; Ph.D. Cristian Naranjo Navas

Título de la obra: SECTOR TURÍSTICO y su Impacto en la Economía Ecuatoriana

Nombres de los autores: Eduardo Germán Zurita Moreano; María Gabriela González Bautista; María Eugenia Borja Lombeida; Diego Enrique Pinilla Rodríguez; Riobamba, 2021

(CUNACH, 2021

Ediciones: Universidad Nacional de Chimborazo (UNACH)

Diseño Gráfico: UNACH

Primera edición - abril 2021

Riobamba - Ecuador

Derechos reservados. Se prohíbe la reproducción de esta obra por cualquier medio impreso, reprográfico o electrónico. El contenido, uso de fotografías, gráficos, cuadros, tablas, y referencias es de exclusiva responsabilidad de los autores.

ISBN: $978-9942-835-38-3$

ISBN: 978 - $9942-835$ - 39 - 0 (DIGITAL)

Registro Biblioteca Nacional

Depósito legal: 059850

DOI: https: / / doi.org/10.37135/u.editorial.05.28

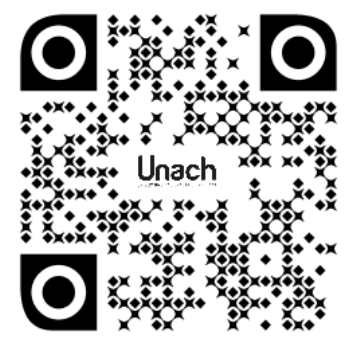




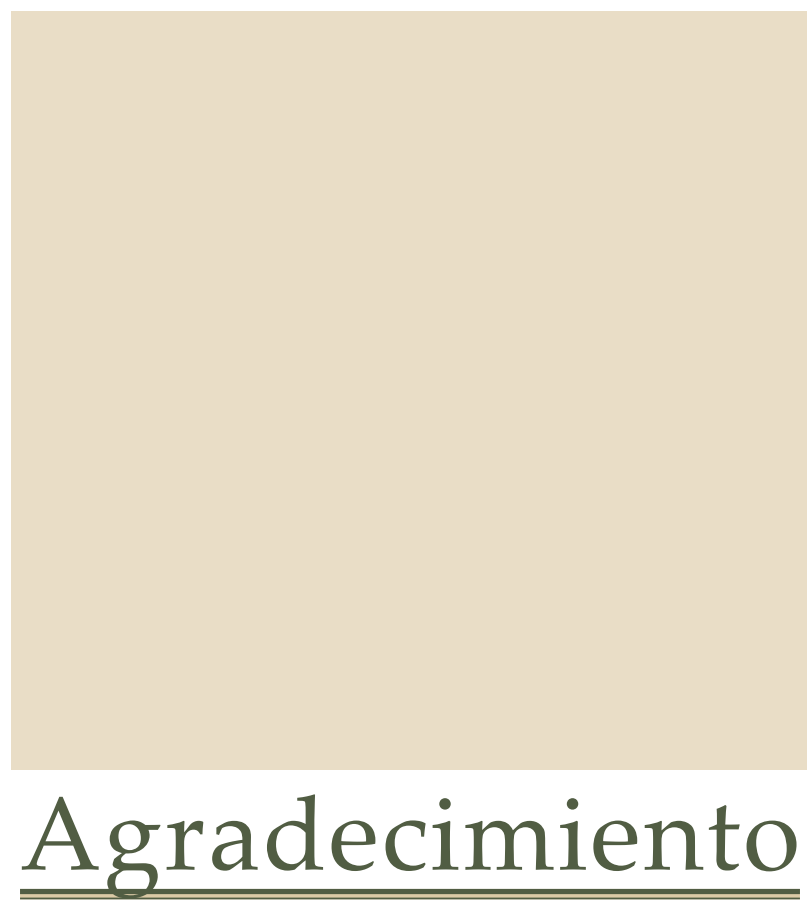

Un agradecimiento especial para los estudiantes quienes colaboraron en el levantamiento de encuestas:

Balarezo Marcelo Alexander

Casanova Guerrero Jordi Adalberto

Jiménez Shinin Ana Karen

Zumba Morales Edinson Omar

Zurita Gallo Alison Dennise 
Índice de contenidos

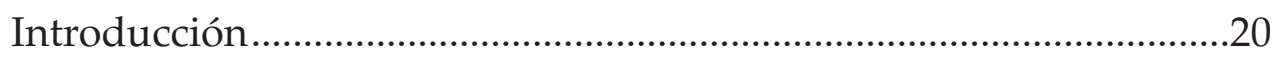

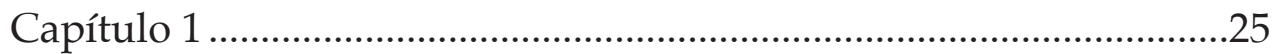

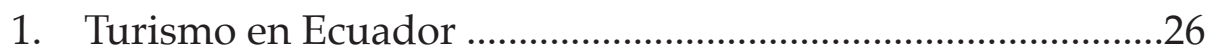

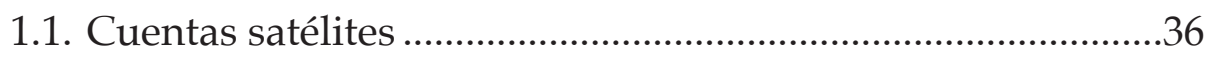

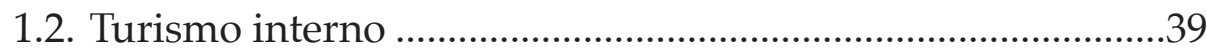

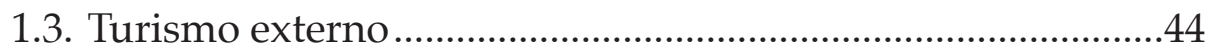

1.4. Turismo y empleo ..................................................................4

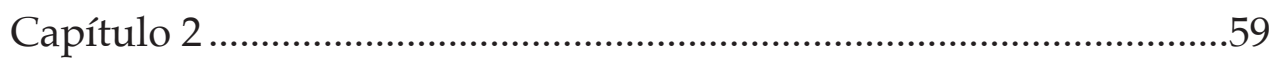

2. El sector turístico y su impacto en el crecimiento económico (modelo econométrico)..............................................................60

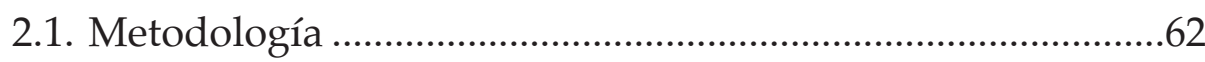

2.2. Población y muestra..................................................................62

2.3. Modelo econométrico .................................................................63

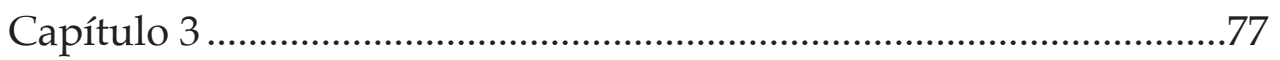

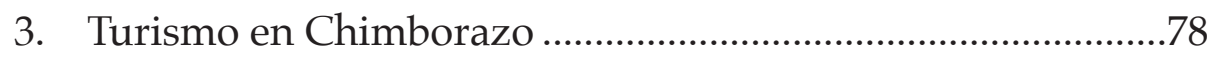

3.1. Importancia del turismo en Chimborazo..................................79

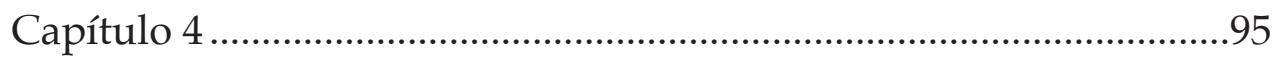

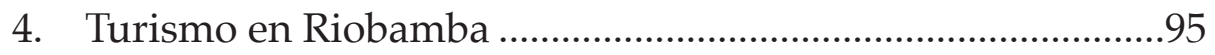

4.1. Caracterización del sector turístico en la ciudad de

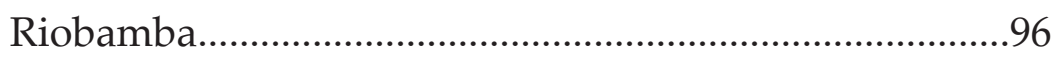

4.1.1. Establecimientos registrados ..........................................99

4.1.2. Establecimientos de alimentos y bebidas .......................100

4.1.3. Lugares turísticos de Riobamba.......................................100

4.1.4. Transporte turístico .........................................................102

4.1.5. Operación e intermediación turística de Riobamba.....102

4.1.6. Distancia de Riobamba a otras ciudades del Ecuador.107

4.2. Perfil turístico de la ciudad de Riobamba ......................108 


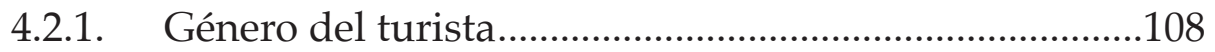

4.2.2. Arribo de visitantes a Riobamba....................................109

4.2.3. Meses de afluencia turística..........................................110

4.2.4. Tiempo de estadía ...........................................................112

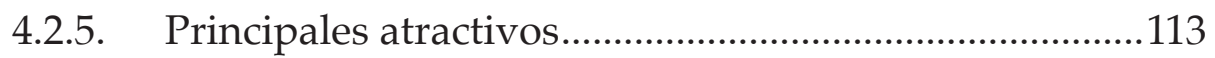

4.2.6. Canales informativos para visitar Riobamba.................118

4.2.7. Motivo de la visita.......................................................120

4.2.8. Servicios que utilizaron los turistas.................................121

4.2.9. Gasto promedio ..............................................................122

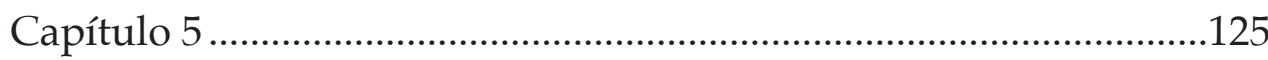

5. Eficiencia del sector hotelero de la ciudad de Riobamba....126

5.1. Elementos teóricos................................................................126

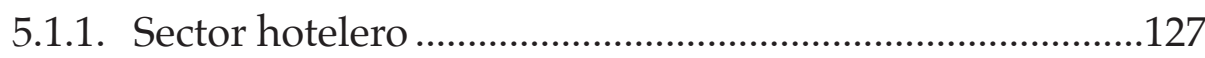

5.1.2. Sector hotelero de la ciudad de Riobamba .......................127

5.1.3. Eficiencia............................................................................130

5.1.4. Base legal del sector hotelero.............................................130

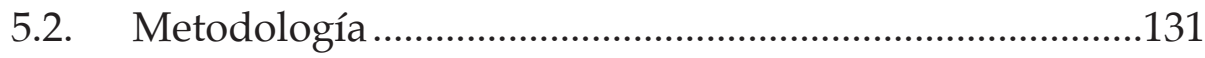

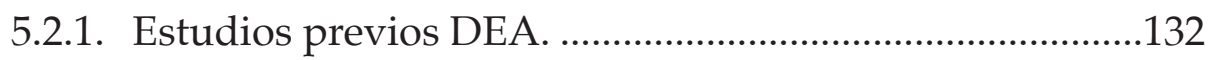

5.2.2. Análisis envolvente de datos (DEA) ................................133

5.2.2.1. Modificaciones del modelo básico.................................134

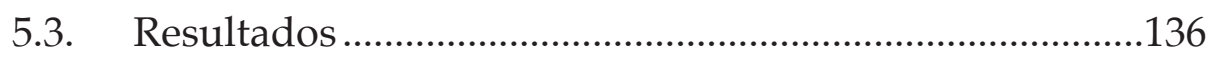

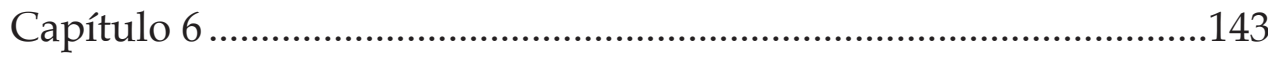

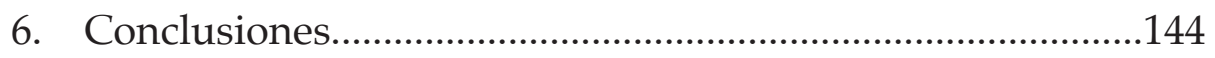

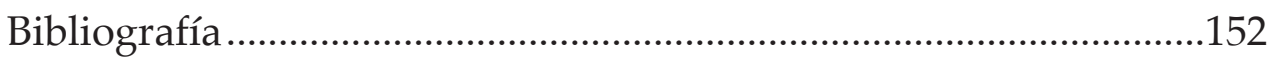


Índice de gráficos

Gráfico 1. Producto interno bruto de Ecuador en millones de dólares, periodo 2000-2018.

Gráfico 2. Producto interno bruto del sector turístico en millones de dólares, periodo 2000-2018. .30

Gráfico 3. Participación del PIB turístico en el PIB total, periodo 2000-2018.

Gráfico 4. Empleo total generado en el Ecuador, periodo 20002018. .32

Gráfico 5. Empleo generado por el sector turístico, periodo 20002018.

Gráfico 6. Participación del empleo turístico con respecto al empleo total, periodo 2000-2018.

Gráfico 7. Formación Bruta de Capital Fijo en millones de dólares, periodo 2000-2018. 35

Gráfico 8. Valor agregado bruto directo turístico, periodo 20072016. .36

Gráfico 9. Gasto turístico receptor y su participación con respecto al PIB, periodo 2007-2016. .37

Gráfico 10. Grado de apertura turística en porcentajes, periodo 2007-2016. 38

Gráfico 11. Grado de cobertura turística, periodo 2007-2016..... 39

Gráfico 12. Destinos más comunes preferidos por los turistas año 2016.

Gráfico 13. Porcentaje de ocupación en feriados 2019. 43

Gráfico 14. Gasto promedio en dólares en feriados 2019 44 
Gráfico 15. Origen de turistas que más visitan Ecuador periodo 2012-2016.

Gráfico 16. Personal ocupado en los establecimientos registrados en el Ministerio de Turismo periodo 2003-2007...... 49

Gráfico 17. Personal ocupado en los establecimientos registrados en el Ministerio de Turismo Años: 2011-2015. 50

Gráfico 18. PIB turístico con relación al PIB nacional (\%) 20072018.

Gráfico 19. Balanza turística \% del PIB periodo I 2010-III 2019. 53

Gráfico 20. Ingresos y egresos por turismo en millones de dólares 2012-2018. .56

Gráfico 21. Llegadas de extranjeros miles de personas .57

Gráfico 22. PIB, Ingresos turismo (I), FBKF en miles de dólares constantes e índice de tipo de cambio real (T) año base 1994. Periodo I.2007-II.2019 66

Gráfico 23. Log PIB, Log I y Log T periodo I.2007-II.2019 ......... 67

Gráfico 24. Función Impulso-Respuesta ....................................... 75

Gráfico 25. Descomposición de la varianza...................................76

Gráfico 26. Valor Agregado Bruto (VAB), sector alojamiento y servicios de comida de la provincia de Chimborazo, en miles de dólares

Gráfico 27. Porcentaje de participación del número de agencias de viajes registradas en el Ministerio de Turismo con respecto a la zona 3, año 2016. 82

Gráfico 28. Trasporte turístico terrestre registrado en el Ministerio de Turismo zona 3, año 2016. 
Gráfico 29. Cantidad de establecimientos de hospedaje clasificados por categorías y registrados en el Ministerio de Turismo en la provincia de Chimborazo año, 2016.

Gráfico 30. Cantidad de habitaciones, clasificadas por categorías y registrados en el Ministerio de Turismo en la provincia de Chimborazo año, 2016........................ 86

Gráfico 31. Recaudación Tributaria Hoteles y Restaurantes en la zona 3, periodo 2012-2016.

Gráfico 32. Porcentaje de participación del personal ocupado en los establecimientos registrados en el Ministerio de Turismo con respecto a la zona 3, año 2016.

Gráfico 33. Visitas de turistas extranjeros y nacionales a la provincia de Chimborazo, año 2016.

Gráfico 34. Arribo de visitantes a la reserva faunística Chimborazo periodo 2012-2016. 94

Gráfico 35. Arribo de visitantes a Riobamba..... 109

Gráfico 36. Procedencia de turistas extranjeros a la ciudad de Riobamba periodo 2017-2019.

Gráfico 37. Procedencia Turística Nacional 2017-2019 117

Gráfico 38. Canales informativos para visitar Riobamba 118

Gráfico 39. Gasto promedio diario de los turistas en la ciudad de Riobamba año 2018 (rangos)

Gráfico 40. Ingreso medio por ocupación habitacional (mensual dólares). 136

Gráfico 41. Gasto medio en servicios públicos y mantenimiento (mensual - dólares). 137 
Gráfico 42. Empleados permanentes y ocasionales (media simple)

Gráfico 43. Servicios que presta (media simple) 139

Gráfico 44. Años de funcionamiento (media simple). 140

Gráfico 45. Nivel de eficiencia del sector hotelero, ocupación habitacional, media simple. .141

Gráfico 46. Frontera de eficiencia del sector hotelero en la ciudad de Riobamba (por categorías). 
Índice de tablas

Tabla 1. Destinos más comunes preferidos por los turistas año 2016

Tabla 2. Origen de turistas que más visitan Ecuador según país de origen periodo 2012-2016. 46

Tabla 3. Personal ocupado en los establecimientos registrados en el Ministerio de Turismo Años: 2003-2007.

Tabla 4. Personal ocupado en los establecimientos registrados en el Ministerio de Turismo Años: 2011-2015

Tabla 5. PIB turístico con relación al PIB nacional 2007-2018...51

Tabla 6. Ingresos y egresos por turismo en millones de dólares periodo 2012-2018 .55

Tabla 7. Llegadas de extranjeros (miles de personas) ...............56

Tabla 8. Prueba de autocorrelación de las variables. .................68

Tabla 9. Prueba de estacionariedad de las variables.................69

Tabla 10. Orden de integración de las variables (test de raíz unitaria con 1era diferencia)

Tabla 11. Regresión mediante mínimos cuadrados. Variable Dependiente: LOGPIB 70

Tabla 12. Regresión mediante mínimos cuadrados de variables significativas al 5\% Variable Dependiente: LOGPIB.. 71

Tabla 13. Prueba de rango de cointegración - Johansen Test .....72

Tabla 14. Ecuación de Cointegración variable dependiente $\mathrm{D}$ (LNPIB) .73

Tabla 15. Wald Test, relación de equilibrio a corto plazo. .74 
Tabla 16. Valor Agregado Bruto (VAB), sector alojamiento y servicios de comida de la provincia de Chimborazo, en Miles de Dólares.

Tabla 17. Agencias de viajes registradas en el Ministerio de Turismo, zona 3, año 2016.

Tabla 18. Trasporte turístico terrestre registrado en el Ministerio de Turismo zona 3, año 2016.

Tabla 19. Capacidad de establecimientos de alojamiento registrados por categorías en la provincia de Chimborazo, año 2016. .84

Tabla 20. Recaudación tributaria hoteles y restaurantes en la zona 3, periodo 2012-2016 .86

Tabla 21. Personal ocupado en los establecimientos registrados en el Ministerio de Turismo en la zona 3, año 2016... 88

Tabla 22. Arribo de visitantes a la reserva faunística Chimborazo periodo 2012-2016 93

Tabla 23. Establecimientos registrados en Chimborazo. 99

Tabla 24. Distribución por clase y categoría de establecimientos de alojamiento registrados del cantón Riobamba 2018. .99

Tabla 25. Establecimientos de alimentos y bebidas registrados del cantón Riobamba, año 2018. 100

Tabla 26. Servicio de transporte turístico en el cantón Riobamba periodo 2015-2018 102

Tabla 27. Operación e intermediación turística de Riobamba periodo 2015-2018 
Tabla 28. Distancia de Riobamba a

otras ciudades del Ecuador.

Tabla 29. Género del turista que visita a la ciudad de Riobamba (porcentaje)

Tabla 30. Arribo de visitantes a Riobamba. 109

Tabla 31. Meses de afluencia turística de la ciudad de Riobamba periodo 2016-2019 (número de personas). 111

Tabla 32. Tiempo de estadía (número de turistas) periodo 20162019.

Tabla 33. Principales atractivos (porcentaje). 114

Tabla 34. Procedencia de turistas extranjeros a la ciudad de Riobamba periodo 2017-2019. 114

Tabla 35. Procedencia Turística Nacional 2017-2019 (porcentaje) 116

Tabla 36. Canales informativos para visitar Riobamba 118

Tabla 37. Tipo de turismo (porcentual).

Tabla 38. Motivo de la visita (porcentaje) 120

Tabla 39. Servicios que utilizaron los turistas (porcentaje) 


\section{Prólogo}


En el presente libro se hace un análisis del sector turístico del Ecuador, esta actividad es una de las de mayor impulso en el ámbito económico que ha recibido en las últimas décadas, esto se evidencia por el nivel de empleo e ingresos que ha generado, siendo fundamental para el desarrollo y el bienestar de los países. En los últimos 20 años el turismo ha tenido un crecimiento sostenido por lo que es importante determinar el impacto de este sector en la actividad económica, para lo cual se detallan distintas características e indicadores que hacen referencia al desarrollo de esta industria. Este libro está dividido en cuatro capítulos:

El capítulo uno, hace referencia al turismo de Ecuador, donde se analizan los distintos indicadores los cuales son de gran importancia para el desarrollo turístico y económico de la sociedad y el país. Este capítulo se divide en tres partes, primero está el turismo interno; el cual se refiere al consumo turístico realizado por residentes del mismo país. Seguido del turismo externo, el mismo que hace referencia al consumo de turistas extranjeros en el Ecuador, por último, la relación existente entre turismo y empleo que se refiere al trabajo generado por el sector turístico en el país.

El capítulo dos denominado, el sector turístico y su impacto en el crecimiento económico, explica que el incremento de los factores, como mano de obra y capital, y a los avances tecnológicos incide en el crecimiento económico de los países, en ese sentido, la función de producción establece un vínculo cuantitativo entre los factores y el nivel de producto, es decir más factores representa más producción. Para el estudio se utilizaron como variables representativas del crecimiento económico y del sector turístico al producto interno bruto (PIB) en términos reales, la formación bruta de capital fijo (FBKF), el ingreso de divisas generado por el sector turístico en términos constantes y el índice de tipo de 
cambio real. Como resultados se obtiene que las variables tienen el signo esperado, es decir, hay una relación positiva indicando que tanto los ingresos del sector turístico como la formación bruta de capital fijo afectan de manera importante en el crecimiento económico. El coeficiente de los ingresos del sector turístico tiene un valor de 0.193070 , lo que indica que por cada uno por ciento que aumente, el PIB aumentará en 0,19\% y el valor del coeficiente de la formación bruta de capital fijo es de 0.281245 , lo que representa que por cada uno por ciento que aumente, la economía crecerá en $0,28 \%$. Además, un shock en el ingreso de divisas del sector turístico contribuiría en $1,57 \%$ en el corto plazo y $6,78 \%$ a la fluctuación del PIB en el largo plazo, mientras que la FBKF contribuiría en 34,50\% en el corto plazo y en $23,67 \%$ a largo plazo.

En el capítulo tres, se realiza un análisis del turismo en la provincia de Chimborazo, se estudia su importancia a partir de un análisis del valor agregado bruto del sector alojamiento y servicios de comida de la provincia de Chimborazo, en donde se evidencia una tendencia irregular, marcando una mayor tasa de crecimiento en el año 2012. A partir de un análisis de la recaudación tributaria de hoteles y restaurantes en la zona 3, se observa que la provincia de Tungurahua presenta una mayor recaudación tributaria, la cual en promedio durante el periodo de estudio ha recaudado \$ 3.111.879 dólares debido a la gran acogida turística que tiene esta provincia especialmente la cuidad de Baños. Por otra parte, la provincia de Chimborazo presenta una recaudación tributaria promedio durante el periodo de estudio de $\$ 1.492 .098$, siendo el lugar más representativo el cantón Alausí donde, que a partir de la reconstrucción de línea férrea Alausí-Nariz del Diablo, la industria turística ha crecido considerablemente. 
Finalmente, en lo que tiene que ver con el personal ocupado en los establecimientos registrados en el Ministerio de Turismo zona 3, año 2016, se observa que Tungurahua tiene una participación de $55 \%$, por lo tanto, se generan empleos ya sean ocasionales o permanentes dependiendo la época de año. La provincia de Chimborazo presenta una participación del $22 \%$ en la generación de empleo ocupando el segundo lugar, debido al incremento en inversión de hoteles, restaurantes entre otras, lo cual se traduce en generación de empleo ya sea directa o indirectamente.

El capítulo cuatro se concentran en el turismo de Riobamba, que al igual que el capítulo anterior toma en cuenta los lugares de visitas más frecuentes, la procedencia de los visitantes o turistas que llegan a la ciudad de Riobamba, los motivos de turistas al igual que los principales tipos de turismos que se realizan en la zona.

El capítulo cinco se centra en la eficiencia del sector hotelero en la ciudad de Riobamba para el año 2018, para lo cual se utilizan variables como el ingreso medio por ocupación habitacional, gasto medio en servicios públicos y mantenimiento, empleados permanentes y ocasionales, servicios que presta, entre otros. Utilizando un análisis envolvente de datos, con el fin de calcular $y$ verificar el nivel de eficiencia con el que trabajan los diferentes hoteles de la ciudad. Referente a la frontera de eficiencia del sector hotelero en la ciudad de Riobamba (por categorías). Tan solo un hotel de categoría tres es eficiente, un hotel de categoría dos es eficiente, mientras que los hoteles de la categoría uno, apenas se acerca a la frontera de eficiencia técnica; mientras tanto los demás hoteles de la muestra que fueron seleccionados para el estudio no cumplen con el nivel de eficiencia adecuado. 


\section{Introducción}


El turismo hace referencia a los viajes que realizan las personas a distintos lugares de destino por un periodo consecutivo inferior a un año con fines de ocio, por negocios y otros. Ecuador paraíso turístico, en los últimos años ha sido un punto estratégico para turistas nacionales y extranjeros. A través de la difusión del patrimonio cultural e inmaterial único del país, que promueve la generación de ingresos.

El turismo en el Ecuador inició su desarrollo moderno en los años 50 del siglo pasado, pero principalmente en las tres últimas décadas empieza a consolidarse como actividad económica y socio-cultural de gran importancia (Ruiz \& Solis, 2007). Para este sector es importante crear normas o leyes, incluso incentivos que lo promuevan y al mismo tiempo salvaguarden los lugares visitados por los turistas.

En el Ecuador, durante el año 2017 se registraron 1'617.914 llegadas internacionales al país, lo que representa un crecimiento del 14\% con relación al año 2016, que dejaron ingresos por $\$ 1,204.5$ millones. Con lo que se puede ver que el turismo cada vez tiene un crecimiento mayor, con lo que su impacto en la economía es cada vez más importante (Coordinación General de Estadística e Investigación del MINTUR, 2018).

Desde el año 2007 al 2011 el gasto de turismo aportó con el 1.1\% del PIB, sin embargo, a partir del año 2012 su aporte al PIB ha ido incrementando, siendo el año 2015 la cifra más alta alcanzada con un $1.6 \%$. Esto evidencia un crecimiento estable del turismo que ha promovido el desarrollo económico en los últimos años (Chávez, Fernandez, \& Gómez, 2017).

En el 2018 la balanza turística creció con relación al 2017 y reflejó un saldo positivo de los ingresos frente a los egresos con 
un saldo de 1.332,3 millones de dólares, según los datos obtenidos de la Balanza de Pagos del Banco Central del Ecuador. Además para el mismo año, el turismo aportó a la economía ecuatoriana con 2.398,1 millones de dólares, lo que lo mantiene como la tercera fuente de ingresos no petroleros, después del banano y el camarón (Ministerio de Turismo, 2019).

Siendo este sector no solo generador de divisas que llegan desde el extranjero sino también una gran fuente de empleo para los locales de muchas ciudades que son destinos turísticos reconocidos tanto por nacionales como por extranjeros, estas fuentes de empleo según el Ministerio de Turismo (2018) son principalmente de hoteles y restaurantes. Así, mientras para el año 2018 se generaron 480.000 empleos directos y 112.000 indirectos, en el año 2019 la cifra aumentó a 512.000 trabajos directos, y 189.000 indirectos, lo que se obtiene que el empleo que brinda el turismo con respecto del total empleos en los últimos años, oscila entre 5\% y $6.5 \%$ siendo este último el porcentaje del año 2018.

El turismo es considerado como una actividad generadora de empleo y redistribución de la riqueza, se dice que por cada empleo generado por el turismo se crean entre 3 y 6 puestos de empleo indirecto (Ministerio de Turismo, 2019).

El Ecuador es considerado un país mega diverso, esto es debido a que tiene más biodiversidad por $\mathrm{km} 2$ que cualquier otro en el mundo, en el Ecuador existe el 11\% de la biodiversidad total del planeta, estudios demuestran que en una sola parroquia del Ecuador existen 450 especies de aves, que es más de lo que tiene Estados Unidos y Europa juntos (Ruiz \& Solis, 2007).

La Región Costa del Ecuador es uno de los destinos más visitados por extranjeros y locales, debido a sus diversos lugares 
turísticos, como son sus playas, parques recreativos tanto artificiales como naturales, etc., ejemplos de estos son playas de Montañita, el Parque Nacional Machalilla, el Malecón 2000 de Guayaquil en la provincia del Guayas y otros. Según el Ministerio de Turismo (2019), la mayoría de turistas arriban desde países como Venezuela, Estados Unidos y Colombia, con un 31,6\%, 18,1\% y $14,3 \%$ respectivamente del total de turistas que visitan el Ecuador datos del primer semestre del 2019.

Del total de turistas extranjeros que visitan el Ecuador se tiene que la Región Costa recibe alrededor de un $47 \%$ de ellos, principalmente la provincia del Guayas. Esto se debe a que en esta zona no solo se puede disfrutar del ecoturismo sino también del turismo gastronómico por su diversidad gastronómica, del turismo cultural por sus museos y lugares culturales que preservan la historia de los ancestros de la zona entre otros (Zambrano, Navas, Olivero, Cabezas, \& Franco, 2019). 



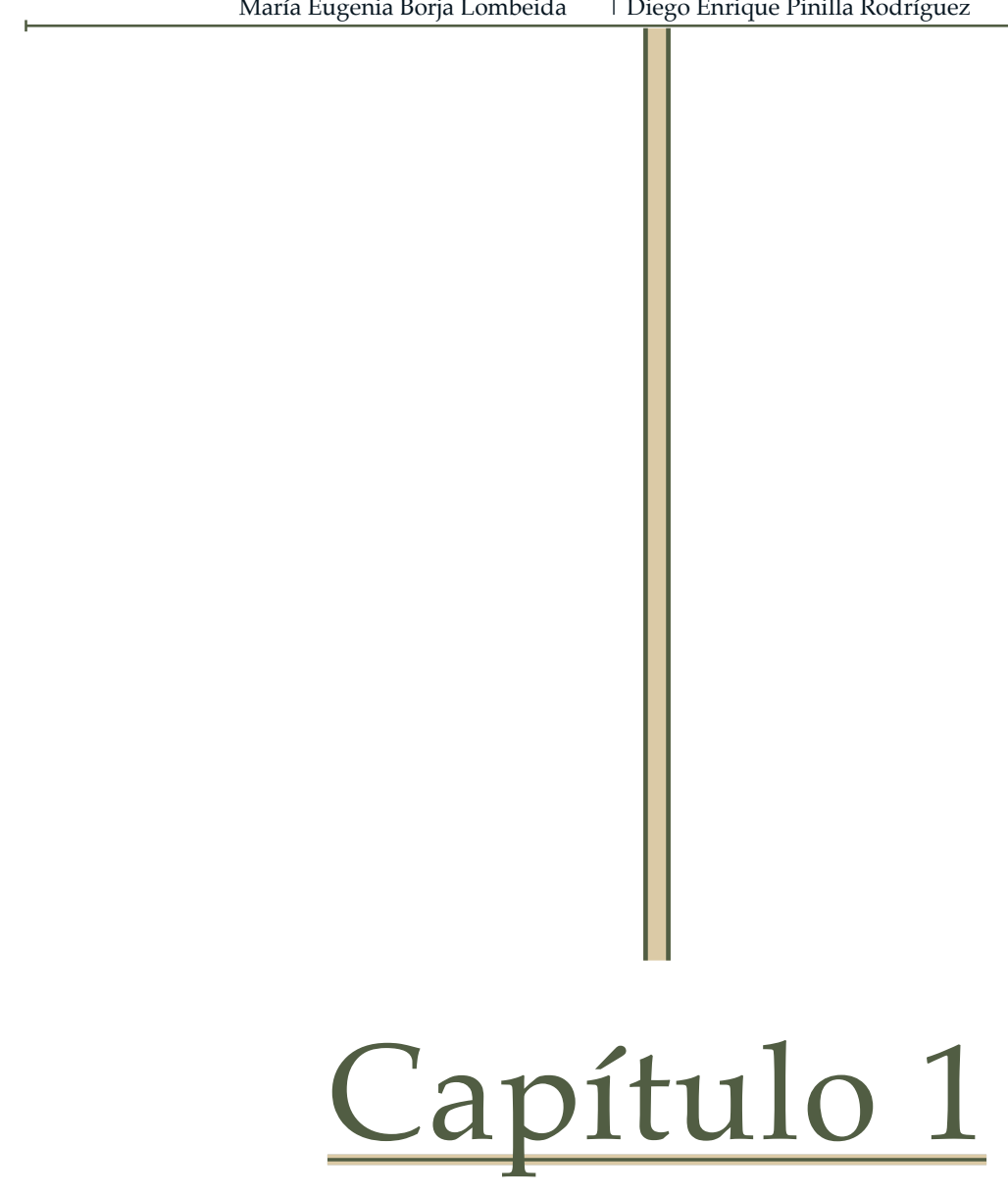

Turismo en Ecuador 


\section{Turismo en Ecuador}

Aun cuando no se puede hablar propiamente de turismo, a partir de los siglos XVII y XVIII, ya existieron algunos desplazamientos importantes hacia el territorio ecuatoriano. Los primeros viajeros en visitar el Ecuador a pesar de la falta de vías de acceso y la dificultad para movilizarse, fueron principalmente científicos y aventureros de Europa. Ellos vinieron principalmente por motivos de estudios y para encontrar diversos recursos o minerales preciosos para enriquecerse. A mediados del siglo XIX el Estado toma interés por el mejoramiento de caminos y carreteras, es así que, en la presidencia de García Moreno, da inicio al transporte rural y la construcción del ferrocarril que se paralizó por casi 20 años para luego ser retomada por Eloy Alfaro (Tapia, 2010).

Entrando al siglo $\mathrm{XX}$, cuando el turismo empieza a tomar forma e interés. Para el año 1903 ya se contaba con más de una forma para transportarse, la vía férrea desde Guayaquil hasta Guamote y un servicio privado de carruajes y caballos con destino a Quito.

Según Tapia (2010), para el año 1903, el problema de alojamiento también mejoró en cierto grado, varias ciudades del país ya contaban con servicio de hospedaje y aunque no eran de lujo, brindaban confort y un espacio adecuado para descansar. Según se registra, en Guayaquil el "Gran Hotel Victoria" y "Hotel Paris"; en Quito el "Hotel de Francia"; en Riobamba la "Posada California"; en Ambato el "Hotel de Francia"; y, en Latacunga "Hotel I del Siglo $X X^{\prime \prime}$.

En el año de 1947, debido a la iniciativa de 3 empresarios ecuatorianos (Cecil Terán, Eduardo Proaño y Pablo Burbano de Lara), inician las primeras operaciones turísticas como tal y se crea la primera agencia de viajes "Ecuadorian Tours". La agencia inició 
como intermediaria de los mayoristas de Estados Unidos y países europeos. En 1974 se crea la Corporación Ecuatoriana de TurismoCETURIS, en abril del mismo año de expide la Ley de Fomento Turístico con lo que se crea la Dirección Nacional de TurismoDITURIS. Los estudios realizados por estas entidades y con apoyo de la Organización de Estados Americanos (OEA) dejaron como aporte la identificación de 8 zonas, 10 núcleos y 9 corredores turísticos los mismos que fueron escogidos para desarrollar el Plan Nacional de Desarrollo (1980 - 1984) (Tapia, 2010).

El 28 de enero de 1997 se promulga según registro oficial 118 la Ley Especial de Desarrollo Turístico. El 25 de septiembre de 1997 se expide la Ley Especial de Descentralización del Estado y Participación Social, con lo cual el Ministerio de Turismo inicia el desarrolloy puesta en marcha de una estrategia de descentralización, para conjuntamente con los gobiernos seccionales dinamizar la actividad turística (Tapia, 2010).

En la actualidad el turismo cuenta con un marco regulatorio que ampara tanto a los turistas extranjeros como nacionales, y protegen a los recursos naturales, forestales y áreas protegidas que son consideradas como patrimonio cultural.

El Ministerio de Turismo (2018), dice que en los cuatro mundos que constituyen el territorio ecuatoriano se puede apreciar una enorme cantidad de opciones; desde la cálida costa bañada por el Pacífico, los valles templados de la cordillera de los Andes, la selva Amazónica repleta de diversidad y las maravillosas Islas Galápagos.

Las diferentes regiones de nuestro país cuentan con atractivos turísticos muy marcados por las condiciones propias de cada una de estas, la región que abordaremos es la Región Sierra, Aye 
(2018), dice que esta región está considerada como una de las más importante de Ecuador. Su gran diversidad cultural y natural abarca páramos, bosques nublados, lagos, volcanes activos, termas, mercados indígenas, ciudades, pueblos y haciendas coloniales. Dichos atractivos permiten que dentro del país se puedan desarrollar variedad de turismos, enfocados a las necesidades y expectativas del turista.

En ese sentido se muestra que existen diferentes tipos de turismo, los que tienen sus propias características y objetivos, a continuación, indicamos los principales.

\section{Cuadro 1: Tipos de turismo.}

\begin{tabular}{|c|c|}
\hline Tipo de turismos & Descripción \\
\hline $\begin{array}{l}\text { Turismo de } \\
\text { sol y playa } \\
\text { (tradicional) }\end{array}$ & $\begin{array}{l}\text { Es la máxima expresión del turismo de masas, ya que las playas } \\
\text { en los diferentes destinos turísticos, son las más visitadas por } \\
\text { los turistas. }\end{array}$ \\
\hline $\begin{array}{l}\text { Turismo de } \\
\text { Reuniones }\end{array}$ & $\begin{array}{l}\text { Consiste en el desplazamiento de viajeros fuera de su entorno } \\
\text { habitual con funes lucrativos. }\end{array}$ \\
\hline Turismo LGBT & $\begin{array}{l}\text { Es un sector en constante crecimiento que aporta más demanda } \\
\text { económica que el turismo convencional, con destinos deonde } \\
\text { no haya discriminación, se respete la diversidad y haya } \\
\text { espacios abiertos con seguridad para su integridad }\end{array}$ \\
\hline $\begin{array}{l}\text { Turismo de } \\
\text { Naturaleza }\end{array}$ & $\begin{array}{l}\text { Busca delimitar un tipo de viajero más exigente, cuya principal } \\
\text { motivación es estar en contacto con la naturaleza. Este tipo de } \\
\text { turismo tiene } 3 \text { grandes derivaciones: El ecoturismo, el turismo } \\
\text { de aventura, y el turismo rural o comunitario. }\end{array}$ \\
\hline $\begin{array}{l}\text { Turismo de } \\
\text { Salud }\end{array}$ & Incluye al turismo médico y al turismo de bienestar. \\
\hline Turismo cultural & $\begin{array}{l}\text { Dentro del turismo cultural, los más conocidos son el turismo } \\
\text { religioso y el gastronómico. }\end{array}$ \\
\hline
\end{tabular}

Fuente: Entorno Turístico (2018).

Elaboración: Autores. 
Para analizar la influencia del turismo en el país se toma en cuenta diversas variables, las cuales son consideradas primordiales en la economía tanto nacional como sectorial, ya que el turismo tiene gran influencia sobre estas.

A continuación, se realiza un análisis de la evolución del producto interno bruto (PIB) de Ecuador, el PIB del sector turístico, participación del PIB turístico en el PIB total, empleo total generado en el Ecuador, empleo generado por el sector turístico, participación del empleo turístico con respecto al empleo total, y la formación bruta de capital fijo.

Gráfico 1. Producto interno bruto de Ecuador en millones de dólares, periodo 20002018.

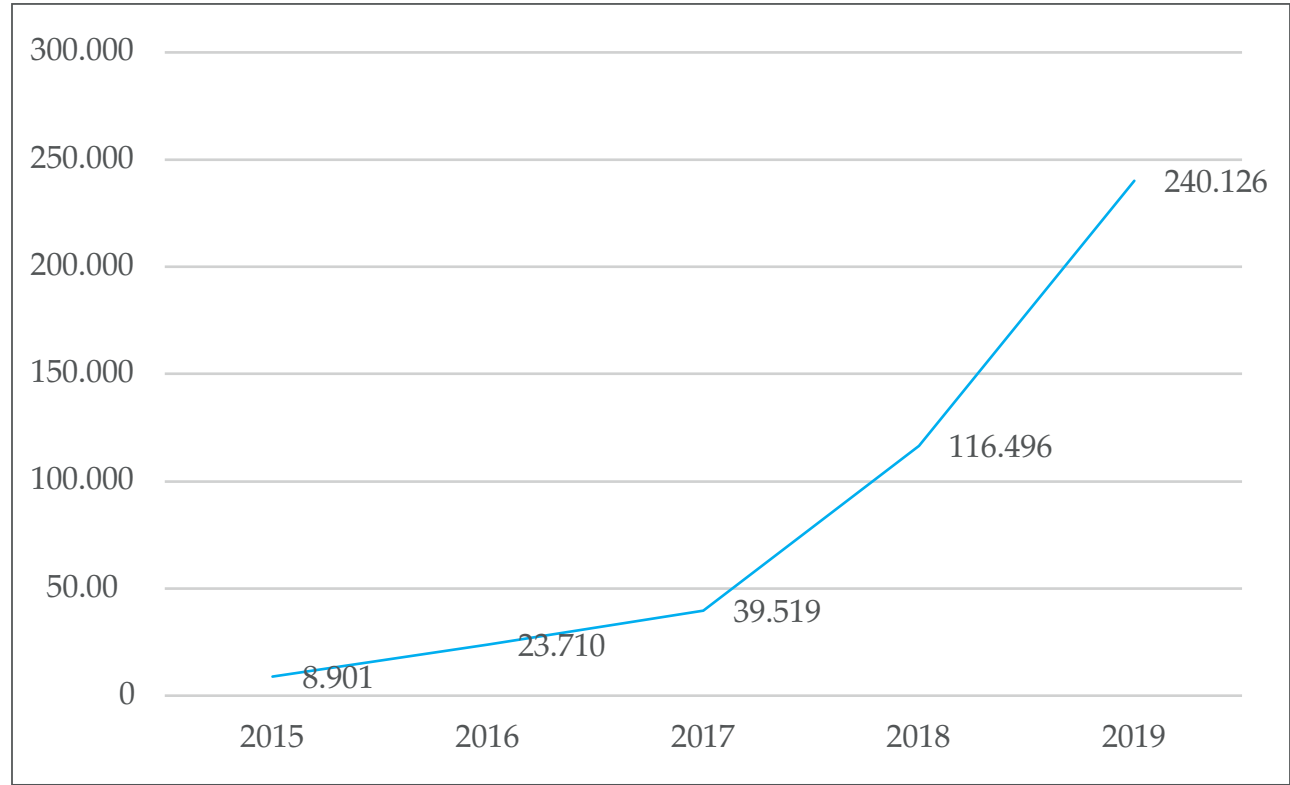

Fuente: Banco Mundial (2018).

Elaboración: Autores.

En el gráfico 1, correspondiente a la evolución del producto interno bruto a precios constantes expresado en millones de dólares, periodo 2000-2018, donde se observa que, durante el periodo de estudio, presenta una tendencia creciente, debido a 
que la economía ecuatoriana se ha logrado consolidar en gran medida, apoyada fuertemente por condiciones externas favorables tales como el precio del petróleo, las remesas en divisas por parte de los emigrantes y como fue en su momento, la construcción del Oleoducto de Crudos Pesados. A partir del año 2008 su crecimiento se debió a los ingresos petroleros y un aumento muy significativo del gasto público.

Gráfico 2. Producto interno bruto del sector turístico en millones de dólares, periodo 2000-2018.

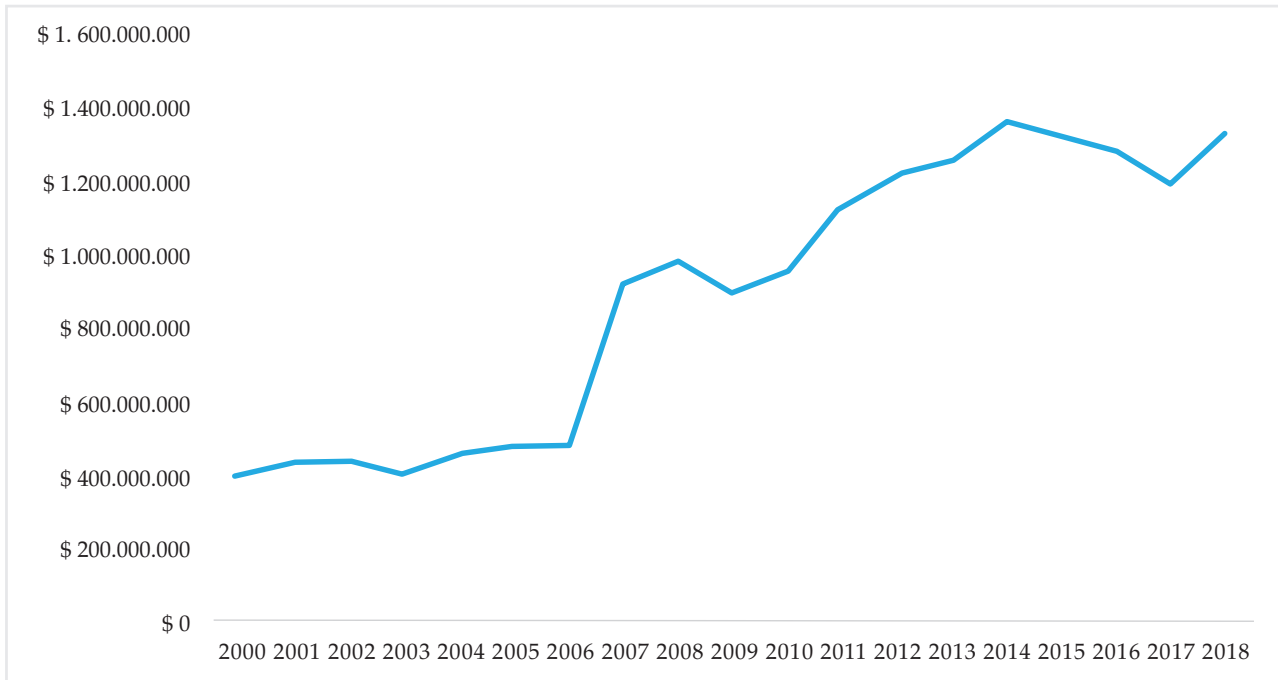

Fuente: Caguana y Janeta (2016), Ministerio de Turismo (2018).

Elaboración: Autores.

En el gráfico 2, correspondiente a la evolución del producto interno bruto del sector turístico a precios constantes expresado en millones de dólares para el periodo 2000-2018. Se observa que a partir del año 2007 se presenta una mayor tasa de crecimiento debido al aumento de llegada de turistas extranjeros (Altamirano, 2016). En ese contexto este crecimiento fue acompañado por una importante inversión privada y pública realizada en este sector (El Universo, 2009). 
Posterior a la crisis financiera del año 2009. El Ministerio de Turismo mediante el proyecto "Plan de Marketing Turístico del Ecuador (PIMTE) aportó al Plan Nacional del Buen Vivir, orientando de esa forma sus acciones para posesionar al Ecuador como un destino turístico de marca referencial a nivel mundial (Ministerio de Turismo, 2014, pág. 12). Por lo tanto, el PIB del sector turístico durante el periodo de estudio ha presentado un crecimiento promedio de $8.38 \%$.

Gráfico 3. Participación del PIB turístico en el PIB total, periodo 2000-2018.

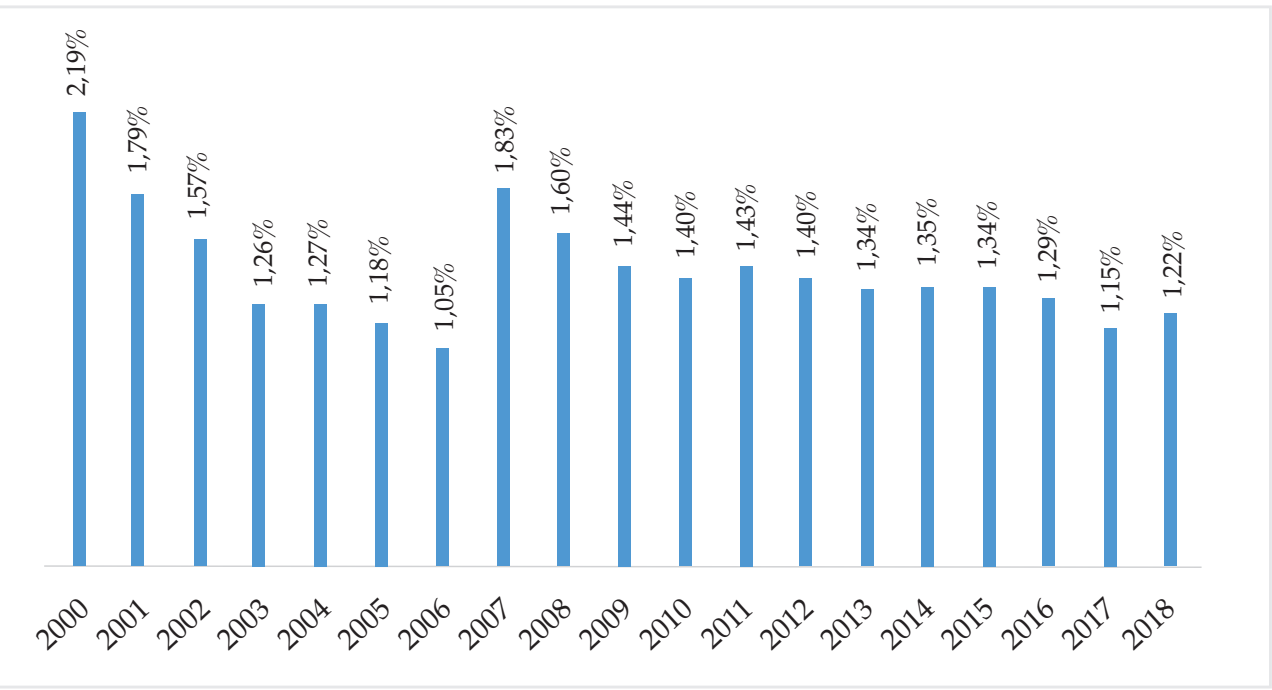

Fuente: Banco Mundial (2018) .

Elaboración: Autores.

En el gráfico 3, correspondiente a la participación del sector turístico con respecto al producto interno bruto (PIB) a precios constantes en el periodo 2000-2018, se observa que la participación del sector en el PIB global se ha mantenido alrededor del 1,4\%, esto indica que el sector no ha logrado despegar completamente y se ha mantenido a la par del crecimiento de la economía. Donde se observa que el año que mayor participación después del año 2000, ha sido el año 2007 con 1,83\% esto se debió al registro de una 
tendencia creciente de visitas de extranjeros al Ecuador (Ministerio de Turismo, 2014).

En el periodo 2011-2014 el gobierno de turno a través de Ministerio de Turismo gestionó la promoción turística del país en busca de nuevos mercados, es así, que se creó la nueva marca país “Ecuador Ama la Vida" esto buscando mejorar la presencia del Ecuador en los mercados internacionales (Ronquillo, 2015).

El decrecimiento registrado a partir del año 2015 se debió principalmente por la, erupción del volcán Cotopaxi y también al terremoto del 2016 que afecto significativamente la zona costera del país lo cual se tradujo en una reducción del interés de visitar al Ecuador (Romero, 2016).

Gráfico 4. Empleo total generado en el Ecuador, periodo 2000-2018.

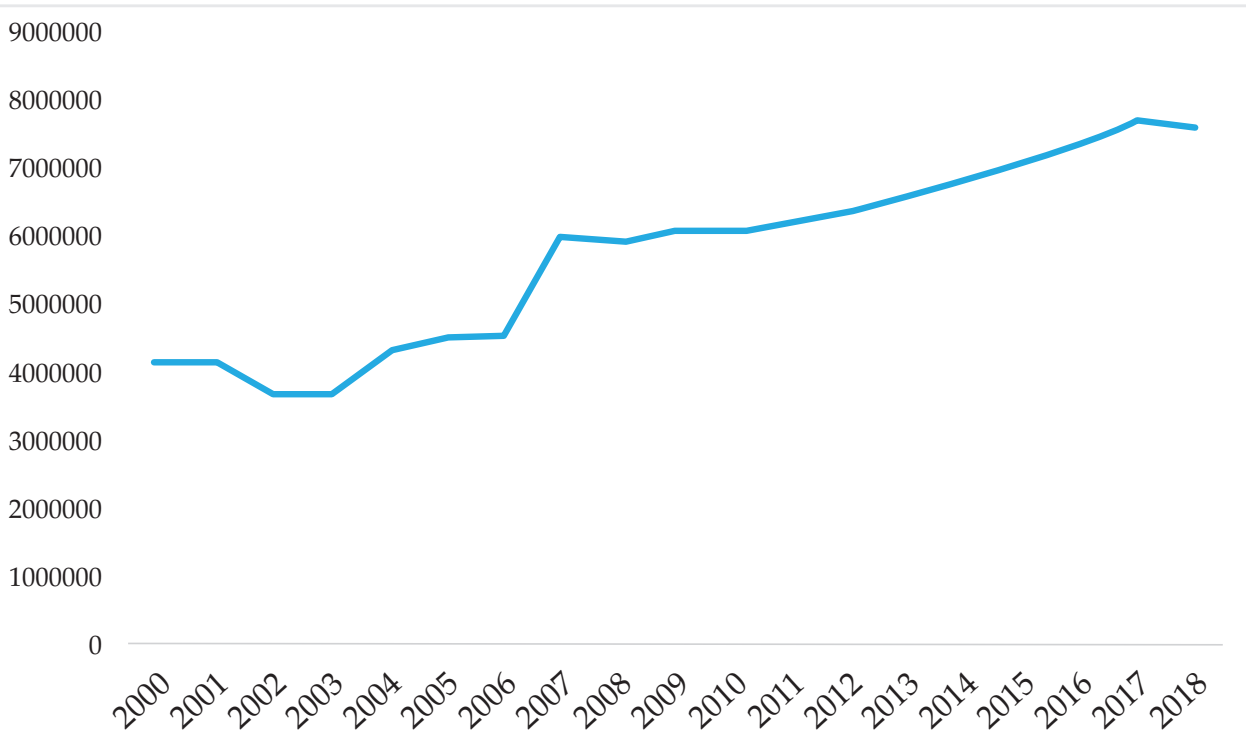

Fuente: Encuesta nacional de empleo desempleo y subempleo (2017).

Elaboración: Autores. 
En el gráfico 4, correspondiente al empleo total que se ha generado durante los diferentes años en el periodo de estudio, se observa que durante el periodo 2002-2003 se ha registrado alrededor de 3.700.000 fuentes de empleo, a partir de esa fecha se observa que esta variable se incrementa hasta el año 2017 con un total de 7.728.698, esto se dio gracias a que la economía creció fundamentada principalmente en el sector público, a partir de este año el empleo disminuye por la debilidad que se da en la actividad económica por la caída de los ingresos petroleros y la falta de impulso de la actividad privada.

Gráfico 5. Empleo generado por el sector turístico, periodo 2000-2018.

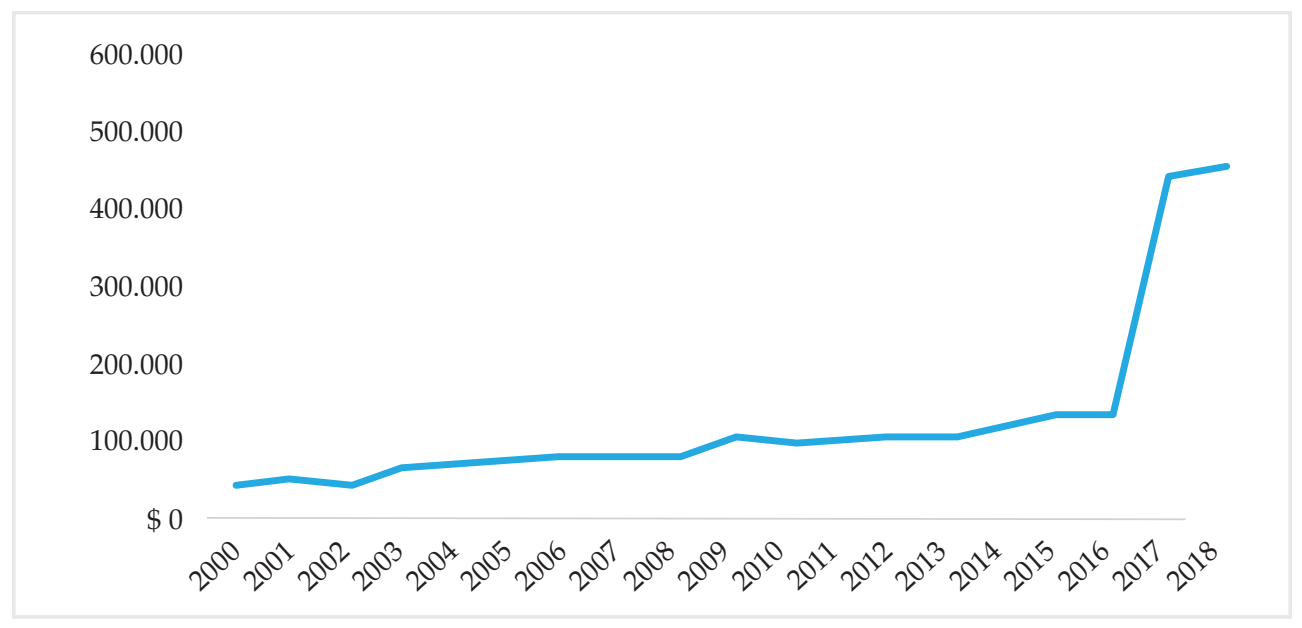

Fuente: Ministerio de Turismo (2018).

Elaboración: Autores.

En el gráfico 5, correspondiente al empleo generado por el sector turístico, periodo 2000-2018 se observa que en el periodo 2000-2016 la tasa de crecimiento es relativamente baja, del 2011 al 2015 la cifra de establecimientos registrados dedicados al turismo se incrementó en 37\% por lo que a partir del año 2017 experimenta un crecimiento muy significativo alcanzando un total de 522.508 
empleados para el tercer trimestre del 2019 en las industrias del turismo (MINTUR 2019).

Gráfico 6. Participación del empleo turístico con respecto al empleo total, periodo $2000-2018$.

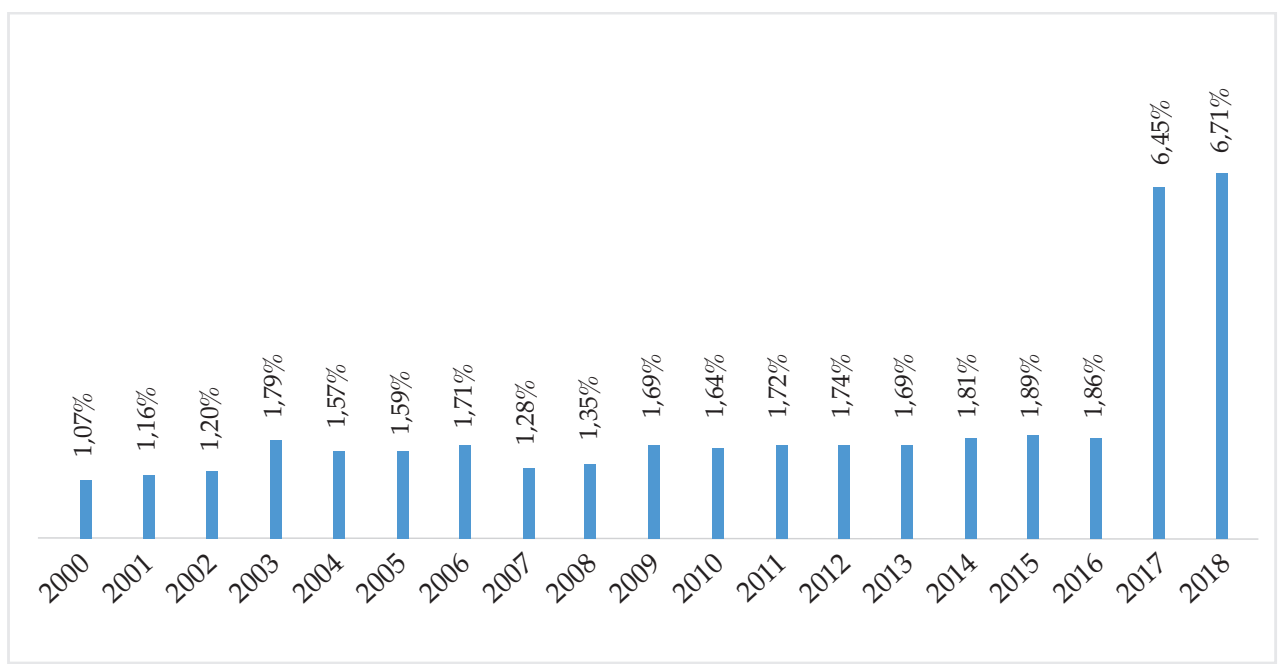

Fuente: Banco Mundial y Ministerio de Turismo (2018).

Elaboración: Autores..

Según el gráfico 6, correspondiente a la participación del empleo turístico con respecto al empleo total, se observa que ha mantenido una participación de entre $1 \%$ a 1,90\% durante el periodo 2000-2016, sin embargo, para el 2017 y 2018 este se incrementa a tasas de hasta $6,45 \%$ del empleo total, ocasionado por la intervención del gobierno en cuanto a la campaña de promoción lanzada el 2017 por el Ministerio de Turismo en motivar a los agentes internacionales a visitar e invertir en territorios ecuatorianos, generando ramas de trabajo e impulsando la producción y el desarrollo económico nacional (Calderón, 2018). 
Gráfico 7. Formación Bruta de Capital Fijo en millones de dólares, periodo 20002018.

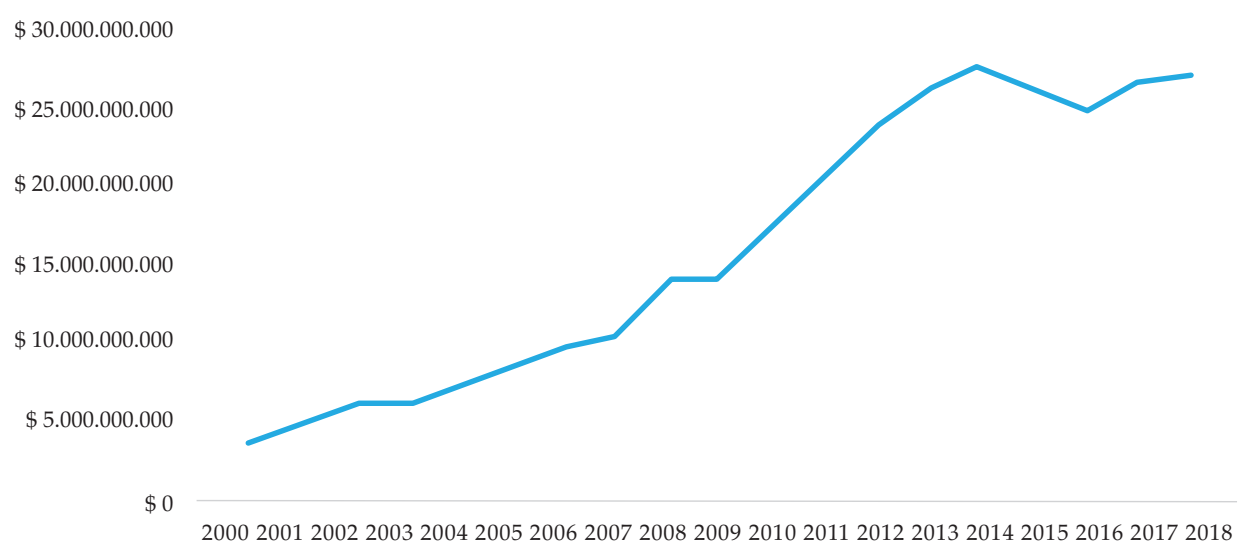

Fuente: Banco Mundial y Ministerio de Turismo (2018).

Elaboración: Autores.

En el gráfico 7, correspondiente a la formación de capital fijo (FBKF), periodo 2000-2018 se observa una tendencia creciente alcanzando el pico más alto en el año 2014 con un total de \$ 27.684.231.000. Esto se debe al aumento de la inversión pública implementada por el Gobierno Nacional mediante la construcción de carreteras, proyectos hidroeléctricos, escuelas, hospitales, entre otros (El Universo, 2014).

En el año 2009 la FBKF tuvo un decrecimiento como consecuencia de la crisis internacional (Banco Central del Ecuador, 2014). Por lo tanto, durante el periodo de estudio, ha registrado un crecimiento promedio de $12.62 \%$. 


\subsection{Cuentas satélites}

Gráfico 8. Valor agregado bruto directo turístico, periodo 2007-2016.

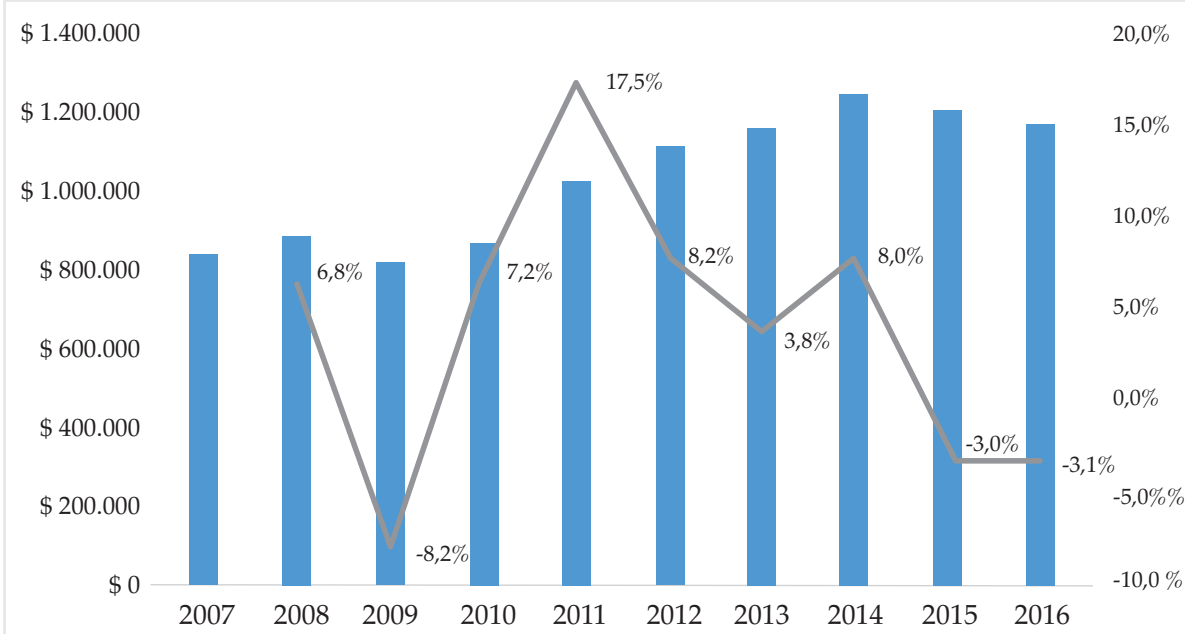

Fuente: Ministerio de Turismo (2020).

Elaboración: Autores.

En el gráfico 8, correspondiente al valor agregado bruto directo turístico (VABDT), periodo 2000-2016. Se observa que en el año 2009 presenta el valor más bajo de la serie, llegando a alcanzar \$ 818.498 millones de dólares, debido a la crisis financiera internacional, el temor de la influenza AH1N1 y la caída de la fuerza promocional de los atractivos turísticos de Ecuador que tuvo lugar en aquel entonces, afectando significativamente todos los indicadores, entre los cuales se puede mencionar la llegada de turistas extranjeros, el saldo de la balanza turística entre otras (Ministerio de Turismo, 2012). A partir del año 2015, el VABDT, presenta un decrecimiento debido a la apreciación del dólar y en el año 2016 afectó el terremoto de abril. El valor agregado bruto directo turístico durante el periodo de estudio presenta una tasa de crecimiento promedio de $4,1 \%$. 
Gráfico 9. Gasto turístico receptor y su participación con respecto al PIB, periodo 2007-2016.

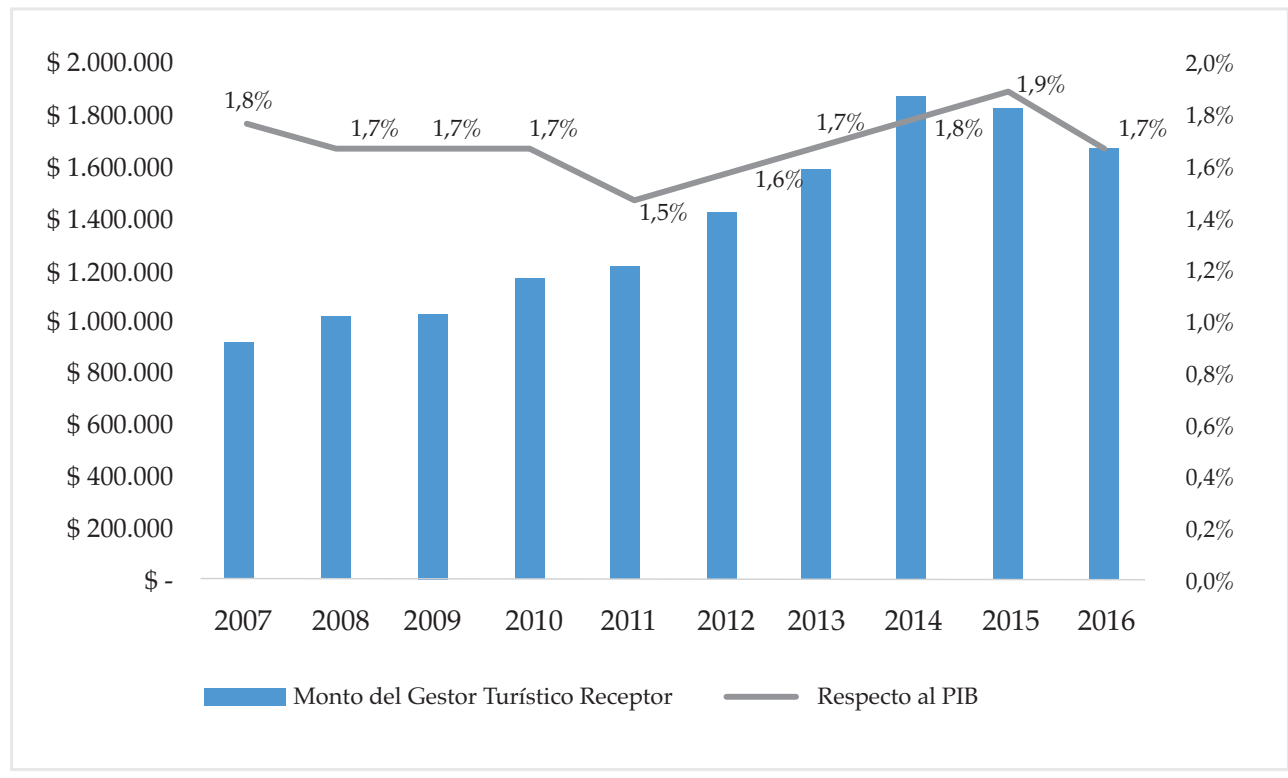

Fuente: Ministerio de Turismo (2018).

Elaboración: Autores.

En el gráfico 9, correspondiente al monto del gasto turístico receptor y su participación con respecto al PIB, periodo 2000-2016. Se observa que hasta el año 2009, presenta un leve decrecimiento del gasto turístico receptor como consecuencia de la crisis financiera, pero su recuperación es inmediata presentando una tendencia al crecimiento alcanzando el pico más alto el año 2014 como consecuencia de un arribo creciente de turistas extranjeros al país (Ministerio de Turismo, 2014).

De igual manera se observa su participación con respecto al PIB donde el año con menor participación ha sido en el 2011 debido a la baja tasa de crecimiento del gasto en turismo receptor y un crecimiento muy acelerado del PIB pasando del 69.56 miles de millones de dólares en el año 2010 a 79.28 miles de millones de dólares (Banco Mundial, 2018). 
Gráfico 10. Grado de apertura turística en porcentajes, periodo 2007-2016.

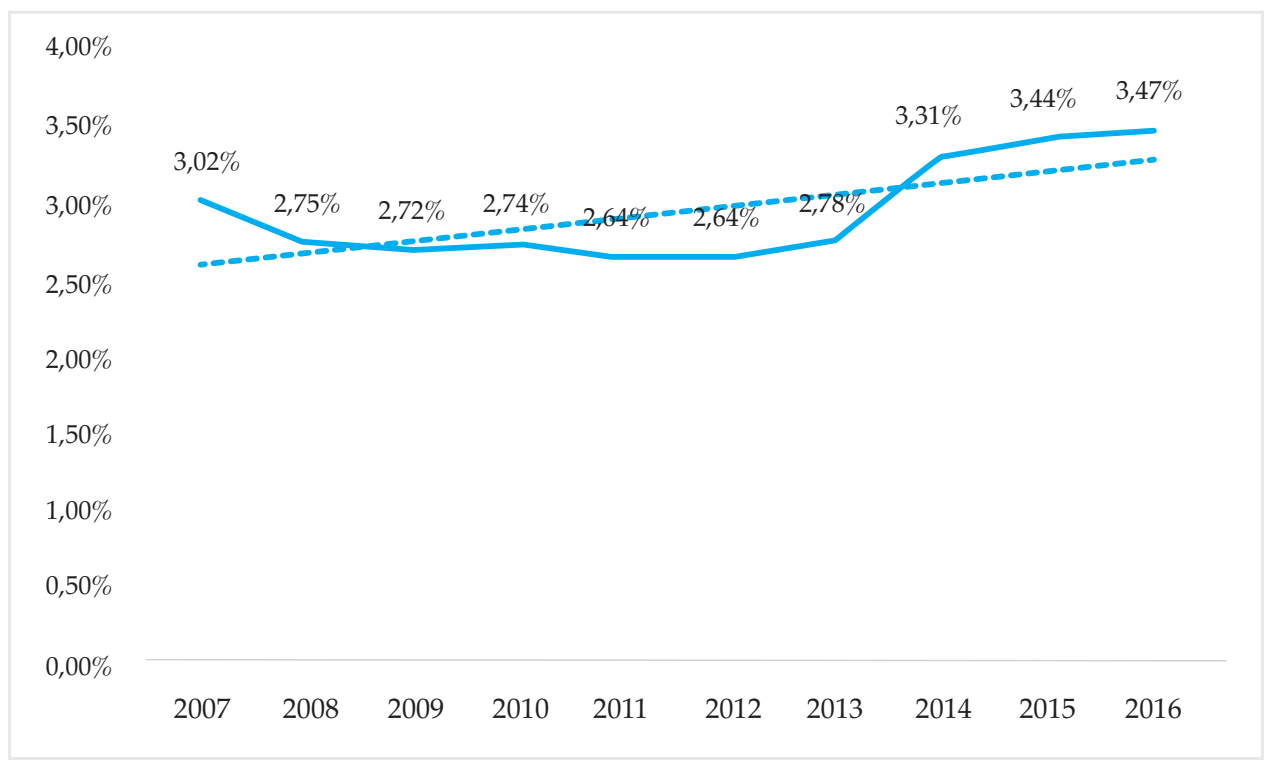

Fuente: Ministerio de Turismo (2018).

Elaboración: Autores.

En el gráfico 10, correspondiente al grado de apertura turística, periodo 2007-2016. Se observa que para el Ecuador en promedio ha sido de $2.95 \%$. Este índice describe la importancia relativa del gasto turístico internacional, que es la suma del gasto turístico receptor y emisor en la economía del país.

Se observa que a partir del año 2014 se registra un mayor crecimiento del grado de apertura debido al aumento de llegada de visitantes internacionales, en estos años el país impulsó varios programas con el objetivo de fortalecer la marca Ecuador como "All You Need is Ecuador", viaja primero Ecuador y Ecuador potencia turística (Ministerio de Turismo, 2014). 
Gráfico 11. Grado de cobertura turística, periodo 2007-2016.

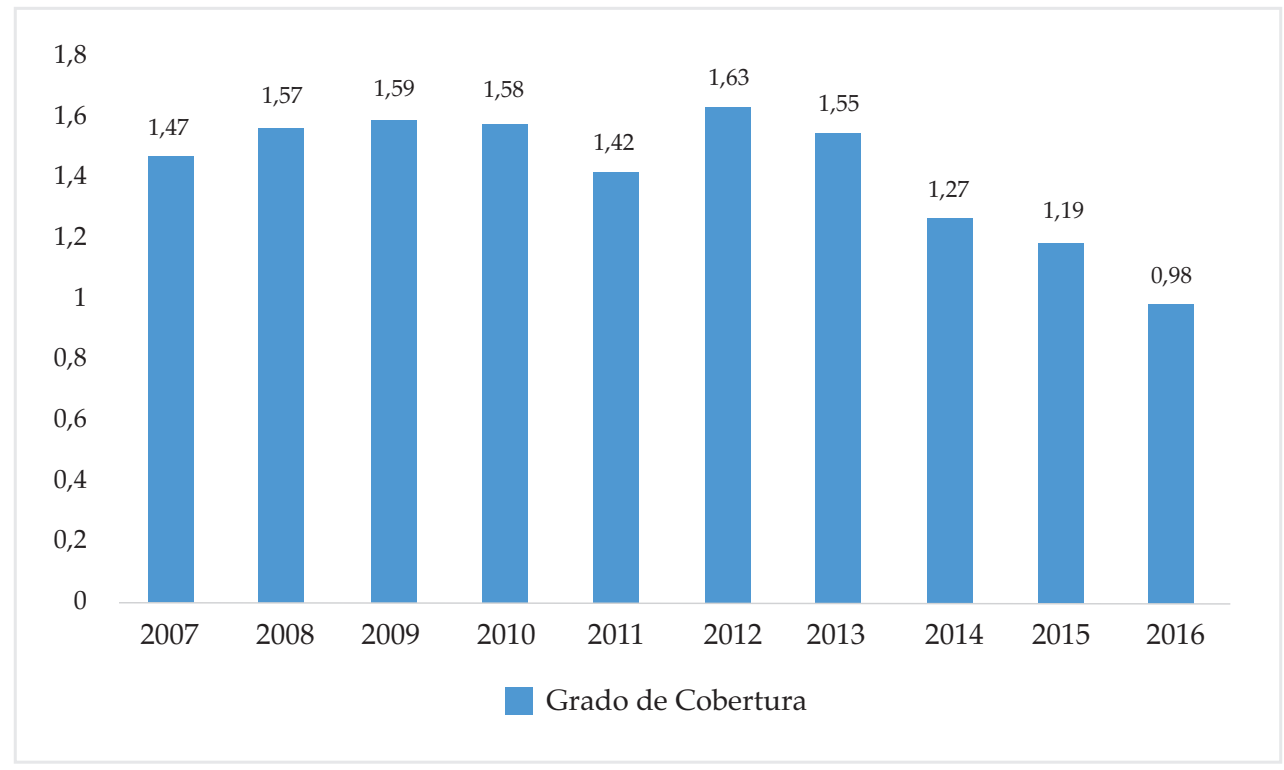

Fuente: Ministerio de Turismo (2018).

Elaboración: Autores.

Como se muestra en el gráfico 11, correspondiente al grado de cobertura turística del Ecuador, periodo 2007-2016 donde se evidencia que supera los ingresos por turismo receptor, por lo tanto, se puede determinar que las corrientes monetarias de entrada son superiores al turismo emisor hasta el año 2012. Siendo desde este periodo donde se presenta un decrecimiento considerable, llegando en el año 2016 a registrar valores inferiores a 1 es decir el gasto turístico receptor es más bajo al gasto turístico del emisor, esto se debió a los múltiples problemas económicos, sociales y naturales como es el caso de terremoto del año 2016 (Quiroz, 2016).

\subsection{Turismo interno}

Esta clase de turismo se produce cuando los residentes de un país sean estos nacionales o extranjeros se movilizan dentro del mismo (Ruiz \& Ortiz, 2006). Por lo general este tipo de turismo se produce 
en Ecuador en días festivos o considerados feriados nacionales, en estas fechas las personas viajan por distintos motivos, entre los que se encuentran placer $\mathrm{u}$ ocio y visitas a familiares.

El turismo interno se caracteriza por la promoción de lugares turísticos, dando a conocer sus bellezas naturales y culturales, resaltando las tradiciones de cada región. Esta clase de turismo es importante en las economías regionales, ya que hace rotar la producción, realiza un reciclaje monetario en cuanto a una redistribución de las rentas y genera nuevos empleos (Ruiz \& Ortiz, 2006).

En la actualidad se puede indicar que aproximadamente unos 50 países reciben anualmente casi un millón de turistas y 40 de estos países ganan casi 1.000 millones de dólares de ingresos por la actividad turística. Cifras que explican la expansión del turismo a varios países. Alrededor del $8 \%$ del valor de las exportaciones mundiales provienen de los ingresos por turismo internacional (Tapia, 2010).

El turismo interno no causa ni entrada ni salida de divisas. El gobierno es el principal promotor de este tipo de turismo ya que trata de evitar que la población salga del país y de esa forma el dinero no se vaya al exterior (Ruiz \& Ortiz, 2006).

Esto hace que la economía nacional y regional tenga una dinamización elevada y que al mismo tiempo pueda crearse nuevas fuentes de empleo, mejorando la calidad de vida de muchos locales de los destinos turísticos.

Los ecuatorianos aprovechan los feriados nacionales para recorrer el país. En 2017, en los nueve feriados (Carnaval, Semana Santa, $1^{\circ}$ de mayo, 24 de Mayo, 10 de Agosto, 9 de Octubre, 2 y 3 
de noviembre, Navidad y fin de año), se estima que se realizaron más de 8,1 millones de viajes que dinamizaron la economía en aproximadamente \$ 463 millones. Mientras que en el año 2016 se registraron 4,92 millones de viajes durante los feriados y dejaron \$285,5 millones, según la Coordinación General de Estadísticas e Investigación del Ministerio de Turismo (Radio Huancavilca, 2018).

El turismo interno es una gran fuente económico-social, aportando millonarias sumas a los ingresos nacionales, influyendo de una forma positiva al crecimiento y desarrollo económico del Ecuador. Hoy los ecuatorianos se inclinan más por hacer turismo nacional. Con un presupuesto menor pueden tener muy buenas experiencias de viajes junto a familia y amigos ya que buscan tomarse un descanso o desconectarse de su ritmo habitual de trabajo y salir de la rutina.

En ese contexto el turismo dentro del país para el 2016 produjo 12,3 millones de viajes, según la Coordinación General de Estadísticas e Investigación del Ministerio de Turismo. En ese año el feriado de fin de año generó 618972 viajes, con un ingreso monetario que superó los 37,6 millones de dólares. La provincia más visitada fue Santa Elena, seguida de Manabí y Esmeraldas. En el 2015 se registraron 6,3 millones de viajes que significó un movimiento económico de 531,2 millones de dólares (Ministerio de Turismo, 2016).

En el 2018 el carnaval fue el feriado que más personas movilizó. La ocupación hotelera alcanzó el $45 \%$ y un promedio de gasto de 66 dólares por persona. El segundo feriado que más personas movilizó fue el de Semana Santa. Este asueto dinamizó 44,4 millones de dólares, siendo la ocupación hotelera de 43,11\% (Pichincha Universal , 2019). 
En la siguiente tabla se observa los lugares más visitados en épocas de feriado:

Tabla 1: Destinos más comunes preferidos por los turistas año 2016

\begin{tabular}{lcc|}
\hline Destino & Visitantes & Comparación País \\
\hline Quito & 20.016 .241 & 0,18 \\
\hline Guayaquil & 13.311 .584 & 0,12 \\
\hline Cuenca & 5.230 .309 & 0,05 \\
\hline Ambato & 4.154 .021 & 0,04 \\
\hline Total & 42.712 .155 & 0,38 \\
\hline Total Ecuador & 112.153 .552 & \\
\hline
\end{tabular}

Fuente: Ministerio de Turismo (2020).

Elaboración: Autores.

Gráfico 12. Destinos más comunes preferidos por los turistas año 2016.

120.000 .000

100.000 .000

80.000 .000

60.000 .000

42712155

40.000 .000

20.000 .000

20016241

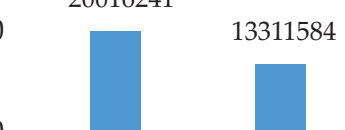

Quito Guayaquil Cuenca Ambato Total $\begin{gathered}\text { Total } \\ \text { Ecuador }\end{gathered}$

Fuente: Ministerio de Turismo (2020).

Elaboración: Autores. 
Para el año 2019, según la encuesta de viajes y gasto en feriados nacionales realizada por el Ministerio de Turismo, que tiene por objeto cuantificar el número de viajes realizados por turistas y excursionistas (nacionales y extranjeros) y estimar el gasto efectuado durante el feriado; a partir de información recopilada en los establecimientos de alojamiento al final de cada feriado. Se tiene que el feriado del 10 de agosto tiene el nivel de ocupación más alto con el 51\%, en cambio el nivel más bajo lo tiene el 9 de octubre con el $12 \%$.

Gráfico 13. Porcentaje de ocupación en feriados 2019.

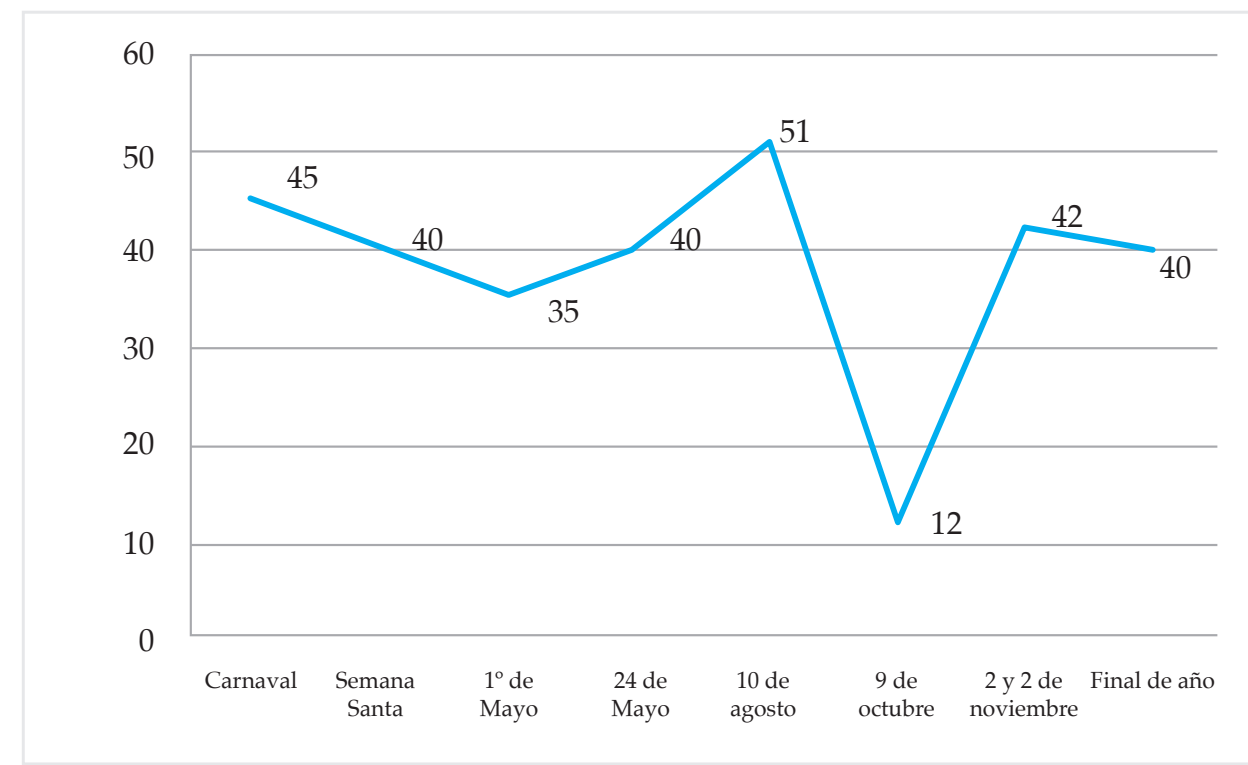

Fuente: Ministerio de Turismo (2020).

Elaboración: Autores.

Con respecto al gasto promedio que realizan los turistas en los diferentes feriados se tiene que el de fin de año es el mayor con $\$ 78$ y el menor es el 9 de octubre con $\$ 54$. Otro punto importante son las pernoctaciones promedio que para ese año fue de $1,05 \mathrm{y}$ el número de ocupantes por habitación de 1,84. 
Gráfico 14. Gasto promedio en dólares en feriados 2019.

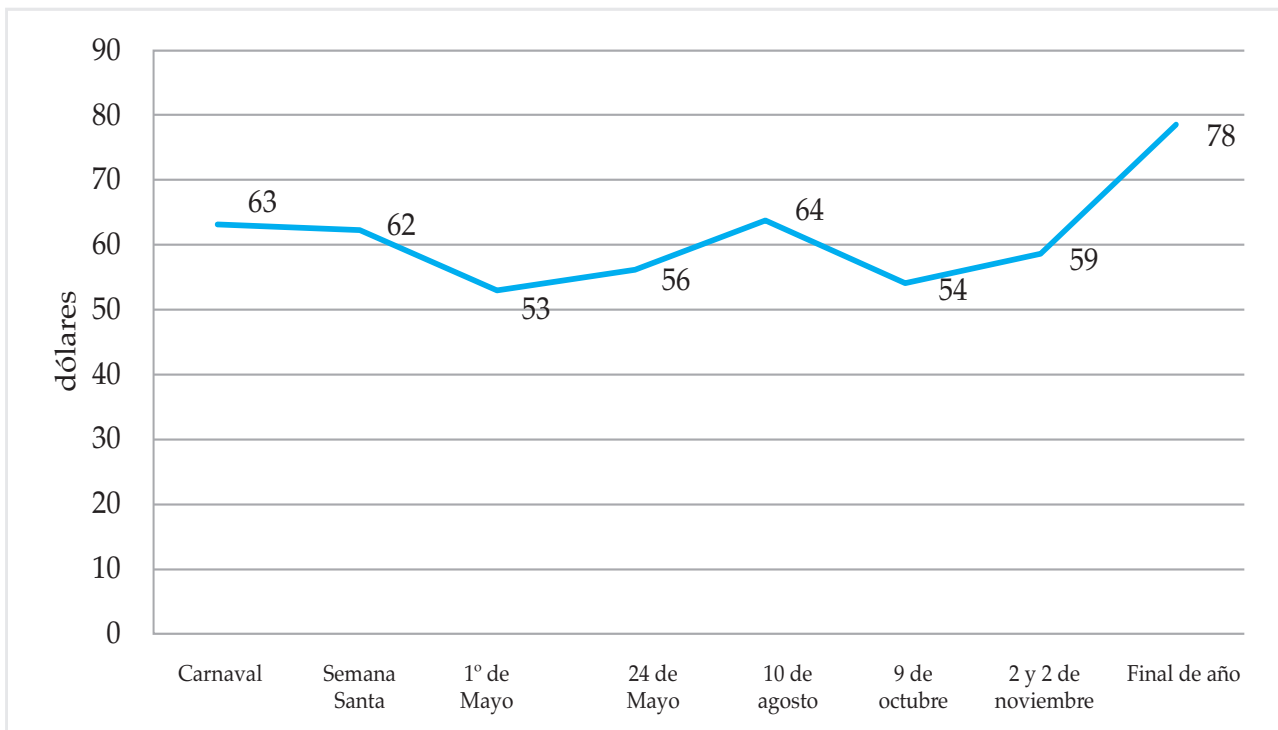

Fuente: Ministerio de Turismo (2020)

Elaboración: Autores.

\subsection{Turismo externo}

El turismo externo se produce cuando se tiene visitantes que residen en otros países con la intención de permanecer un tiempo limitado y realizar actividades determinadas en el país de destino. Este tipo de turismo tiene como característica principal la entrada de divisas hacia el país (Ruiz \& Ortiz, 2006).

E1 69\% de llegadas de extranjeros al Ecuador están motivadas por turismo, siendo el $52 \%$ realizada por personas económicamente activas, de las cuales el $40 \%$ corresponde a personal de apoyo administrativo y el $25 \%$ a profesionales, científicos e intelectuales, entre otros. El $42 \%$ de las llegadas de extranjeros motivadas por turismo se catalogó a personas no activas y el restante $6 \%$ fueron personas que no declararon su categoría de actividad y ocupación (Ministerio de Turismo, 2019). 
Los turistas extranjeros viajan a otros países con la finalidad de conocer nuevas culturas y experimentar las maravillas naturales que los destinos turísticos ofrecen. El turismo externo es beneficioso debido a que genera dinamismo económico. Según Ruiz y Ortiz (2006), este turismo es tomado en cuenta en la evaluación económica de los países ya que es un factor muy crítico para el desarrollo.

En el primer semestre del año 2017, han ingresado alrededor de 914477 visitantes o turistas, lo cual significa un crecimiento del 9,3\% en comparación al año 2016, además, los ingresos por turismo internacional alcanzaron la cifra de 399,5 millones de dólares, con un crecimiento del 1,6\% (Chávez, Fernandez, \& Gómez, 2017).

En el año 2011 Ecuador registró un total de 1'146.968 arribos internacionales, de los cuales un $28 \%$ corresponde al mercado estadounidense, país que de acuerdo a la Conferencia Anual de los miembros de USTOA, representa el tercer destino por descubrir o emergente con mayor popularidad para el 2012, después de Vietnam y la India (Caiza \& Molina, 2012).

El Gobierno es el principal beneficiado por el aumento de la llegada de turistas al país, ya que gracias a estas los ingresos por divisas entrantes cada vez aumentan generando no solo beneficio económico sino también dar a conocer las maravillas ofrecidas en Ecuador.

Desde el año 2010, el Ministerio de Turismo con su proyecto: "Plan de Marketing Turístico del Ecuador" (PIMTE) contribuyó con el Plan Nacional del Buen Vivir dirigiendo sus acciones al posicionamiento del Ecuador como un destino turístico a nivel mundial, aumentando los arribos de turistas internacionales y a la vez respetando la diversidad de flora y fauna existente en el país (Ministerio de Turismo, 2015). 
La población turística para satisfacer sus distintas necesidades busca lugares con distintos climas y culturas, al igual que biodiversidad en flora y fauna, por lo que Ecuador es unos de los preferidos por visitantes de todo el mundo. Según Ministerio de Turismo (2015), países como Estados Unidos, Colombia, Venezuela, Perú y España son los principales emisores de viajeros hacia el país, siendo Colombia el país que más emisión de turistas genera hacia Ecuador, con 344.363 personas, seguido por Estados Unidos con 250.785, Perú con 150.805 y España con 65.245 (pág. 12).

Hoy en día, Ecuador ha ido ganando espacio para ser considerado como uno de los destinos turísticos más reconocidos a nivel mundial, gracias a su aplicación estratégica de promoción que le permitieron obtener varios premios y reconocimientos mundiales en los 4 últimos años, el más destacado es el "World's Leading Green Destination 2013" otorgado por World Travel Awards en la Worldwide Edition en Doha, Qatar (Ministerio de Turismo, 2015).

Los países que más visitan o arriban a Ecuador se observan en la siguiente tabla:

Tabla 2. Origen de turistas que más visitan Ecuador según país de origen, periodo 2012-2016.

\begin{tabular}{lrrrrr}
\multicolumn{1}{c}{ País } & \multicolumn{5}{c}{ Año } \\
& $\mathbf{2 0 1 2}$ & $\mathbf{2 0 1 3}$ & $\mathbf{2 0 1 4}$ & $\mathbf{2 0 1 5}$ & $\mathbf{2 0 1 6}$ \\
Estados Unidos & 248.064 & 248.852 & 259.406 & 263.081 & 266.989 \\
\hline Colombia & 349.455 & 343.004 & 368.079 & 348.151 & 318.868 \\
\hline Perú & 137.084 & 150.427 & 175.405 & 165.223 & 147.601 \\
Venezuela & 45.701 & 101.643 & 119.763 & 105.553 & 102.619 \\
España & 65.764 & 64.726 & 67.623 & 67.545 & 62.984 \\
\hline
\end{tabular}

*Nota: último dato encontrado año 2016.

Fuente: Ministerio de Turismo (2020).

Elaboración: Autores. 
Gráfico 15. Origen de turistas que más visitan Ecuador, periodo 2012-2016.

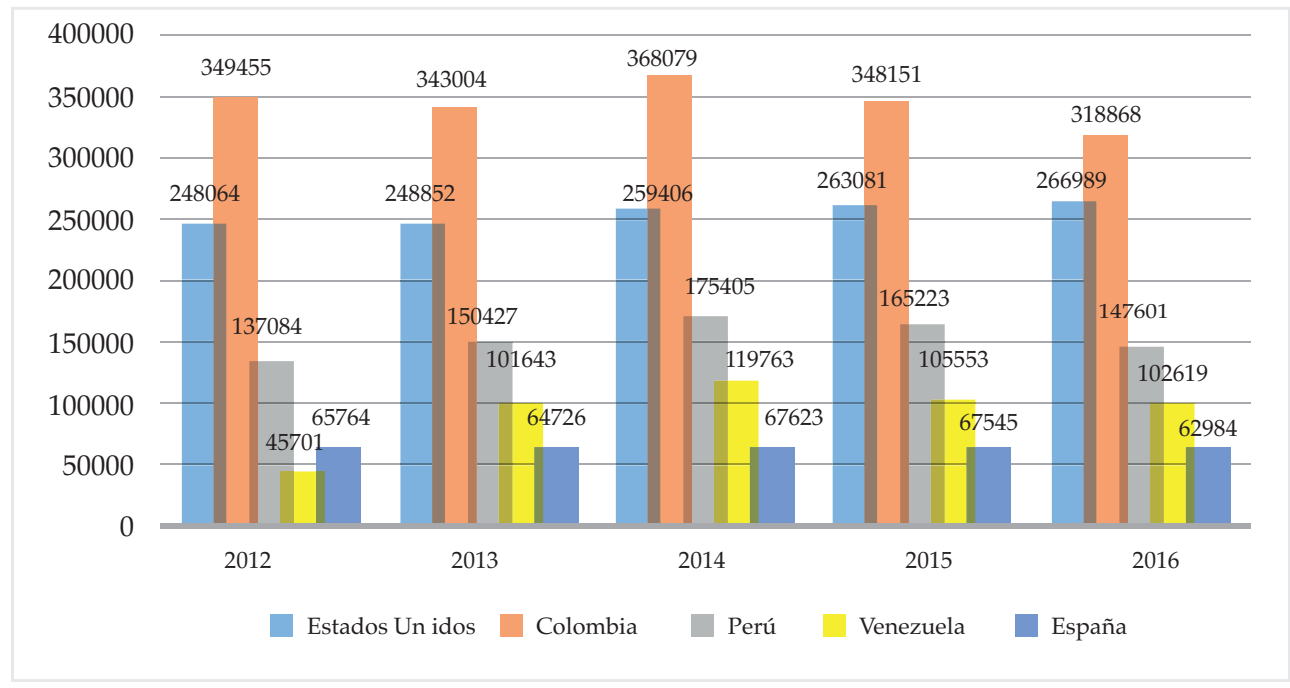

Fuente: Ministerio de Turismo (2020).

Elaboración: Autores.

\subsection{Turismo y empleo}

El nivel de importancia e impacto que tiene la actividad turística en materia de empleo tanto en el Ecuador como a nivel mundial, resulta difícil de evaluar con exactitud, debido al efecto que ocasiona en ramas como la agricultura, la industria y los servicios.

Según Neffa (1999), el empleo es la relación existente entre una persona y una empresa o institución que se ampara bajo normas jurídicas y un marco institucional ya existente y amparado por la ley. El empleo que genera el turismo en Ecuador es algo muy beneficioso para muchos sectores de la economía, al igual que para la capacidad económica de las personas inmersas en esta actividad. Según el Ministerio de Turismo (2018), entre enero y marzo del 2018 se registraron en el país 491.698 empleos relacionados con el sector del turismo, lo que revela un crecimiento del 5,1\% respecto 
al mismo periodo de 2017, esta cifra representa el 6,3\% del total de empleados en la economía del país.

Tapia (2010), manifiesta que existen diversas formas de empleo en el ámbito turístico las cuales son:

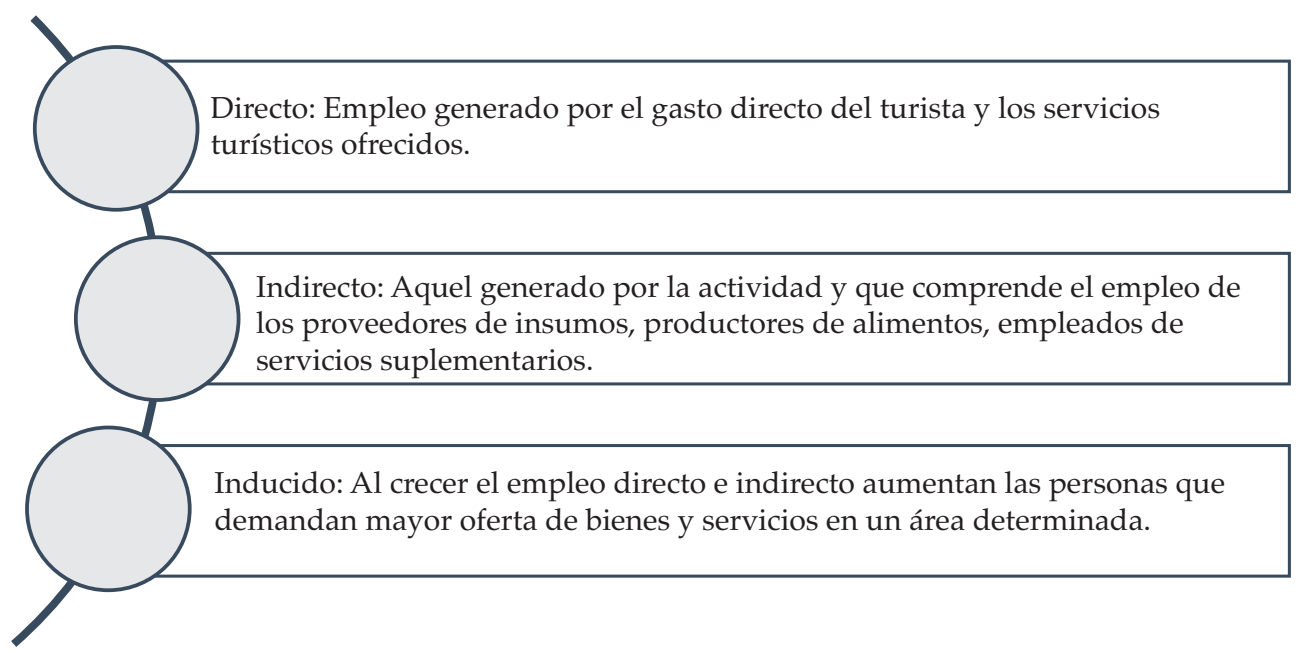

Figura 1. Formas de empleo.

Fuente: Tapia (2010).

Tabla 3: Personal empleado en los establecimientos registrados en el Ministerio de Turismo (2003 - 2007).

Personal empleado en establecimientos turísticos

\begin{tabular}{lrrrrr}
\hline Actividad/años & $\mathbf{2 0 0 3}$ & $\mathbf{2 0 0 4}$ & $\mathbf{2 0 0 5}$ & $\mathbf{2 0 0 6}$ & $\mathbf{2 0 0 7}$ \\
Alojamiento & 19.886 & 19.915 & 21.684 & 22.636 & 21.635 \\
\hline Comidas y Bebidas & 33.510 & 34.831 & 37.173 & 41.745 & 42.977 \\
Agencias de viajes & 6.710 & 6.671 & 5.539 & 5.877 & 5.793 \\
Recreación & 3.694 & 3.635 & 3.544 & 3.876 & 3.200 \\
Otras & 3.326 & 3.302 & 4.166 & 4.397 & 3.409 \\
\hline Total & 678.126 & 68.354 & 72.106 & 78.531 & 77.032 \\
\hline
\end{tabular}

Fuente: Tapia (2010).

Elaboración: Autores. 
Gráfico 16. Personal ocupado en los establecimientos registrados en el Ministerio de Turismo, periodo $2003-2007$.

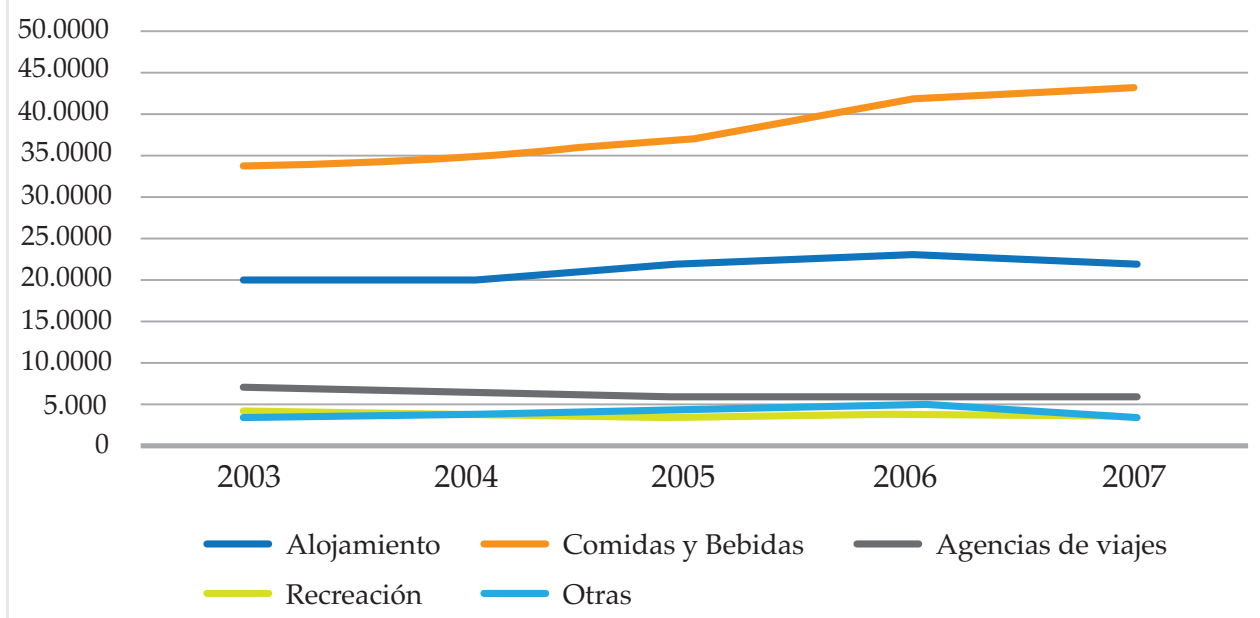

Fuente: Tapia (2010).

Elaboración: Autores.

La fuente que más aporta a la generación de empleo es el de comidas y bebidas con lo que se puede decir que también es la que más aporta al desarrollo económico del turismo o al PIB turístico con 33510 fuentes de empleo en el año 2003 llegando a 42977 en el año 2007, en segundo lugar, se encuentra el sector hotelero o de alojamiento con una generación de empleo de 19886 en el año 2003 y para el año 2007 llega a 21635.

Tabla 4: Personal ocupado en los establecimientos registrados en el Ministerio de Turismo Años: 2011 - 2015

Personal empleado en establecimientos turísticos

\begin{tabular}{lrrrrr|} 
Actividad/años & $\mathbf{2 0 1 1}$ & $\mathbf{2 0 1 2}$ & $\mathbf{2 0 1 3}$ & $\mathbf{2 0 1 4}$ & $\mathbf{2 0 1 5}$ \\
\hline Alojamiento & 29.632 & 31.904 & 34.130 & 35.476 & 34.306 \\
\hline Comidas y Bebidas & 65.140 & 69.782 & 78.152 & 85.654 & 88.263
\end{tabular}




\begin{tabular}{lrrrrr} 
Agencias de viajes & 2.437 & 2.675 & 2.773 & 3.046 & 3.335 \\
Transportación & 2.704 & 2.965 & 2.995 & 3.061 & 3.216 \\
Otras & 6.399 & 6.787 & 7.445 & 8.066 & 8.527 \\
\hline Total & 106.312 & 114.113 & 125.495 & 135.303 & 137.647 \\
\hline
\end{tabular}

Fuente: Tapia (2010).

Elaboración: Autores.

Gráfico 17. Personal ocupado en los establecimientos registrados en el Ministerio de Turismo Años: 2011 - 2015.

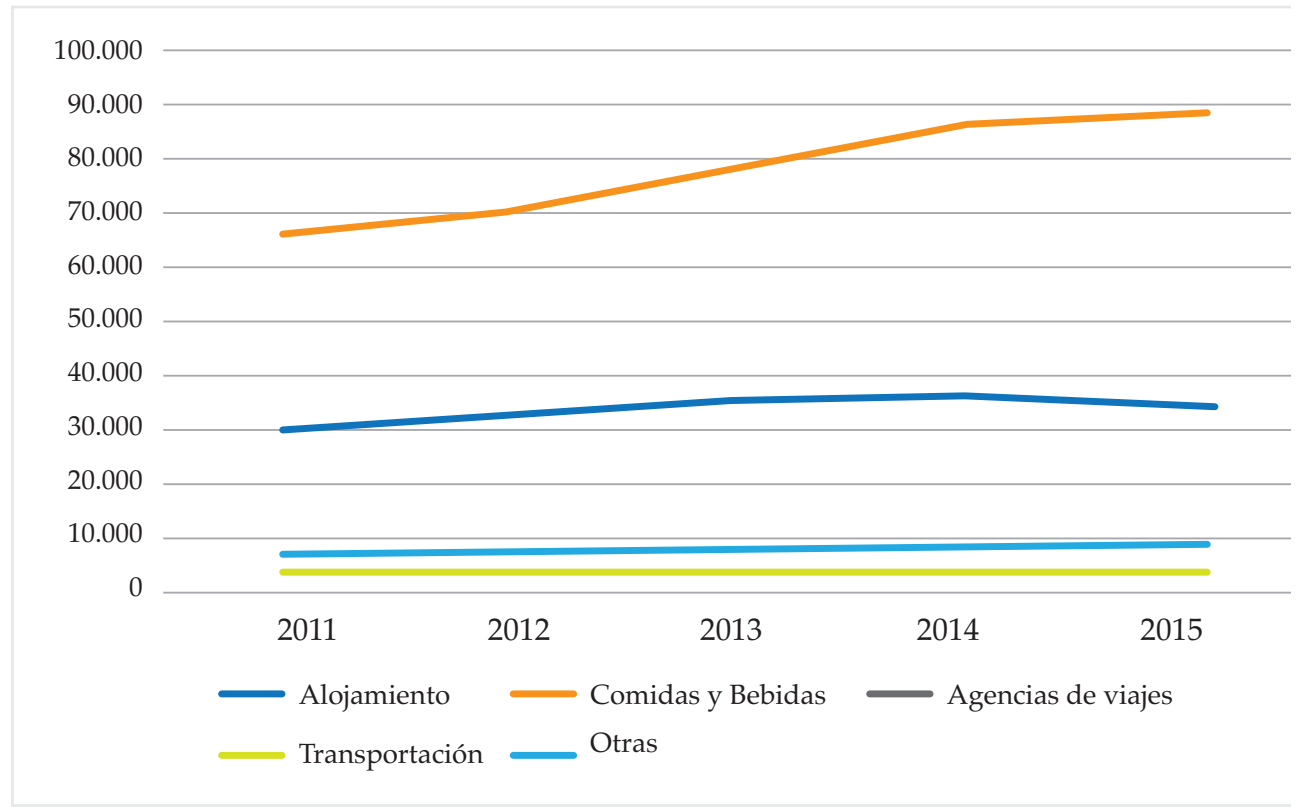

Fuente: Ministerio de Turismo (2020).

Elaboración: Autores.

En el gráfico 17, se analiza que para el periodo 2011 al 2015, la actividad de comidas y bebidas es la mayor generadora de empleo con 88263 puestos para el año 2015 con una tasa de crecimiento entre el 2003 y 2015 de 163,4\%. El alojamiento se mantiene como el segundo generador de empleo en el sector turístico con un crecimiento de 72,5\% entre el 2003 y 2015. 
Esto evidencia que el turismo es una de las principales fuentes de empleo a nivel nacional ya que la llegada de turistas hace que se generen nuevos negocios para satisfacer sus necesidades y genere dinámica económica.

El impacto del turismo en la economía puede resultar muy beneficioso como se ha podido observar. Su efecto contrario en comparación a otras industrias resulta beneficioso no solo para el sector en sí; ya que favorece a otros sectores que necesariamente no se encuentran vinculados directamente a la actividad (Tapia, 2010).

Tabla 5: PIB turístico con relación al PIB nacional 2007-2018.

Años PIB miles de \$ PIB Turismo miles de \$ \% PIB Turismo/PIB

\begin{tabular}{|llll}
\hline 2007 & 51.007 .777 & 931.000 & 1,83 \\
\hline 2008 & 61.762 .635 & 987.173 & 1,60 \\
\hline 2009 & 62.519 .686 & 903.081 & 1,44 \\
\hline 2010 & 69.555 .367 & 970.363 & 1,40 \\
\hline 2011 & 79.276 .664 & 1.131 .986 & 1,43 \\
\hline 2012 & 87.924 .544 & 1.226 .942 & 1,40 \\
\hline 2013 & 95.129 .659 & 1.273 .306 & 1,34 \\
\hline 2014 & 101.726 .331 & 1.374 .966 & 1,35 \\
\hline 2015 & 99.290 .381 & 1.334 .934 & 1,34 \\
\hline 2016 & 99.937 .696 & 1.293 .904 & 1,29 \\
\hline 2017 & 104.295 .862 & 1.204 .500 & 1,15 \\
\hline 2018 & 108.938 .000 & 1.332 .300 & 1,22 \\
\hline
\end{tabular}

Fuente: Ministerio de Turismo (2018).

Elaboración: Autores. 
Gráfico 18. PIB turístico con relación al PIB nacional (\%) 2007-2018.

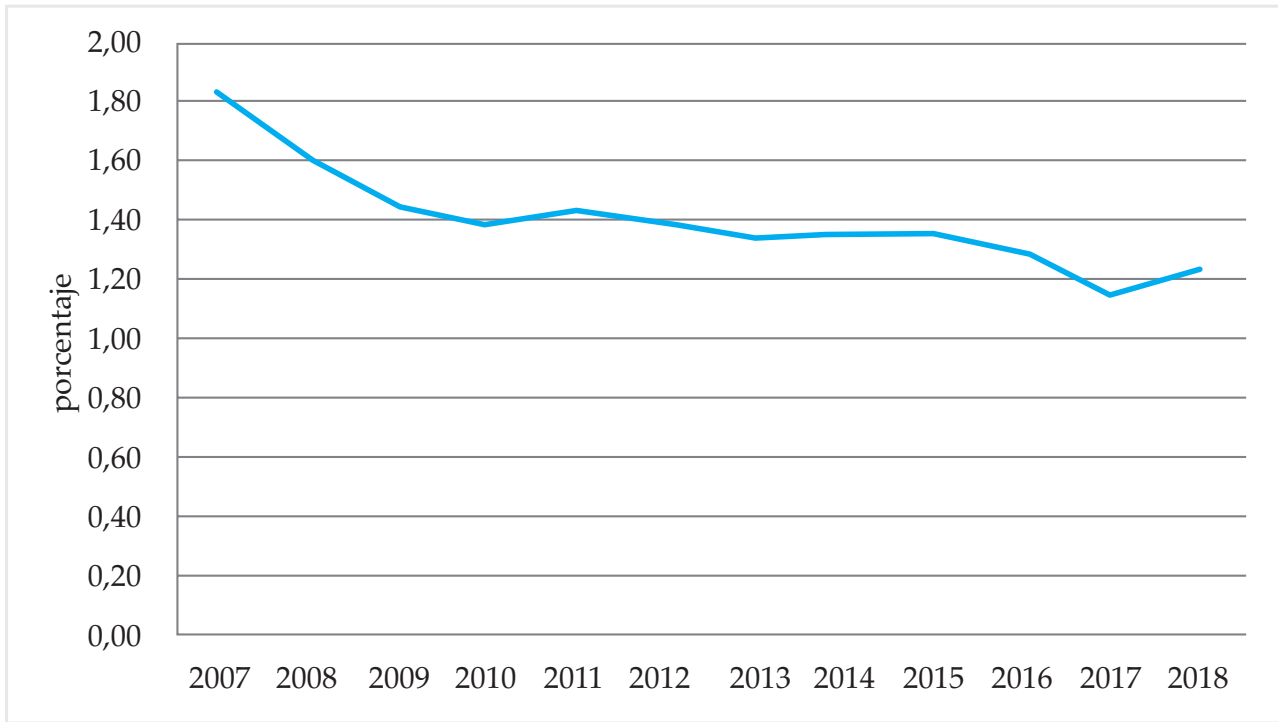

Fuente: Ministerio de Turismo (2018).

Elaboración: Autores.

En los últimos 11 años, el PIB nacional ha tenido una tendencia hacia el alza, con una tasa de crecimiento en el periodo de $113,6 \%$, este crecimiento se fundamentó principalmente en el gasto público impulsado por ingresos importantes del sector petrolero y aumentos en la recaudación tributaria, el otro componente fue el consumo privado, que en promedio más contribuyó al crecimiento de este indicador durante la década 2007-2018.

El PIB del sector turístico también se ha incrementado gracias al aumento del arribo de extranjeros al país y a la política de feriados impulsada por el gobierno, así para el periodo tiene una tasa de crecimiento de $43,10 \%$, es menor al PIB global, por lo que su participación ha disminuido de 1,83 en el 2007 a 1,22 para el 2018. La participación porcentual del turismo en el PIB nacional en Ecuador es todavía relativamente baja. 
Las personas queinciden en el turismonacional se distribuyen en varias áreas, las cuales son de vital importancia para la atención de los turistas que llegan a estos sitios y para el cumplimiento de sus necesidades. Según Ministerio de Turismo (2019), el 64,1\% están empleados en la actividad de comidas y bebidas, el 24,9\% en alojamiento y el $11 \%$ en otras actividades turísticas.

El turismo en Ecuador a más de ser una de las fuentes más importantes deingresos, también aporta a la economía maximizando la calidad de vida de las personas de la localidad turística siendo una gran fuente de empleo que permite el desarrollo tanto humano como económico.

Gráfico 19. Balanza turística \% del PIB, periodo I 2010 - III 2019.

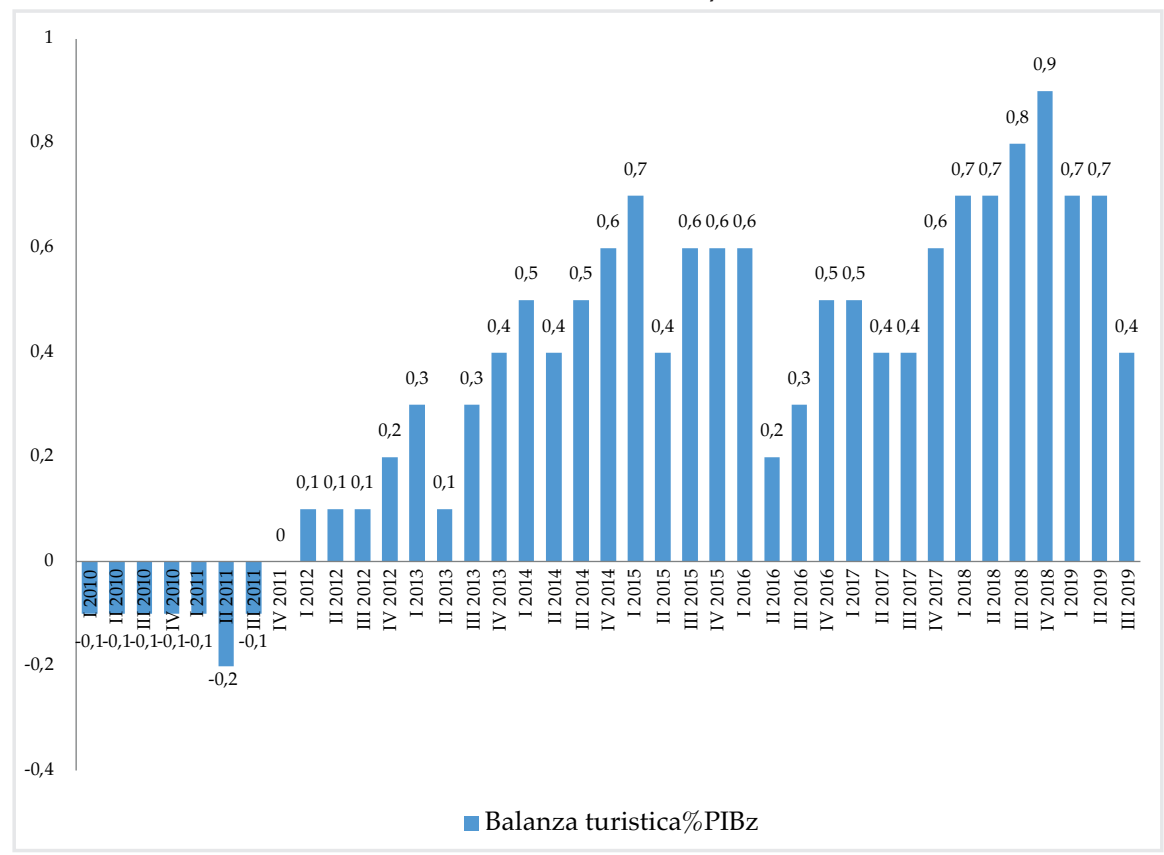

Fuente: Ministerio de Turismo (2018).

Elaboración: Autores.

El grafico 19, describe la importancia relativa del turismo al relacionar el déficit o superávit de la balanza turística frente 
al PIB, en ese sentido se observa que para el primer semestre del 2010 hasta el cuarto trimestre del 2011 es negativa indicando que el déficit de la balanza refleja un saldo negativo de los ingresos frente a los egresos. A partir del primer semestre del 2012 existe una relación positiva indicando que los ingresos son mayores a los egresos y al mismo tiempo esta participación como porcentaje del PIB ha ido en aumento reflejando la mayor importancia del turismo en el crecimiento económico del país.

\section{Ingresos por Turismo}

En el Ecuador los ingresos generados por el sector turístico al pasar de los años han variado. El turismo es unos de los principales contribuyentes a los ingresos que registra el país. Según Ministerio de Turismo (2019), el ingreso de divisas registrado en la balanza de pagos asciende a 1.878,6 millones de dólares durante el año 2018, valor que comparado con los recursos provenientes de las exportaciones de los principales productos, ubica al turismo como el tercer rubro de aporte en ingresos, después del banano y camarón.

Los efectos que tiene el turismo en el sector económico de un país no son claramente notorios, debido a que los diferentes servicios y bienes que se ofertan a los turistas tanto nacionales como internacionales tienen su origen en varias ramas de la producción y además solo una parte de ellos se venden directamente al turista, mientras que el resto es destinado a otras formas de demanda o intermediarios (Tapia, 2010).

En el periodo del 2000 - 2018 el turismo representa en promedio el 1,432\% del PIB. En términos nominales, el PIB turístico registra 2.392 millones de dólares para el 2018, indicadores que ponen en evidencia la importancia del sector en la economía (Ministerio de Turismo, 2019). 
El turismo es fuente de recursos los cuales son de gran ayuda para el desarrollo económico de la sociedad, para el mejoramiento de la calidad de vida y la sostenibilidad, según Tapia (2010), existen diversos efectos que se presentan a continuación:
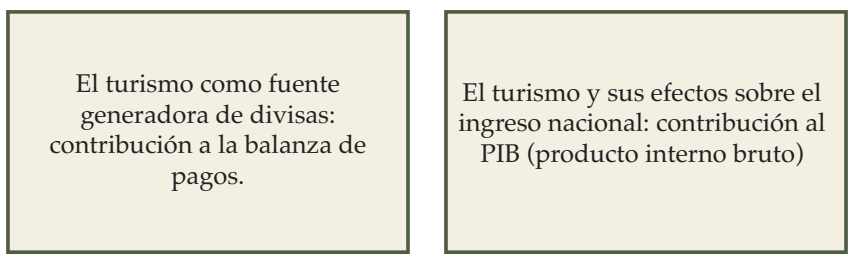

El turismo como factor de expansión del mercado nacional: el gasto adicional en la compra de productos manufacturados nacionales no catalogados como turísticos, que equivale a una exportación.
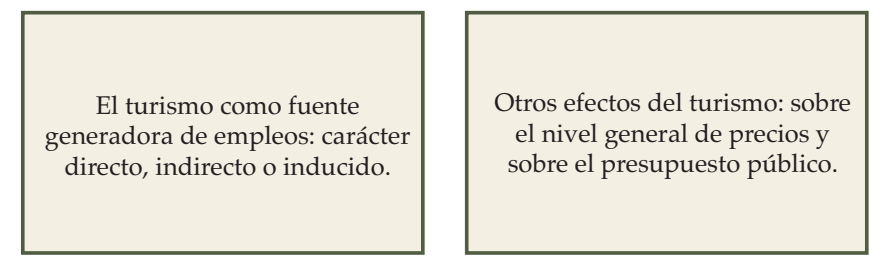

Figura 2. Efectos del turismo en la economía

Fuente: Tapia (2010)

Tabla 6: Ingresos y egresos por turismo en millones de dólares, periodo 2012-2018

\begin{tabular}{cccc}
\hline Años & Ingresos & Egresos & Saldo \\
\hline 2012 & 1038,8 & 943,6 & 95,1 \\
\hline 2013 & 1251,2 & 988,2 & 263 \\
\hline 2014 & 1487,2 & 989,8 & 497,4 \\
\hline 2015 & 1557,4 & 993,9 & 563,5 \\
\hline 2016 & 1449,3 & 1034,1 & 415,2 \\
\hline 2017 & 1663 & 1085,5 & 577,5 \\
\hline 2018 & 2398,1 & 1065,8 & 1332,3 \\
\hline
\end{tabular}

Fuente: Ministerio de Turismo (2020).

Elaboración: Autores. 
Gráfico 20. Ingresos y egresos por turismo en millones de dólares 2012-2018.

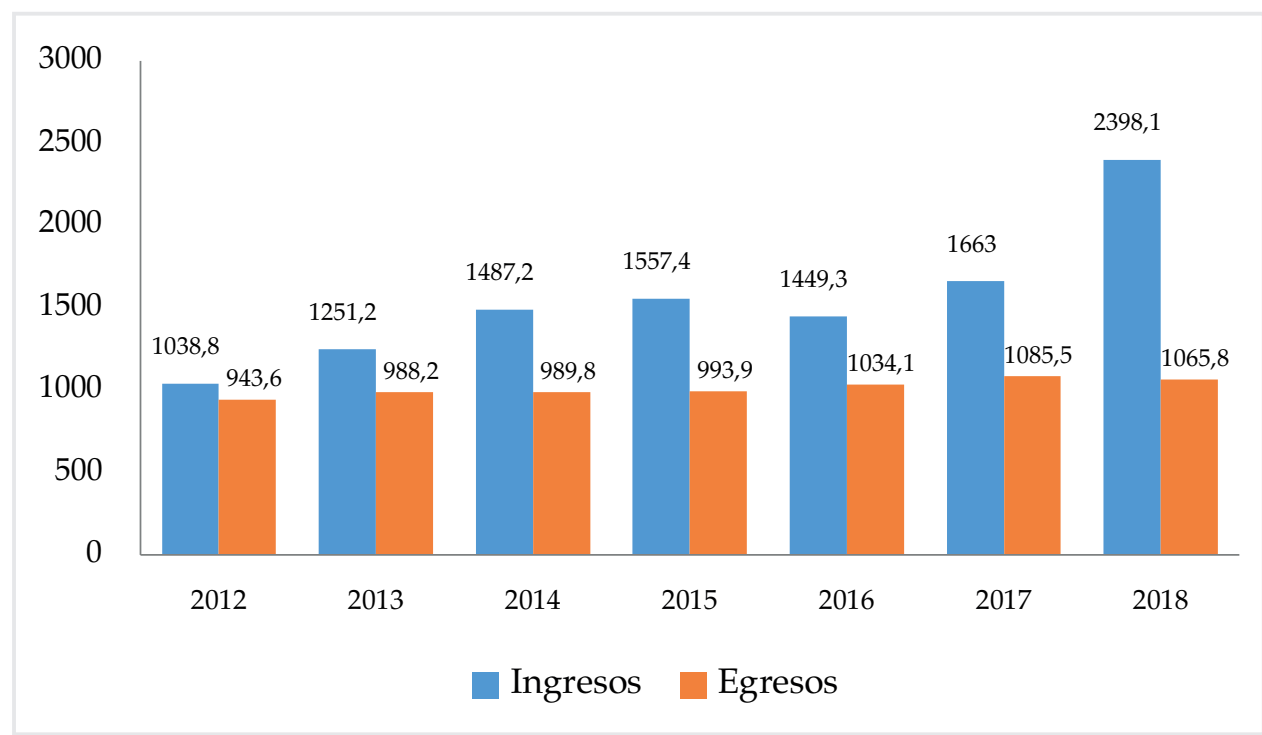

Fuente: Ministerio de Turismo (2020)

Elaboración: Autores.

El país registra por 7 años consecutivos un superávit en la balanza turística. Los ingresos registrados en el país por turismo desde el 2012 ha ido subiendo paulatinamente sin embargo es en el año 2016 donde sufre una disminución, debido a factores externos como la apreciación del dólar y el terremoto ocurrido en el mes de abril de 2016, pero al mismo tiempo el saldo en comparación con los egresos registrados por turismo-deja un saldo favorable para el país.

Tabla 7: Llegadas de extranjeros (miles de personas)

\begin{tabular}{|c|r|}
\hline Años & \multicolumn{1}{|r|}{ Extranjeros } \\
\hline 2009 & 939 \\
\hline 2010 & 1.016 \\
\hline 2011 & 1.103 \\
\hline 2012 & 1.226 \\
\hline
\end{tabular}




\begin{tabular}{l|l}
2013 & 1.262 \\
2014 & 1.437 \\
2015 & 1.439 \\
2016 & 1.569 \\
2017 & 1.806 \\
2018 & 2.535 \\
2019 & 2.108 \\
\hline
\end{tabular}

Fuente: Ministerio de Turismo (2020).

Elaboración: Autores.

Gráfico 21. Llegadas de extranjeros miles de personas.

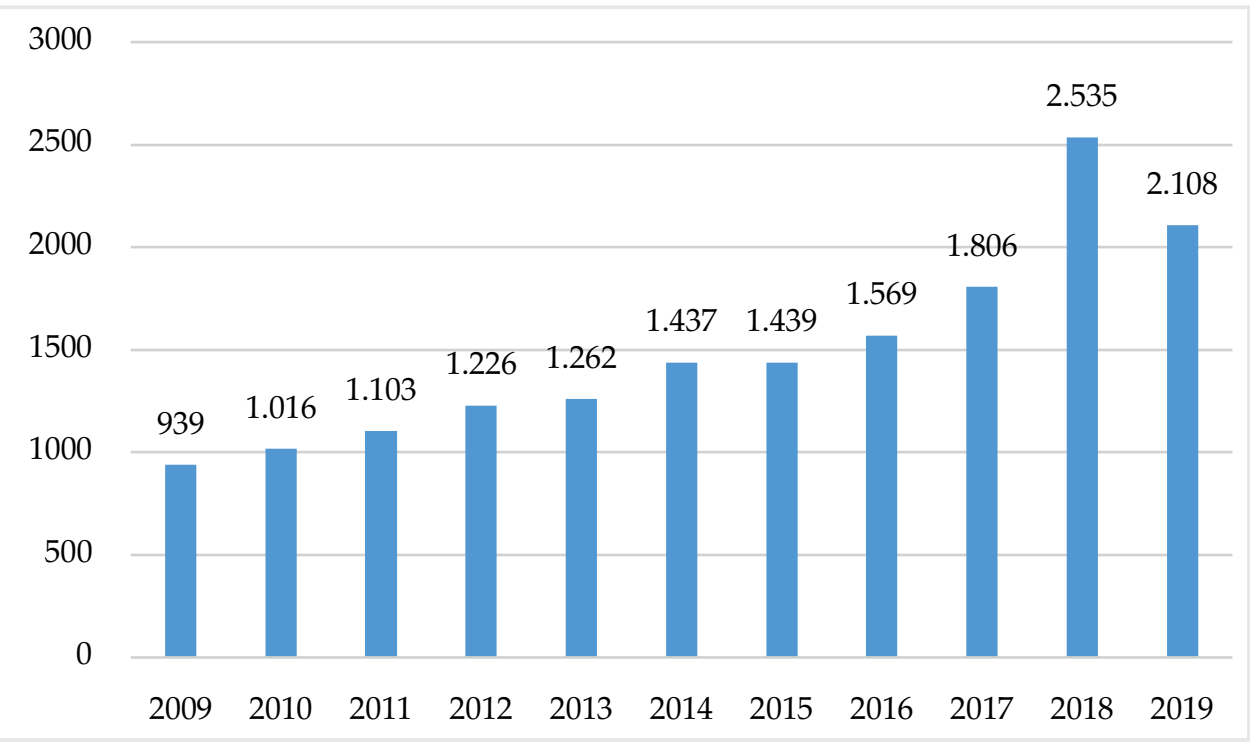

Fuente: Ministerio del Turismo (2020).

Elaboración: Autores.

En el gráfico 21, se observa la tendencia de llegada de personas extranjeras al país, la cual ha sido positiva con un claro crecimiento para el periodo 2009 al 2018, esto ha permitido que se fortalezca este sector como un generador de divisas y empleo. El turismo tiene un efecto multiplicador de $1,6 \%$ lo que quiere 
decir que este sector es un excelente dinamizador de la economía, porque redistribuye la riqueza y permite que las divisas no salgan del país.

El gobierno se ha empeñado en realizar una campaña de venta de los destinos turísticos de Ecuador que busca motivar a los ecuatorianos a recorrer el país con productos a precios asequibles, con el fin de reactivar toda la industria nacional, para esto ha realizado una serie de eventos como: Feria "Ecuador ama la vida", Workshops en Destinos, Programa Pueblos Mágicos, Entrega del Plan de Fortalecimiento Institucional, Diseño y Desarrollo de Productos, Implementación del Sistema de Gestión de Calidad, Capacitaciones, Mintur Talks, Guía "Ecuador, Destino Seguro", entre otros (MINTUR, 2019). 


\section{El sector turístico y su impacto en el crecimiento económico (modelo econométrico).}




\section{El sector turístico y su impacto en el crecimiento económico (modelo econométrico).}

El crecimiento económico es el resultado de la acumulación de factores de producción, particularmente el capital, y del incremento de la productividad, así también la acumulación del capital es una función del ahorro y del crecimiento demográfico (Dornbusch, Fischer, \& Startz, 2009). El crecimiento económico se lo puede definir como el aumento de la cantidad de bienes y servicios producidos en un determinado periodo generando un mejoramiento de las condiciones de vida de un individuo promedio, este usualmente se mide por el producto interno bruto real (PIB) (Larraín \& Sachs, 2002).

La idea de crecimiento económico es un concepto que ha sido analizado en la historia moderna después de 1800, ya que las condiciones de las poblaciones cambiaron muy poco en épocas pasadas, así, las tasas de crecimiento difieren de una manera importante entre los diferentes países, las diferencias relativamente leves en las tasas de crecimiento anual tienen un efecto importante en el ingreso per cápita en el largo plazo (Larraín \& Sachs, 2002).

Según Simon Kuznets el crecimiento moderno empezó con la revolución industrial, que tuvo lugar entre 1780 y 1820 en Inglaterra, en los Estados Unidos entre 1810 y 1860 y en Alemania de 1820 y 1870, y que coincidió con el desarrollo del capitalismo como sistema económico imperante.

El crecimiento económico se debe al crecimiento de los factores, como mano de obra y capital, y a los avances tecnológicos, en este sentido la función de producción establece un vínculo 
cuantitativo entre los factores y el nivel de producto, es decir más factores representa más producción.

$$
\mathrm{Y}=\mathrm{AF}(\mathrm{K}, \mathrm{N})
$$

Donde (Y) es el producto, (N) la mano de obra, (K) el capital y (A) representa el nivel tecnológico (productividad). Es sustancial indicar que en la función de producción (1) se omiten por simplificación una serie de factores que pueden ser importantes en momentos y lugares específicos, como los recursos naturales, el capital humano, entre otros (Dornbusch, Fischer, \& Startz, 2009).

En ese sentido, el turismo es uno de los principales sectores que impulsa la creación de empleo, la inversión extranjera y nacional, la estabilidad económica y la dinamización de la economía con expectativas positivas para el crecimiento de mediano y largo plazo, además es respetuoso con la naturaleza.

En ese contexto es importante determinar el impacto que tiene esta actividad como una herramienta para disminuir la pobreza y generar crecimiento económico, siendo un elemento esencial para aumentar el nivel de vida de la población. Para eso se parte de la función de producción Cobb Douglas pero como un factor adicional la actividad turística, con el fin de determinar el impacto de este sector en el crecimiento económico del Ecuador.

$$
Y=A\left(K^{\alpha} L^{\theta} I^{\beta}\right)
$$

Dónde:

Y es el producto, (A) es un parámetro mayor que cero que mide la productividad de la tecnología existente, (K) es el capital, (L) el factor trabajo y (I) el factor turístico, $\theta, \beta$ y $\alpha$ son coeficientes que miden la participación de cada factor en el producto. 


\subsection{Metodología}

La investigación se basa principalmente en el método hipotético-deductivo, el cuál en esencia parte de la observación del problema, para luego plantear una hipótesis que es una afirmación o una proposición aún no comprobada acerca de un factor o fenómeno que es de interés para el investigador, inmediatamente se genera las proposiciones a partir de la hipótesis, para terminar con la comprobación de los enunciados. En este caso el problema de investigación es determinar la contribución del turismo en el crecimiento económico, parte de la hipótesis que este sector tiene un efecto positivo en la actividad económica y la comprobación lo hace a través del modelo econométrico que permite probar de forma empírica la hipótesis planteada.

\subsection{Población y muestra}

El objetivo de la mayoría de los proyectos de investigación de economía es obtener información acerca de las características o parámetros de la población, que es la suma de todos los elementos que comparten algún conjunto común de rasgos y que constituyen el universo para los propósitos del problema de la investigación económica.

La información sobre los parámetros de la población puede obtenerse mediante la realización de un censo o la obtención de una muestra.

Una muestra es un subgrupo de la población, que se selecciona para participar en el estudio. Después se utilizan las características de la muestra, llamadas estadísticos, para hacer inferencias sobre los parámetros de la población. 
En la investigación se considera la población estadística al conjunto de datos disponibles en fuentes oficiales que en este caso se consideran desde el año 1927 hasta 2019, para efecto de la investigación se toma como muestra estadística el periodo comprendido desde el primer trimestre del 2007 al segundo trimestre del 2019, al ser información secundaria oficial no es necesario la validación estadística de la muestra, ya que son datos obtenidos con una metodología científica. La muestra es consistente para el método clásico de regresión lineal ya que cumple con todos los supuestos. La información estadística fue recolectada en Ecuador de instituciones como el Banco Central, Ministerio de Turismo, Instituto Nacional de Estadística y Censos, y Banco Mundial.

\subsection{Modelo econométrico}

En términos generales la metodología econométrica parte del planteamiento de la teoría o hipótesis. En el presente trabajo, se realiza un análisis de la relación del turismo y el crecimiento económico. La revisión de la literatura de trabajos realizados sobre este tema permite establecer que dicha relación es positiva (Brida, Monterubbianesi, \& Aguirre, 2011). Realizan un estudio para Colombia donde analiza el rol del turismo y sus efectos sobre el crecimiento económico y el desarrollo, centrándose en cuatro importantes regiones turísticas de Colombia, ven su contribución en el corto y largo plazo, los análisis realizados muestran una participación creciente del turismo en el crecimiento económico, mostrando una clara causalidad positiva y unidireccional desde el gasto en turismo hacia el producto per cápita en cada región.

Altamira y Muñoz (2007) hacen un análisis del turismo como base teórica para explicar su incidencia en el crecimiento económico de un país dentro una economía globalizada, determinan que las capacidades del turismo para generar crecimiento económico 
radican del nivel de competitividad de dicho país y específicamente del sector.

Brida, London y Rojas (2014), presentan un modelo en el que se analiza cómo la preferencia por el futuro afecta la inversión según una actividad particular (turismo). En el trabajo verifican que sistemas con alta impaciencia (preferencia por el consumo presente) y teniendo como supuestos una tasa de inversión que en el extremo es negativa (e igual a la depreciación), junto con la destrucción (basada en el "no cuidado") de los recursos naturales, y junto con la dinámica del modelo es posible analizar tres resultados: crecimiento continuo, crecimiento moderado según valores bajos pero positivos de $\mathrm{Q}$, y trampa de la pobreza, en aquellas sociedades en las que la valoración por el futuro es extremadamente baja.

Partiendo de los estudios empíricos mencionados y de la fundamentación teórica, que el desarrollo turístico influye positivamente en el crecimiento económico, el modelo de la investigación parte de la siguiente expresión:

$$
Y=(K, I, T)
$$

Donde $\mathrm{Y}$ es el producto, $\mathrm{K}$ representa la inversión $(\mathrm{FBKF})^{1}$, I es el ingreso de divisas generado por el sector turístico y $\mathrm{T}$ es el índice de tipo de cambio real, todas en términos constantes y tomadas trimestralmente. Estas variables han sido tomadas como factores determinantes que influyen en el crecimiento de la economía. La inversión siempre es un elemento importante en el crecimiento de mediano y largo plazo, estudios empíricos han cuantificado esta relación como positiva y el sustento teórico, así lo respalda. La

1 Formación bruta de capital fijo: corresponde a la inversión de un país, representada por la variación de los activos fijos no financieros tanto privados como públicos, (total de adquisiciones menos ventas de activos fijos), en un periodo de tiempo determinado (Banco Central del Ecuador, 2020). 
literatura que estudia la relación entre el tipo de cambio real (TCR) y crecimiento económico sugiere que la apreciación de la moneda puede ser un factor en el lento crecimiento de algunos países. Estos estudios han hallado una relación fuerte entre el TCR y la tasa de crecimiento a mediano plazo. Según esta correlación, mientras que una moneda se devalúa impulsa el crecimiento, lo contrario (revalúa) lo dificulta (Ibarra, 2016).

El turismo es una industria que tiene un impacto positivo sobre el crecimiento y el desarrollo económico, actualmente es la tercera industria que más genera divisas para el país. Los principales impactos económicos se relacionan con los ingresos por divisas, la contribución a los ingresos públicos y la generación de empleo y oportunidades de negocios (Brida, Pereyra, \& Such, 2008). Por tanto, el modelo para el estudio econométrico queda explicado de la siguiente manera.

$$
Y_{t}=\beta_{0}+\beta_{1} X_{1 t}+\beta_{2} X_{2 t}+\beta_{3} X_{3 t}+u_{t}
$$

\section{Dónde:}

$\mathrm{Y}_{\mathrm{t}}=\mathrm{PIB}=$ Producto interno bruto que explica el comportamiento del crecimiento económico del país, en términos reales.

$\mathrm{X}_{1 \mathrm{t}}=\mathrm{FBKF}=$ Formación bruta de capital fijo, componente del sector real de la economía que refleja la inversión realizada en el país, en términos constates.

$\mathrm{X}_{2 \mathrm{t}}=\mathrm{I}=\mathrm{es}$ el ingreso de divisas generado por el sector turístico, en términos constantes.

$\mathrm{X}_{3 \mathrm{t}}=\mathrm{T}=$ es el índice de tipo de cambio real. 
$\beta^{\prime} \mathrm{s}=$ coeficientes a calcular

$\mu \mathrm{t}=$ Término de perturbación estocástico.

$\mathrm{t}=\mathrm{el}$ tiempo en trimestres.

Para empezar el análisis empírico debemos definir el periodo que abarcan estas cifras trimestrales, el cual va de I-2007 al II-2019, para un total de 50 datos recopilados del Banco Central del Ecuador y del Ministerio de Turismo. Para un primer análisis trazamos las gráficas correspondientes.

Gráfico 22. PIB, Ingresos turismo (I), FBKF en miles de dólares constantes e indice de tipo de cambio real (T) año base 1994. Periodo I.2007-II.2019
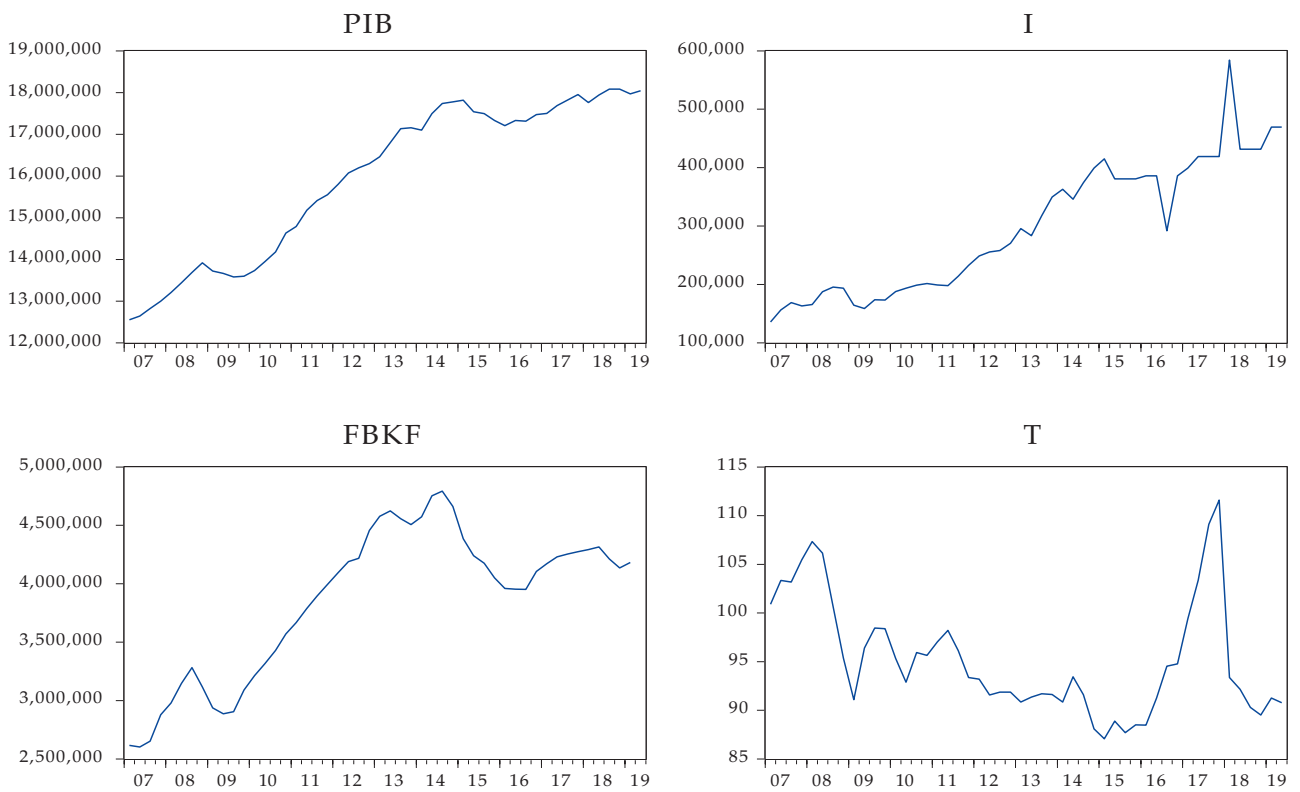

Fuente: Eviews.

Elaboración: Autores.

Como se observa en el gráfico 22, las tres variables PIB, I y FBKF tienen un comportamiento de tendencia, por lo que es necesario realizar un proceso de transformación logarítmica 
para estabilizar la varianza y suavizar el comportamiento de los coeficientes, obteniendo la siguiente expresión:

$$
\operatorname{LnY}_{t}=\beta_{0}+\beta_{1} \operatorname{LnX} X_{1 t}+\beta_{2} \operatorname{LnX}_{2 t}+\beta_{3} \operatorname{Ln} X_{3 t}+u_{t}
$$

Es práctica común graficar el logaritmo de una serie de tiempo para tener una idea de la tasa de crecimiento de dicha serie, como vemos en el gráfico 23 , las series tienden hacia arriba.

Gráfico 23. $\log$ PIB, $\log$ I y $\log$ T, periodo I.2007-II.2019

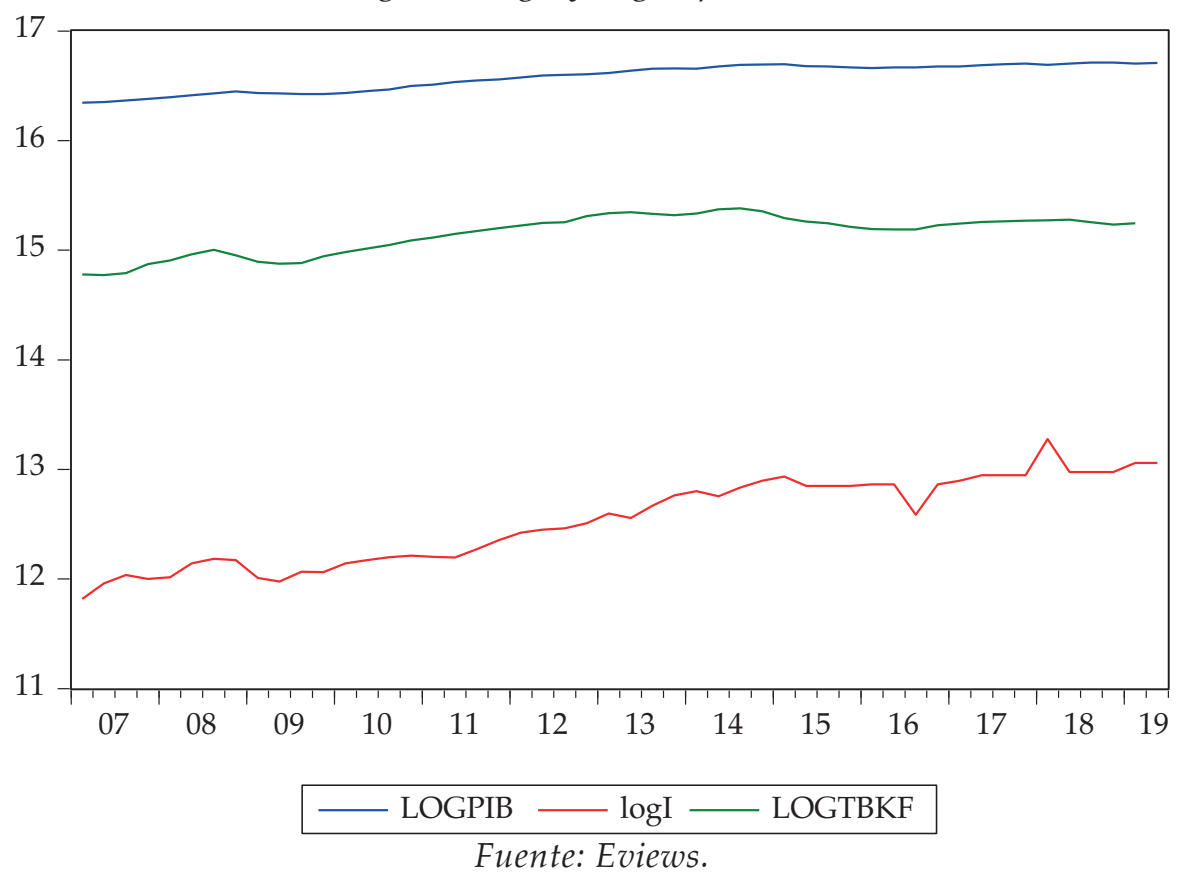

Elaboración: Autores.

En el análisis de series de tiempo es importante determinar si se tratan de procesos estocásticos aleatorios o no, con el fin de identificar si su media y varianza son constantes en el tiempo y si el valor de la covarianza entre dos periodos depende solo de la distancia o rezago entre estos dos periodos. Para saber si es 
estacionaria o no la variable podemos identificar varios métodos como el gráfico, el de correlograma y uno más formal el test de raíz unitaria.

Es importante identificar el carácter de estacionario o no de las variables en análisis, en vista que se podría inferir falsas relaciones significativas de causalidad, dado por el carácter no estacionario de las series y caer en el fenómeno de la regresión espuria.

\section{Test de raíz unitaria.}

Una prueba sobre estacionariedad (o no estacionariedad) que se populariza cada vez más se conoce como prueba de raíz unitaria, para lo que se forma un juego de prueba de hipótesis:

$H_{0}:$ Raíz Unitaria (hipótesis nula) $H_{1}$ :No hay raíz unitaria (hipótesis alternativa) Las condiciones por cumplir para rechazar o no $H_{0}$ son las siguientes:

$\mathrm{Si}, A D F^{2}$ calculado $>$ Valor Crítico $\rightarrow$ no rechazo $H_{0}$ $\mathrm{Si}, \mathrm{o}<$ Valor Crítico $\rightarrow$ rechazo $\mathrm{H}_{0}$

En primer lugar, debemos determinar que las variables no presenten autocorrelación, para esto utilizamos el estadístico de Durbin-Watson, cuyos valores pueden tener un rango entre 1,85 y 2,15 .

Tabla 8. Prueba de autocorrelación de las variables.

\begin{tabular}{lc|}
\multicolumn{1}{c}{ Variable } & DW \\
\hline LogPIB & 2.054624 \\
\hline Log I & 2.125182 \\
\hline
\end{tabular}

2 Augmented Dickey-Fuller test statistic 


\begin{tabular}{ll}
$\operatorname{LogFBKF}$ & 1.736083 \\
$\log \mathrm{T}$ & 1.557160 \\
\hline
\end{tabular}

Fuente: Eviews.

Elaboración: Autores.

En un primer vistazo de la Tabla 8 vemos que las variables FBKF y $T$, tienen unos valores de 1.736083 y de 1.557160 que indican problemas de autocorrelación por lo que procedemos a arreglar este problema aumentando dinámica a las series, en este caso tenemos los siguientes resultados. Para LogT el valor con un retardo, el Durbin-Watson es de 2.031920 y el valor para LogFBKF es de 1.933299 con dos retardos.

Una vez arreglados los problemas de autocorrelación se analizan los resultados del test de raíz unitaria a través del test estadístico aumentado de Dickey-Fuller. Donde tenemos los siguientes resultados.

Tabla 9. Prueba de estacionariedad de las variables

\begin{tabular}{lllc} 
Variable & ADF Calculado & Valor Crítico* & DW \\
\hline LogPIB & -2.020593 & -2.923780 & 2.054624 \\
\hline $\log$ I & -0.961981 & -2.923780 & 2.125182 \\
\hline LogFBKF & -2.275661 & -2.926622 & 1.933299 \\
\hline $\log T$ & -2.844803 & -2.923780 & 2.031920 \\
\hline
\end{tabular}

Fuente: Eviews; Elaboración: Propia

${ }^{*} 5 \%$ de significancia

Como se observa en la Tabla 9 los valores críticos calculados para un nivel de significancia del $5 \%$ de las cuatro variables se encuentran a la derecha del ADF calculado para las mismas, prueba que indica respuesta a favor de la hipótesis nula lo que revela que tienen raíz unitaria, es decir son no estacionarias. 
Para determinar el orden de integración entre las series, se efectúa la prueba de raíz unitaria con n diferencias (determina el orden) a fin de hacer a las variables estacionarias, por lo que se tiene:

Tabla 10. Orden de integración de las variables (test de raíz unitaria con 1era

diferencia)

\begin{tabular}{llllcc} 
Variable & $\begin{array}{l}\text { ADF } \\
\text { Calculado }\end{array}$ & $\begin{array}{l}\text { Valor } \\
\text { Crítico* }^{*}\end{array}$ & DW & Retardos & Diagnóstico \\
LogPIB & -4.218559 & -2.923780 & 2.083358 & 0 & $\mathrm{I}(1)$ \\
Log I & -9.398726 & -2.923780 & 2.139132 & 0 & $\mathrm{I}(1)$ \\
\hline LogFBKF & -3.720171 & -2.928142 & 1.851309 & 2 & $\mathrm{I}(1)$ \\
LogT & -4.847838 & -2.925169 & 2.015170 & 1 & $\mathrm{I}(1)$ \\
\hline
\end{tabular}

Fuente: Eviews

Elaboración: Propia

Una vez aplicado la primera diferencia y de acuerdo al estadístico de Dickey-Fuller las variables se vuelven estacionarias, los ADF calculados están a la izquierda de los valores críticos de cada una de las series. Por lo tanto, se rechaza la hipótesis nula y se concluye que $\log$ PIB, $\log I, \operatorname{LogFBKF}$ y $\log \mathrm{T}$ son variables estacionarias integradas de orden uno.

Regresión mediante mínimos cuadrados de todas las variables

Tabla 11. Regresión mediante mínimos cuadrados. Variable Dependiente: LOGPIB

\begin{tabular}{|ccccc|}
\hline Variable & Coefficient & Std. Error & t-Statistic & Prob. \\
\hline C & 10.33424 & 0.556789 & 18.56042 & 0.0000 \\
\hline LOGI & 0.193675 & 0.014595 & 13.27010 & 0.0000 \\
\hline LOGFBKF & 0.269517 & 0.034037 & 7.918437 & 0.0000 \\
\hline LOGT & -0.058675 & 0.058638 & -1.000631 & 0.3224 \\
\hline
\end{tabular}




\begin{tabular}{cccc} 
R-squared & 0.971587 & & \\
F-statistic & 512.9303 & Mean dependent var & 16.57532 \\
\hline Prob(F-statistic) & 0.000000 & Durbin-Watson stat & 1.324017 \\
\hline
\end{tabular}

Fuente: Eviews.

Elaboración: Autores.

Una vez que se corre la regresión de LOGPIB en función de LOGI, LOGFBKF y LOGT se obtiene que la variable LOGT presenta una probabilidad 0,3224 mayor al nivel de confianza por default de $\alpha=0.05$ siendo no significativa para el modelo, por tanto, se procede a sacarla y a generar una nueva regresión, con las variables que son significativas al $5 \%$.

Tabla 12. Regresión mediante mínimos cuadrados de variables significativas al 5\% Variable Dependiente: LOGPIB.

\begin{tabular}{lllll} 
Variable & Coefficient & Std. Error & t-Statistic & Prob. \\
\hline C & 9.896861 & 0.344903 & 28.69463 & 0.0000 \\
\hline LOGI & 0.193070 & 0.014583 & 13.23984 & 0.0000 \\
\hline LOGFBKF & 0.281245 & 0.031956 & 8.801073 & 0.0000 \\
\hline R-squared & 0.970955 & & & \\
\hline F-statistic & 768.8737 & Mean dependent var & 16.57532 \\
\hline Prob(F-statistic) & 0.000000 & Durbin-Watson stat & 1.217056 \\
\hline
\end{tabular}

Fuente: Eviews

Elaboración: Autores.

Las series son no estacionarias por tanto la aplicación de regresión mediante el método de mínimos cuadrados, puede resultar en estimaciones falsas (espuria), Sin embargo, esta regresión se la aplicó para verificar la significancia de las variables, como se ve en la Tabla 12 las variables tienen el signo esperado, es decir, hay una relación positiva indicando que tanto los ingresos 
del sector turístico como la formación bruta de capital fijo afectan de manera importante en el crecimiento económico.

El coeficiente de los ingresos del sector turístico tiene un valor de 0.193070 , lo que indica que por cada uno por ciento que aumente, el PIB aumentará en 0,19\% y el valor del coeficiente de la formación bruta de capital fijo es de 0.281245 , lo que representa que por cada uno por ciento que aumente, la economía crecerá en $0,28 \%$.

\section{Test de Cointegración de Johansen}

Como indicamos que las variables son no estacionarias es importante identificar que estas estimaciones no sean espurias, es decir, tenemos que probar que hay una relación estable de largo plazo, para esto se debe verificar si estas están cointegradas, y para ello se utiliza el método de Johansen, planteando dos juegos de hipótesis:

$H_{0}$ : No hay vector de cointegración

$H_{1}$ :A lo sumo hay vector de cointegración

Tabla 13. Prueba de rango de cointegración - Johansen Test

\begin{tabular}{|c|c|c|c|c|}
\hline Variables & Traza & $\begin{array}{c}0,05 \\
\text { Valor crítico }\end{array}$ & P-valor* & Diagnóstico \\
\hline None & 37.47891 & 29.79707 & 0.0149 & ------ \\
\hline At most 1 & 12.77838 & 15.49471 & 0.0735 & 1 vector \\
\hline At most 2 * & 0.115329 & 3.841466 & 0.0962 & ------ \\
\hline
\end{tabular}

Fuente: Eviews.

Elaboración: Autores.

En el test de Johansen tenemos que el valor significativo es para la ecuación que plantea que al menos hay un vector de cointegración, ya que el p-valor es mayor al 5\%, es decir se rechaza la hipótesis nula y se acepta la alternativa. De esta manera se ha 
encontrado certeza de cointegración entre las variables de estudio, por tanto, se descarta la presencia de una relación espuria, estas variables contribuyen para una relación de equilibrio a largo plazo. Ahora podemos aplicar el método de corrección de errores.

\section{Método de vector de corrección de errores}

El método de vector de corrección de errores (VEC) intenta establecer un marco único en el que se integren tanto las relaciones de largo plazo estacionarias (recogidas a través de las relaciones de cointegración) junto con las dependencias dinámicas de corto plazo captadas a través de modelos VAR. En este caso podemos aplicar ya que las series son no estacionarias pero integradas de orden uno, lo que quiere decir que existe evidencia para determinar un equilibrio de largo plazo.

El rango de cointegración está dado por el número de vectores que se encontraron en la prueba de Johansen, en la cual se encontró al menos un vector de cointegración, en este sentido se obtiene una ecuación de cointegración, las variables analizadas una vez que se aplica el VEC se transforman a su primera diferencia.

Tabla 14. Ecuación de Cointegración variable dependiente D (LNPIB)

\begin{tabular}{lcccc} 
& Coeficiente & Standard Errors & t-Statistics & Probabilidad \\
C1 & -0.107878 & 0.067781 & -1.591571 & 0.1196 \\
C2 & -0.146631 & 0.144758 & -1.012935 & 0.3173 \\
C3 & 0.136846 & 0.120684 & 1.133928 & 0.2637 \\
C4 & -0.024404 & 0.014956 & -1.631727 & 0.1108 \\
C5 & 0.000930 & 0.012802 & 0.072675 & 0.9424 \\
C6 & 0.224920 & 0.043442 & 5.177503 & 0.0000 \\
C7 & 0.068241 & 0.058318 & 1.170151 & 0.2490 \\
\hline
\end{tabular}

Fuente: Eviews.

Elaboración: Autores. 
En la Tabla 14, podemos establecer el coeficiente de cointegración del modelo C1con un valor de -0.107924 , este es el término de corrección o velocidad de ajuste hacia el equilibrio, es este valor con el que se determinará el equilibrio a largo plazo, el mismo que tiene que ser negativo y significativo. En este caso el coeficiente es negativo pero no significativo ya que su $\mathrm{p}$ valor es mayor al 5\%, indicando que no hay causalidad a largo plazo que se ejecuta desde las variables LOGI, LOGFBKF hacia el LOGPIB.

\section{Condición de relación en el corto plazo}

Para el análisis de equilibrio a corto plazo se aplica el test Wald para los coeficientes de las variables explicativas, y se plantea la siguiente condición:

Si $\mathrm{H}_{0}=(4)=(5)=\ldots=(7)=0 \rightarrow$ no existe relación a corto plazo

Tabla 15. Wald Test, relación de equilibrio a corto plazo.

Wald Test:

Equation: EQ01

\begin{tabular}{lccc}
\hline \hline Test Statistic & Value & df & Probability \\
\hline \hline F-statistic & 10.03887 & $(4,39)$ & 0.0000 \\
Chi-square & 40.15547 & 4 & 0.0000 \\
\hline \hline
\end{tabular}

Null Hypothesis: $C(4)=C(5)=C(6)=C(7)=0$

Null Hypothesis Summary:

\begin{tabular}{lcc}
\hline \hline Normalized Restriction $(=0)$ & Value & Std. Err. \\
\hline \hline C(4) & -0.024404 & 0.014956 \\
$\mathrm{C}(5)$ & 0.000930 & 0.012802 \\
$\mathrm{C}(6)$ & 0.224920 & 0.043442 \\
$\mathrm{C}(7)$ & 0.068241 & 0.058318 \\
\hline \hline
\end{tabular}

Restrictions are linear in coefficients.

Fuente: Eviews.

Elaboración: Autores. 
Como se muestra en la Tabla 15, existe evidencia estadística para rechazar Ho ya que el p-valor $=0,000$ es significativo al 5\% concluyendo que hay causalidad a corto plazo que se ejecuta desde las variables LOGI, LOGFBKF hacia el LOGPIB.

\section{Función impulso-respuesta}

Esta mide el impacto de shocks o innovaciones inesperadas positivas o negativas en el corto o largo plazo sobre cada variable. En este sentido interesa saber el efecto del PIB ante shocks de parte de los ingresos turísticos y de la FBKF, esto se ve en el gráfico dos y tres, como vemos en el primer gráfico la respuesta es positiva pero solo en el corto plazo luego hasta el periodo tres, luego decae y se pierde, mientras en el siguiente el impacto también es positivo pero se mantiene en el largo plazo a pesar que el efecto decae desde el periodo cuarto.

Gráfico 24. Función Impulso-Respuesta
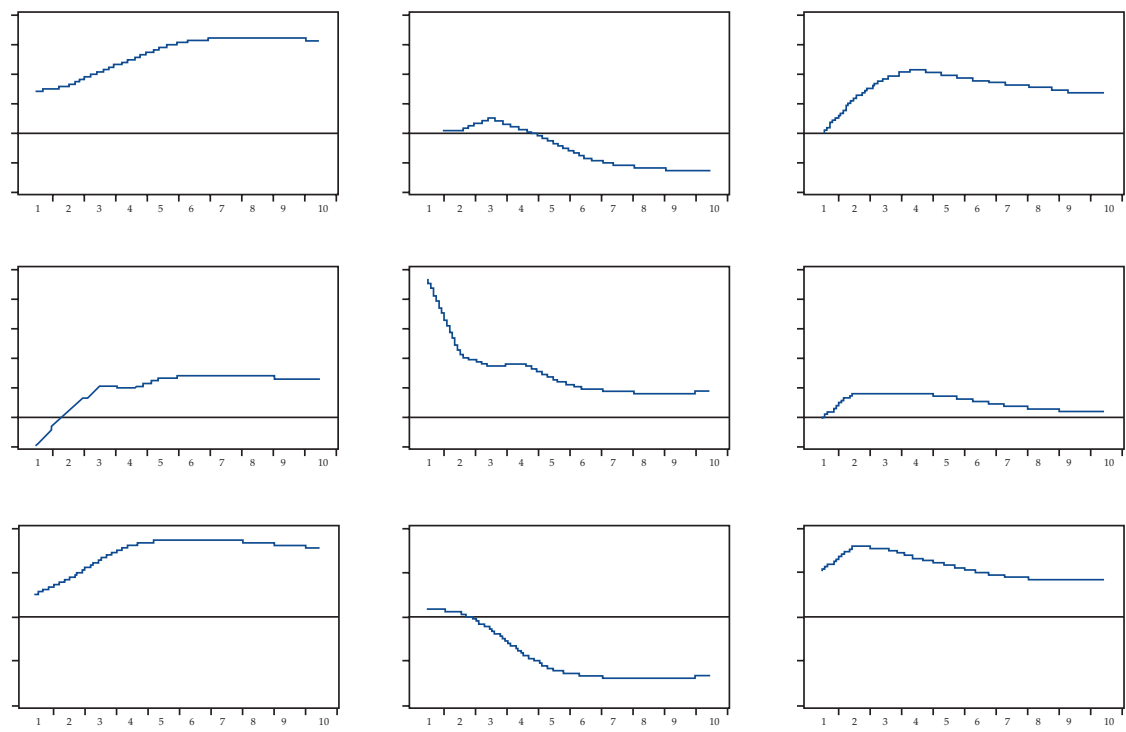

Fuente: Eviews.

Elaboración: Autores. 


\section{Descomposición de la varianza}

El estudio de la descomposición de varianza, técnica que facilita la longitud del efecto, es decir la contribución porcentual de cada shock para explicar la variación en la variable dependiente, es decir el efecto de corto y largo plazo.

Gráfico 25. Descomposición de la varianza

Percent LOGPIB variance due to LOGPIB

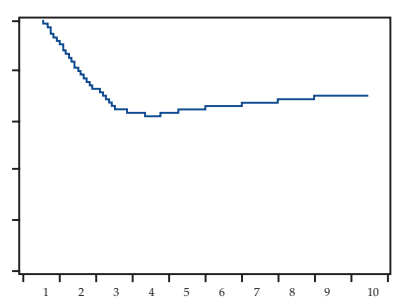

Percent LOGPIB variance due to LOGI

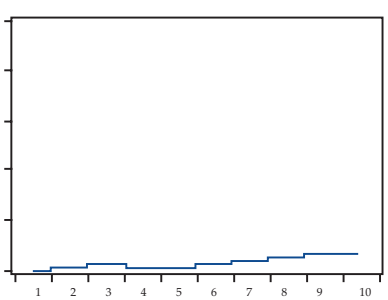

Fuente: Eviews.
Percent LOGPIB variance due to LOGFBKF

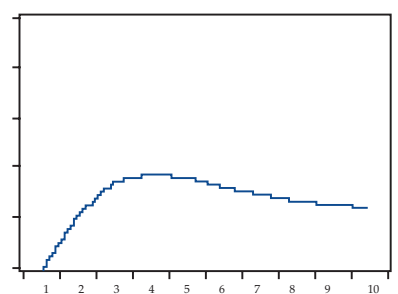

Elaboración: Autores.

Como vemos en el gráfico 25, se tiene que: un shock en el ingreso de divisas del sector turístico contribuiría en 1,57\% en el corto plazo y 6,78\% a la fluctuación del PIB en el largo plazo, mientras que la FBKF contribuiría en $34,50 \%$ en el corto plazo y en $23,67 \%$ a largo plazo. 


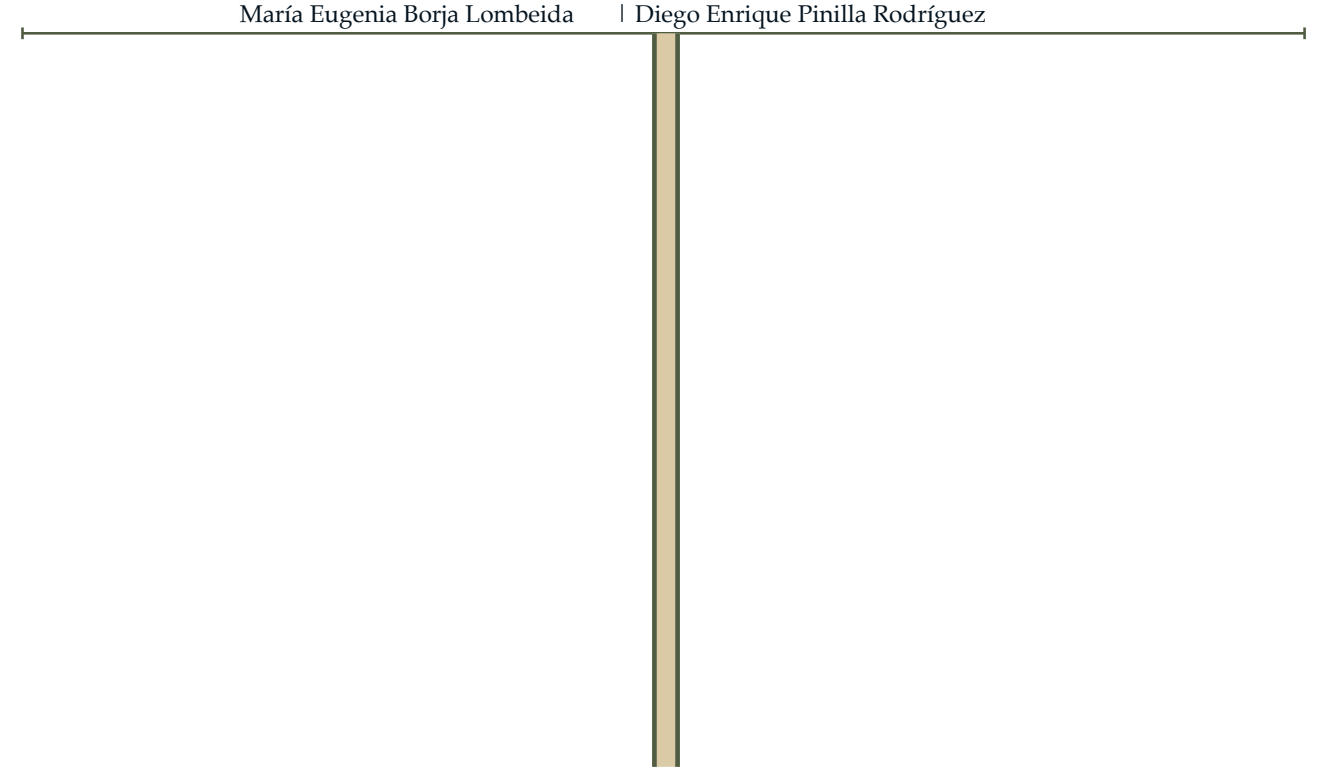

Capítulo 3

Turismo en Chimborazo 


\section{Turismo en Chimborazo}

La provincia de Chimborazo está situada al centro sur del país en la zona geográfica conocida como Región Interandina o Sierra, principalmente sobre la hoya de Chambo en el noreste y las hoyas de Chimbo y Chanchán en el suroccidente, posee una superficie de $6.495 \mathrm{~km}^{2}$ divididos en 10 cantones los cuales son: Riobamba, Alausí, Colta, Chunchi, Guamote, Penipe, Pallatanga Chambo, y Cumandá (Iwanatrip, 2019).

La provincia de Chimborazo es una zona muy rica, en costumbres y tradiciones, posee muchos atractivos turísticos, razón por la cual tiene un alto potencial para el desarrollo del turismo. La artesanía se ha hecho presente en ciertos lugares de la provincia como es el caso del cantón Guano, donde se elabora artículos y otras manufacturas elaboradas con lana, cuero y otras materias primas las cuales se constituyen como una de las principales actividades económicas de este sector (Guía Virtual de Turismo Accesible, 2014).

La provincia presenta muchos atractivos turísticos que hacen de ella un tesoro natural, entre las cuales se pueden mencionar el volcán Chimborazo, lagunas de Ozogoche, la nariz del Diablo, laguna de Atillo, iglesia de Balbanera, laguna de Colta, nevado el Altar, aguas termales de Guallabamba o Aguallanchi, cementerio Paleontológico de Punín, museo de la Concepción (Gobernación de Chimborazo, s.f.).

La ciudad de Riobamba y el cantón Alausí, son claros ejemplos del crecimiento económico generado por el ingreso de turistas, estos lugares han podido mejorar su calidad de vida gracias al encadenamiento productivo que genera la actividad turística (Erazo, 2009). 
Por lo tanto, se puede decir que el turismo tiene un efecto positivo en la economía ya que mejora la calidad de vida de las personas mediante la generación de empleo, debido a la apertura de agencias de viajes, hoteles, restaurantes entre otros.

\subsection{Importancia del turismo en Chimborazo}

El turismo es de gran importancia puesto que este genera dinamismo para la economía de los lugares receptores. La región que abarca dicha provincia está llena de rincones naturales y culturales aptos para atraer turistas de cualquier parte del planeta. Pero al mismo tiempo tiene uno de los ingresos per-cápita más bajos del país con \$4.481,55 para el año 2017 (Observatorio Económico de la UNACH, 2020), con este antecedente, el concepto de plantear una alternativa de desarrollo eco-turístico sustentable es una prioridad. En la provincia todavía no hay una importante afluencia de turistas nacionales y extranjeros a los atractivos naturales. Los meses de mayor visita a la provincia por parte de los turistas nacionales son febrero y marzo por motivos de carnaval, mientras que para los extranjeros es el mes de julio por motivos vacacionales (Observatorio Económico de la UNACH, 2019).

La falta de promoción de los atractivos, así como, la insuficiencia de inversión no ha permitido un desarrollo turístico global, lo que tiene un impacto en el avance socioeconómico de las comunidades indígenas de la región. Por lo tanto, el estudio de las variables turísticas es de suma importancia puesto que mediante estas se puede generar políticas de estado para incentivar a este sector, y así generar grandes beneficios a la sociedad tales como: generación de empleo, recaudación tributaria, encadenamientos productivos, entre otras. 
Tabla 16: Valor Agregado Bruto (VAB), sector alojamiento y servicios de comida de la provincia de Chimborazo, en Miles de Dólares.

\begin{tabular}{ccc} 
Año & Valor Agregado Bruto & Tasa de Variación \\
\hline 2007 & 23.907 & \\
\hline 2008 & 24.850 & $3.9 \%$ \\
\hline 2009 & 31.288 & $25.9 \%$ \\
\hline 2010 & 33.685 & $7.7 \%$ \\
\hline 2011 & 27.282 & $-19.0 \%$ \\
\hline 2012 & 36.662 & $34.4 \%$ \\
\hline 2013 & 31.895 & $-13.0 \%$ \\
\hline 2014 & 33.433 & $4.8 \%$ \\
\hline 2015 & 37.793 & $13.0 \%$ \\
\hline 2016 & 38.460 & $1.8 \%$ \\
\hline 2017 & 43.590 & $13.3 \%$ \\
\hline
\end{tabular}

${ }^{* * *}$ Nota: Último dato encontrado.

Fuente: Banco Central de Ecuador (2018).

Elaboración: Autores.

Gráfico 26. Valor Agregado Bruto (VAB), sector alojamiento y servicios de comida de la provincia de Chimborazo, en miles de dólares

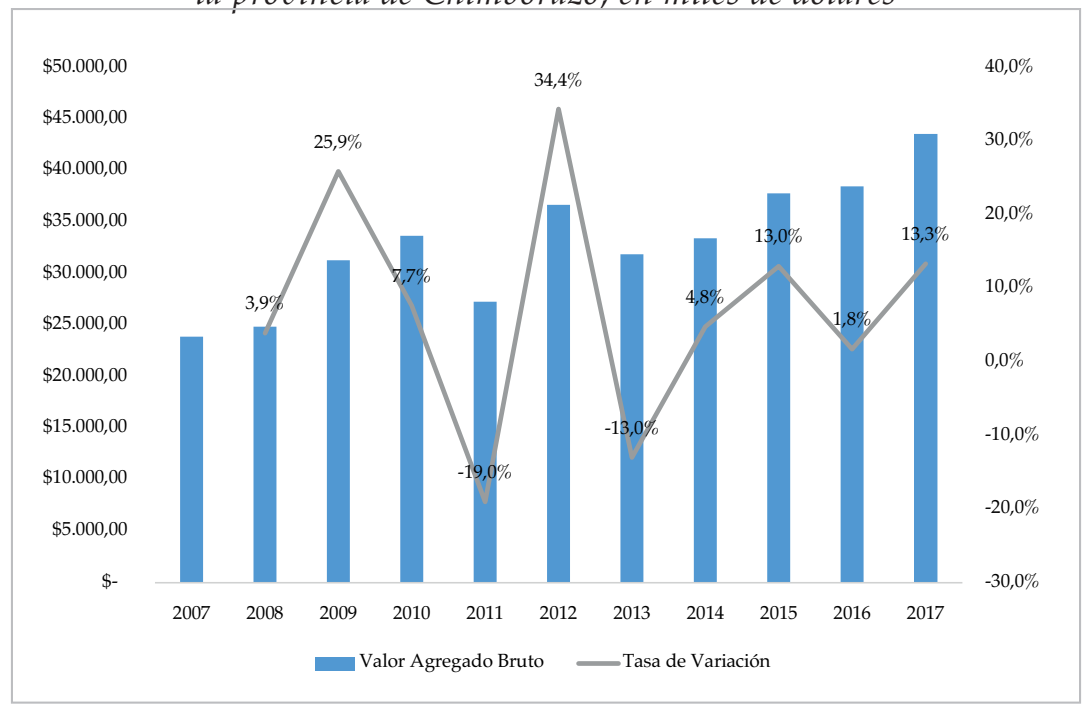

Fuente: Banco Central de Ecuador (2018).

Elaboración: Autores. 
En el gráfico 26, correspondiente al valor agregado bruto del sector alojamiento y servicios de comida de la provincia de Chimborazo, periodo 2007-2017. Se observa que, durante el periodo de estudio presenta una tendencia irregular, marcando una mayor tasa de crecimiento en el año 2012 del 34,4\% debido al proyecto de Fortalecimiento de la Red Social de Turismo Sostenible de la provincia de Chimborazo, donde el objetivo fue mejorar las condiciones de desarrollo social con base en la regulación de actividades de turismo sostenible en la provincia ( Herrera, 2012). De igual manera en los refugios del Nevado Chimborazo, se realizaron obras de mejoramiento (Ministerio de Turismo, 2012).

Por otra parte, la tasa de crecimiento más baja se registró en al año 2011. Es por ello que el Ministerio de Turismo contrató la elaboración del estudio de mejoramiento de los refugios de la Reserva de Producción de Fauna Chimborazo, con la finalidad de optimizar el servicio a turistas nacionales y extranjeros (Ministerio de Turismo, 2012). Por lo tanto, el Valor Agregado Bruto de alojamiento y servicios de comida durante el periodo de estudio, presenta una tasa promedio de crecimiento de 7,3\%.

Tabla 17: Agencias de viajes registradas en el Ministerio de Turismo, zona 3, año 2016.

\begin{tabular}{lll} 
Provincia & $\mathbf{N}^{\mathbf{0}}$ de Agencias & $\%$ Participación \\
\hline Cotopaxi & 22 & $11.7 \%$ \\
\hline Chimborazo & 34 & $18.1 \%$ \\
\hline Pastaza & 11 & $5.9 \%$ \\
\hline Tungurahua & 121 & $64.4 \%$ \\
\hline Total, zona 3 & 188 & $100 \%$ \\
\hline
\end{tabular}

${ }^{* * *}$ Nota: Último dato registrado

Fuente: Ministerio de Turismo (2017).

Elaboración: Autores. 
Gráfico 27. Porcentaje de participación del número de agencias de viajes registradas en el Ministerio de Turismo con respecto a la zona 3, año 2016.

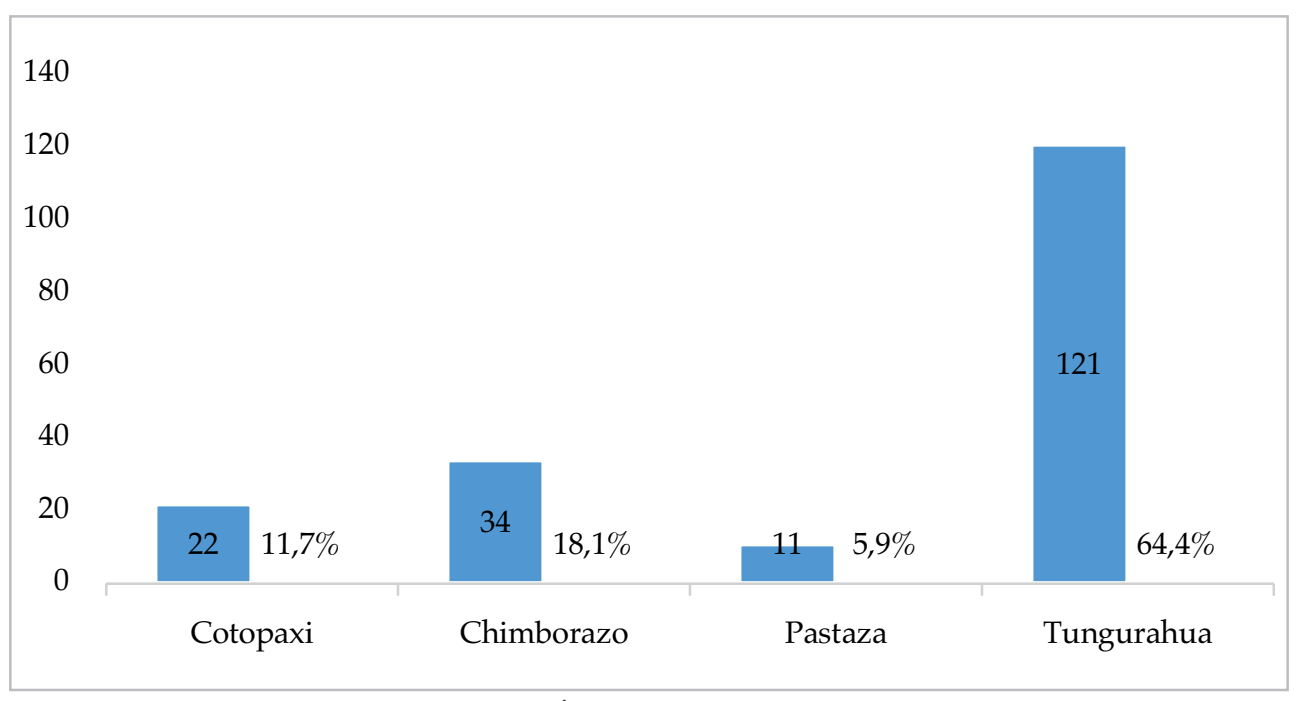

${ }^{* * *}$ Nota: Último dato registrado.

Fuente: Ministerio de Turismo (2017).

Elaboración: Autores.

En el gráfico 27, correspondiente al número de agencias de viajes de la zona 3 registradas en el Ministerio de Turismo, año 2016. Donde se observa que Tungurahua tiene un mayor porcentaje de participación con respecto a las demás provincias, debido a la importancia que tiene la ciudad de Baños por sus grandes atractivos turísticos. De igual manera en las ciudades de Ambato, Riobamba, Latacunga y Puyo se concentran operadoras de turismo que ofertan tours a distintos destinos turísticos del país especialmente de la zona 3 (Monge, Gaviño, Vaca, \& Salazar, 2018). Por lo tanto, la provincia de Chimborazo presenta un porcentaje de participación del 18\% es decir que, a la fecha de análisis, se registró 34 agencias de viajes en el Ministerio de Turismo. 
Tabla 18: Trasporte turístico terrestre registrado en el Ministerio de Turismo zona 3, aก̃ก 2016.

\begin{tabular}{|c|c|c|}
\hline Provincia & $\mathbf{N}^{0}$ de Empresas ${ }^{* *}$ & $\%$ Participación \\
\hline Cotopaxi & 3 & $15 \%$ \\
\hline Chimborazo & 5 & $25 \%$ \\
\hline Pastaza & 2 & $10 \%$ \\
\hline Tungurahua & 10 & $50 \%$ \\
\hline Total, zona 3 & 20 & $100 \%$ \\
\hline
\end{tabular}

***Nota: Último dato registrado; ${ }^{* *}$ Empresas de trasporte terrestre.

Fuente: Ministerio de Turismo (2017).

Elaboración: Autores.

Gráfico 28. Trasporte turístico terrestre registrado en el Ministerio de Turismo zona 3, año 2016.

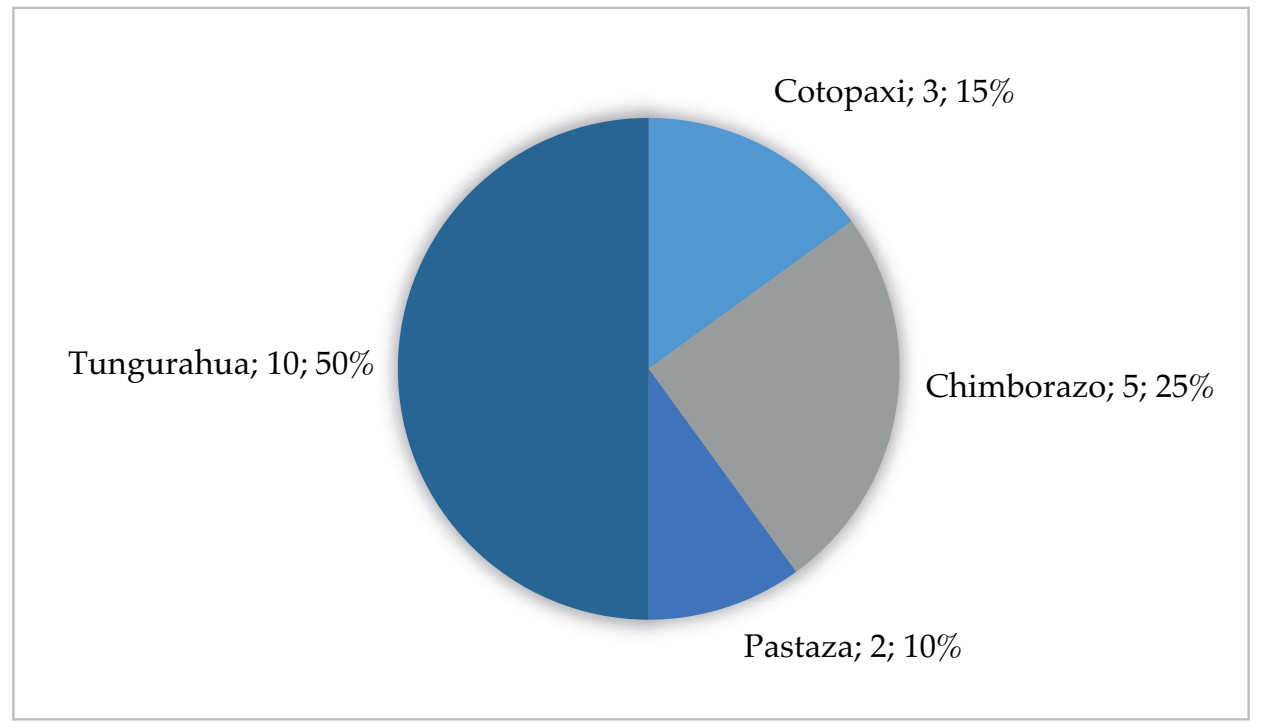

${ }^{* * *}$ Nota: Último dato registrado; ${ }^{* *}$ Empresas de trasporte terrestre.

Fuente: Ministerio de Turismo (2017).

Elaboración: Autores. 
En el gráfico 28, correspondiente al trasporte terrestre de la zona 3 registrado en el Ministerio de Turismo durante el año 2016. Se observa que la provincia de Tungurahua posee una participación del $50 \%$ siendo esta, la más alta de la zona 3, debido a que la ciudad de Baños es un referente turístico a nivel nacional e internacional (Monge, Gaviño, Vaca, \& Salazar, 2018). Por lo tanto, se encuentran más empresas de trasportes registradas en la provincia. De igual manera la provincia de Chimborazo presenta una participación del $25 \%$ con respecto a las demás provincias de la zona tres.

Tabla 19: Capacidad de establecimientos de alojamiento registrados por categorías en la provincia de Chimborazo, año 2016.

\begin{tabular}{lcc} 
Categoría & \multicolumn{2}{c}{ Total } \\
\hline 1 estrella o cuarta & Establecimientos & Habitaciones \\
\hline 2 estrellas o tercera & 35 & 517 \\
3 estrellas o segunda & 39 & 687 \\
4 estrellas o primera & 23 & 440 \\
\hline 5 estrellas o lujo & 6 & 102 \\
\hline Única & 1 & 51 \\
\hline
\end{tabular}

${ }^{* * *}$ Nota: Último dato registrado.

Elaboración: Autores.

Fuente: Ministerio de Turismo (2017). 
Gráfico 29. Cantidad de establecimientos de hospedaje clasificados por categorias y registrados en el Ministerio de Turismo en la provincia de Chimborazo, año 2016.

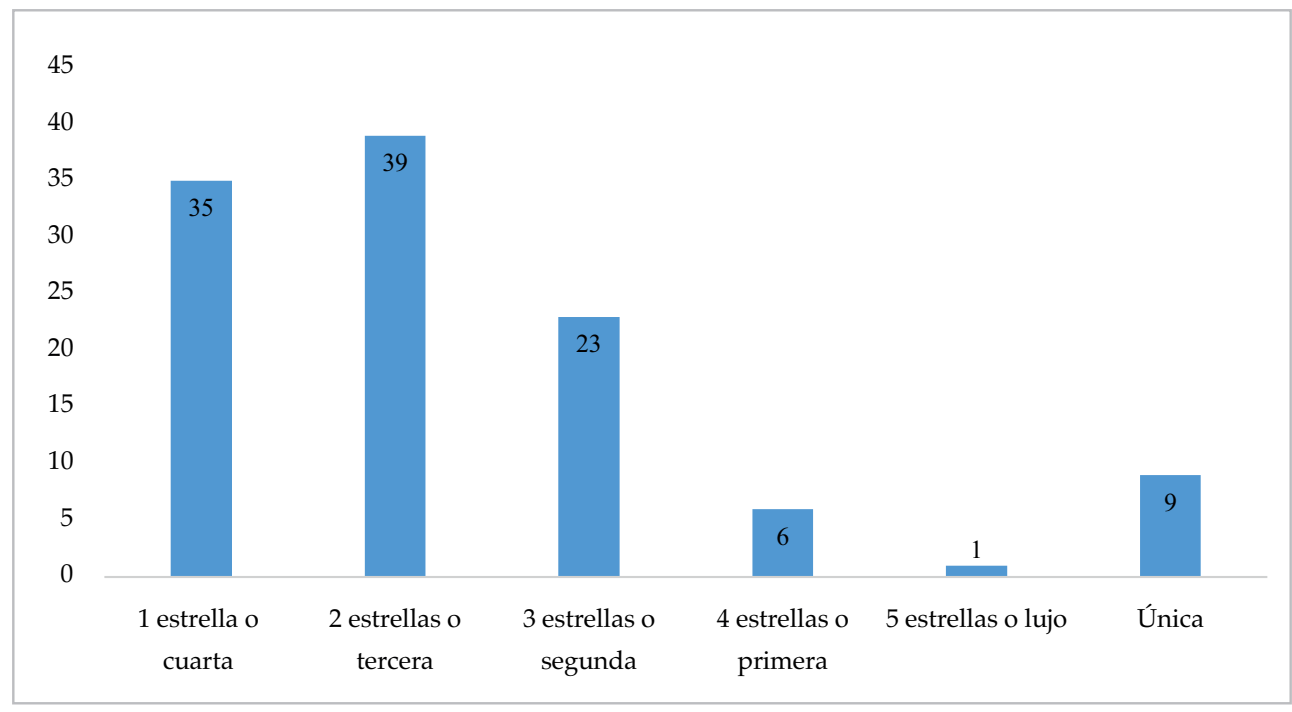

***Nota: Último dato registrado.

Fuente: Ministerio de Turismo (2017).

Elaboración: Autores.

En el gráfico 29, correspondiente a la cantidad de establecimientos por categoría registrados en el Ministerio de Turismo en la provincia de Chimborazo (2016). Se observa que los establecimientos de dos estrellas tienen una mayor participación seguido por los hoteles de una estrella con una cantidad de 35 establecimientos, la cantidad de establecimientos de 5 estrellas o de lujo es muy pequeña en la provincia de Chimborazo. 
Gráfico 30. Cantidad de habitaciones, clasificadas por categorías y registrados en el Ministerio de Turismo en la provincia de Chimborazo, año 2016.

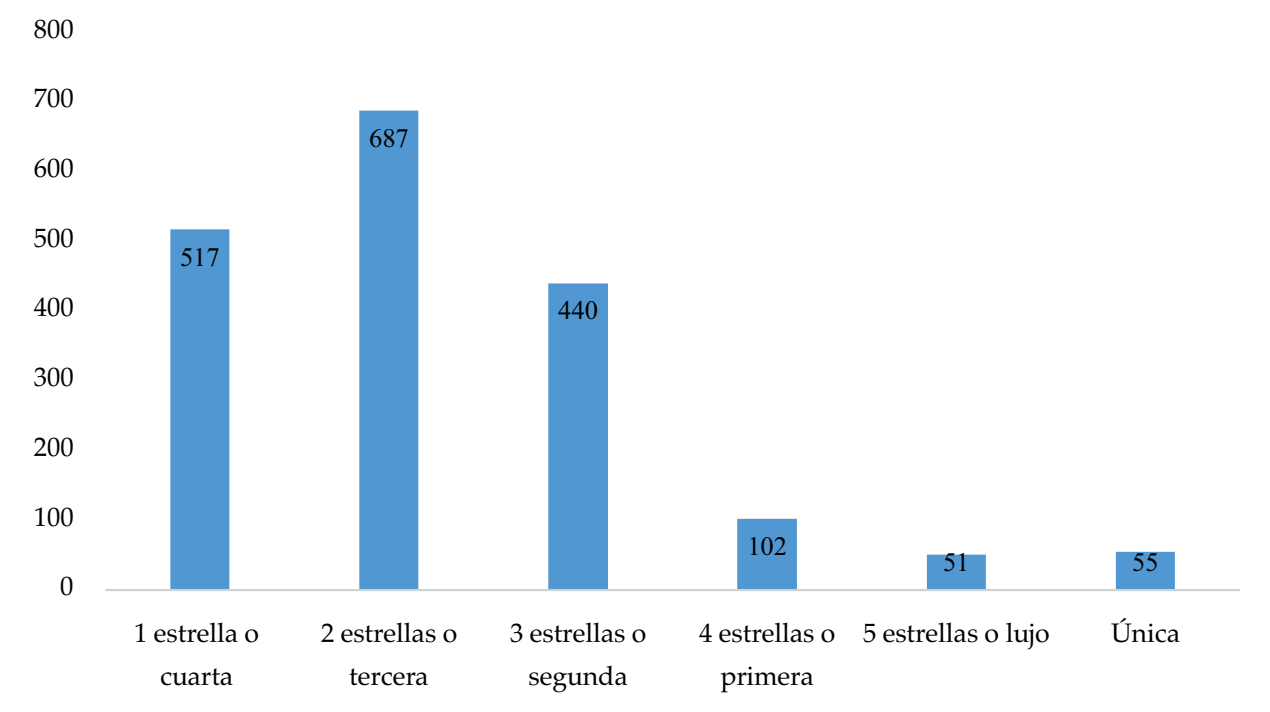

${ }^{* * *}$ Nota: Último dato registrado.

Elaboración: Autores.

Fuente: Ministerio de Turismo (2017).

En el gráfico 30, correspondiente a la cantidad de habitaciones, clasificadas por categorías y registrados en el Ministerio de Turismo en la provincia de Chimborazo año 2016. Se observa que existen registradas 687 habitaciones de dos estrellas, de igual manera la categoría de lujo o cinco estrellas, es la que menos habitaciones posee, pues registra 51.

Tabla 20: Recaudación tributaria hoteles y restaurantes en la zona 3, periodo 20122016.

\begin{tabular}{|ccccccc|}
\hline & \multicolumn{5}{c|}{ Valor Recaudado } \\
Zona 3 & 2012 & 2013 & 2014 & 2015 & 2016 \\
\hline Chimborazo & 1.389 .469 & 1.310 .651 & 1.623 .856 & 1.644 .414 & 1.444 .772
\end{tabular}




\begin{tabular}{lrrrrr} 
Tungurahua & 2.323 .072 & 2.753 .616 & 3.413 .674 & 3.957 .155 & 3.737 .550 \\
Pastaza & 239.231 & 297.142 & 326.673 & 299.672 & 223.892 \\
\hline Cotopaxi & 789.557 & 967.187 & 1.168 .508 & 1.133 .543 & 1.029 .349 \\
\hline
\end{tabular}

Elaboración: Autores.

Fuente: Ministerio de Turismo (2017).

Gráfico 31. Recaudación Tributaria Hoteles y Restaurantes en la zona 3, periodo 2012-2016.

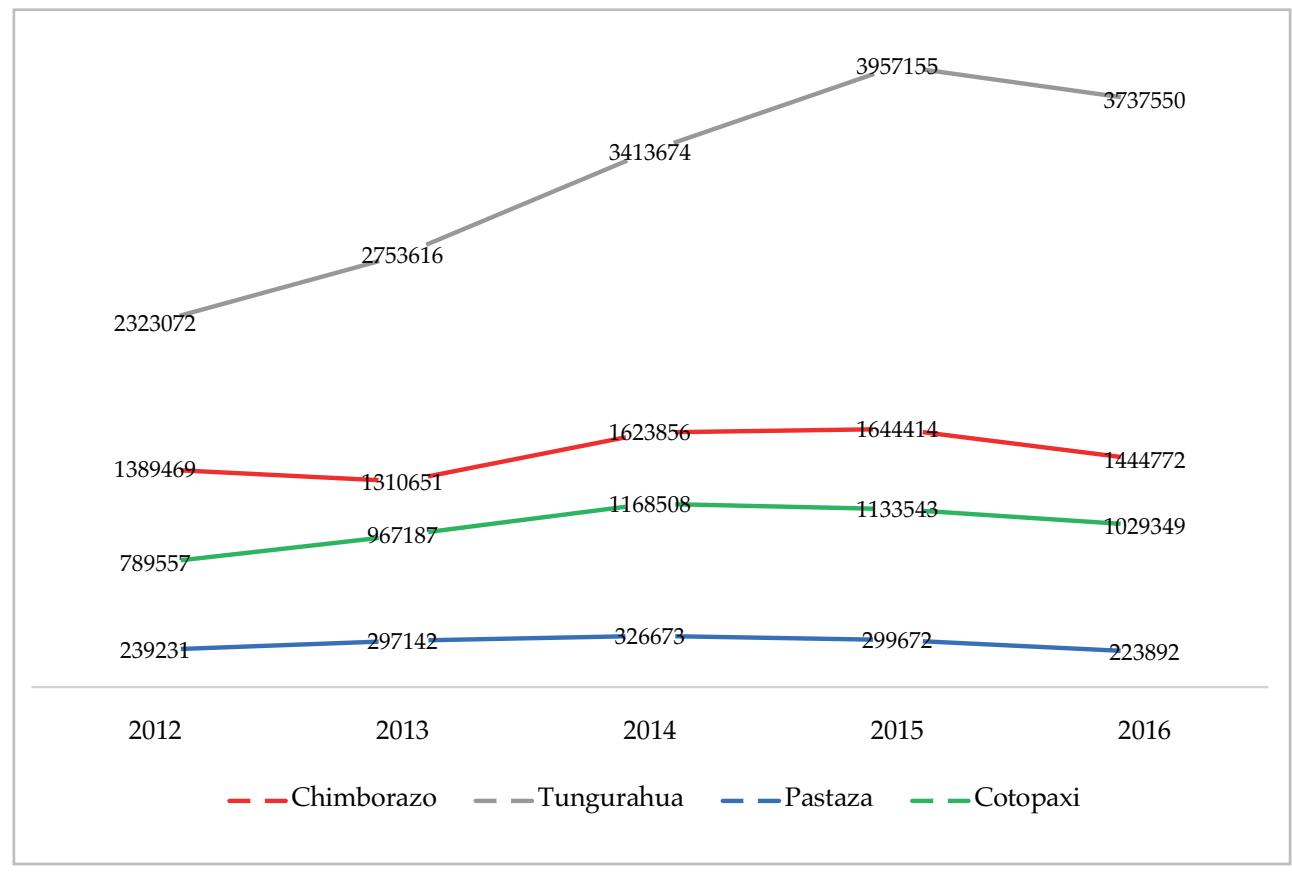

Fuente: Ministerio de Turismo (2017).

Elaboración: Autores.

En el gráfico 31, correspondiente a la recaudación tributaria de hoteles y restaurantes en la zona 3, periodo 2012-2016. Se observa que la provincia de Tungurahua presenta una mayor recaudación tributaria, la cual en promedio durante el periodo de estudio ha recaudado $\$ 3.237 .013,4$ dólares debido a la gran acogida 
turística que tiene la vecina provincia especialmente la ciudad de Baños (Monge, Gaviño, Vaca, \& Salazar, 2018). Por otra parte, la provincia de Chimborazo presenta una recaudación tributaria promedio durante el periodo de estudio de $\$ 1.482 .632,4$. siendo el lugar más representativo el cantón Alausí donde a partir de la reconstrucción de línea férrea Alausí-Nariz del Diablo la industria turística ha crecido considerablemente, por la llegada de turistas procedentes de distintas partes del mundo, por lo tanto, aportan significativamente a la recaudación tributaria del país (Márquez, 2018). Cotopaxi se encuentra en tercer lugar con un ingreso promedio de recaudación de \$1.017.628,8, y finalmente Pastaza con $\$ 277.322,0$

Tabla 21: Personal ocupado en los establecimientos registrados en el Ministerio de Turismo en la zona 3, año 2016.

\begin{tabular}{lcccc}
\hline Zona 3 & Hombre & Mujer & Total & $\%$ Participación \\
\hline Chimborazo & 1.231 & 1.273 & 2.504 & $21.83 \%$ \\
\hline Tungurahua & 2.871 & 3.403 & 6.274 & $54.70 \%$ \\
\hline Pastaza & 352 & 531 & 883 & $7.70 \%$ \\
\hline Cotopaxi & 814 & 995 & 1.809 & $15.77 \%$ \\
\hline Total & 5.268 & 6.202 & 11.470 & $100 \%$ \\
\hline
\end{tabular}

${ }^{* * *}$ Nota: Último dato registrado.

Elaboración: Autores.

Fuente: Ministerio de Turismo (2017). 
Gráfico 32. Porcentaje de participación del personal ocupado en los establecimientos registrados en el Ministerio de Turismo con respecto a la zona 3, año 2016.

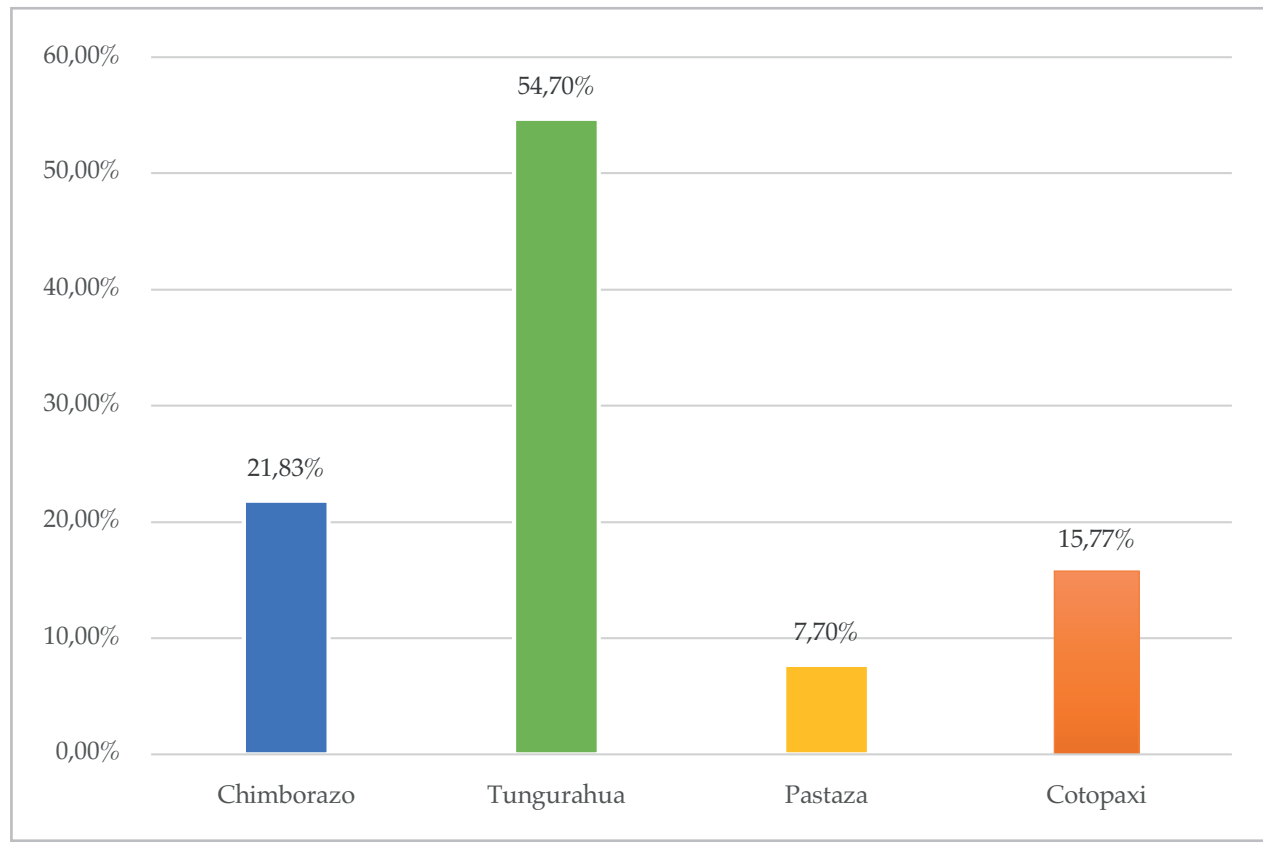

***Nota: Último dato registrado.

Elaboración: Autores.

Fuente: Ministerio de Turismo (2017)

En el gráfico 32, correspondiente al personal ocupado en los establecimientos registrados en el Ministerio de Turismo zona 3 (2016). Se observa que Tungurahua tiene una participación de $55 \%$, siendo esta la más alta de la zona 3 , debido al incremento de la llegada de turistas, a los distintos atractivos turísticos, por lo tanto, se generan empleos ya sean ocasionales o permanentes dependiendo la época de año (Bayas, 2017).

La provincia de Chimborazo presenta una participación del 22\% en la generación de empleo ocupando el segundo lugar, debido al incremento en inversión de hoteles, restaurantes entre otras, lo cual se traduce en generación de empleo ya sea directa o indirectamente (Márquez, 2018). 
Según Ecu Red (2018), la provincia de Chimborazo a la que se le denomina el "Corazón del Ecuador" o "Provincia de las Cumbres". Cuenta con un paisaje privilegiado, rico en tradiciones, folclor, música, danza y creencias que envuelven al turista quien busca conocer estas atracciones al igual que conocer los nevados en el que destaca el Chimborazo, considerado como el punto terrestre más cercano al sol.

Esta provincia brinda diversos lugares turísticos los cuales a más de las maravillas naturales también otorga cultura de las personas del sector. Existen varios lugares a los que los turistas frecuentan lo cuales se dan en diversos cantones como: Riobamba, Alausí, Guano y otros.

La provincia de Chimborazo posee un importante desarrollo turístico centralizado en sus atractivos importantes como son: El volcán Chimborazo, las lagunas de Ozogoche, la ladera Nariz del Diablo, cantón Riobamba y las lagunas de Atillo. Estos generan sinergias a las comunidades cercanas, como desarrollo de infraestructura y planta turística.

La actividad turística en la provincia de Chimborazo ha tenido un efecto positivo en el crecimiento del PIB provincial y por ende del nacional durante los últimos años ya que ayuda a generar encadenamientos productivos construcción de locales de alojamientos restaurantes entre otros generándose de esa forma empleo para la población chimboracense.

Las comunidades que cuentan con atractivos turísticos de interés se han organizado para impulsar estas actividades, una organización fuerte por su trayectoria y presencia nacional es la Federación Plurinacional de Turismo Comunitario del Ecuador (FEPTCE) que está constituida por 62 proyectos de turismo 
comunitario distribuidos en las tres regiones continentales del país y clasificadas de acuerdo a su ámbito geográfico en regionales, siendo una de ellas la establecida en la Región Sierra-Centro con sede en la Corporación para el Desarrollo del Turismo Comunitario de Chimborazo (CORDTUCH); cada una de estas experiencias de turismo comunitario oferta una gran variedad de actividades y servicios turísticos combinando la experiencia de vivir en comunidad con otras modalidades del turismo alternativo como: el turismo de aventura, el turismo científico, el turismo de salud, el agroturismo, el ecoturismo, etc. (Gallegos, 2016).

Gráfico 33. Visitas de turistas extranjeros y nacionales a la provincia de Chimborazo, año 2016.

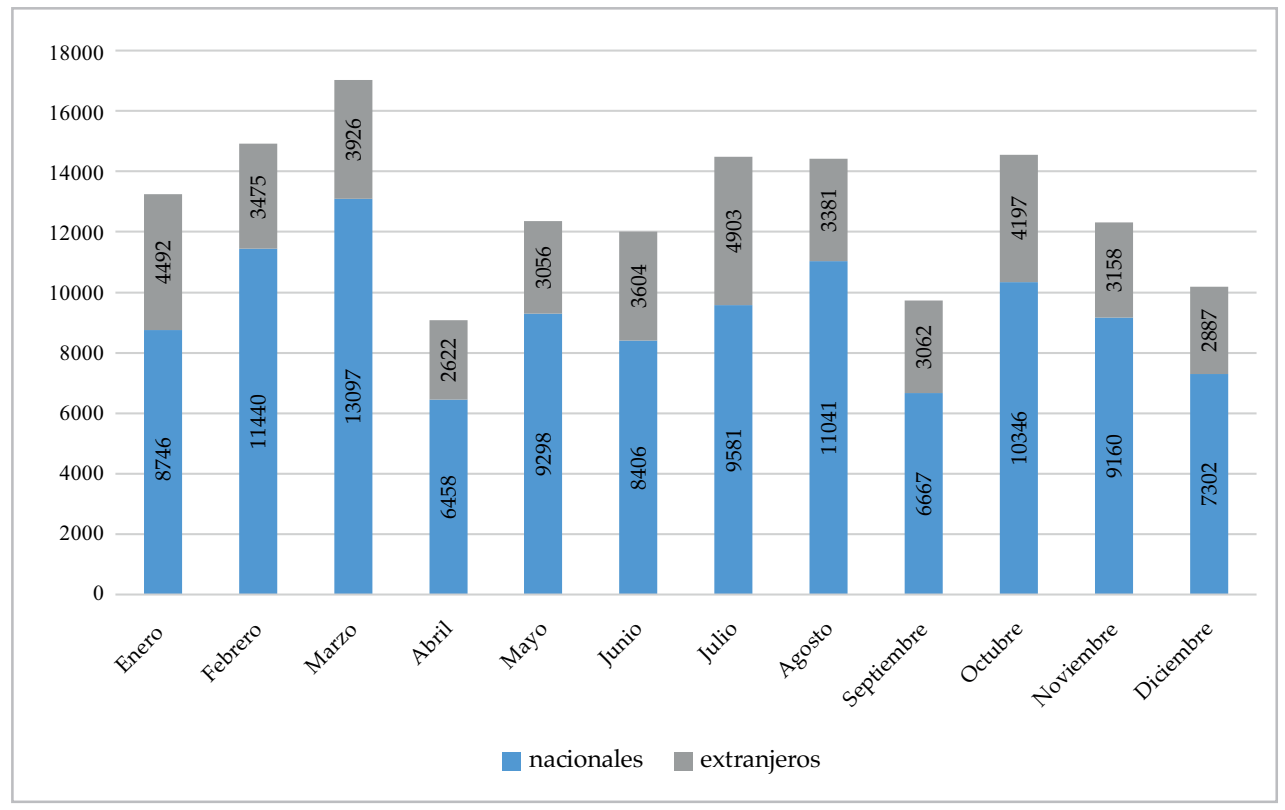

Fuente: Ministerio de Turismo (2018).

Elaboración: Autores

En el gráfico 33, se representa la visita de turistas extranjeros y nacionales a la provincia de Chimborazo para el año 2016, donde los meses de mayor visita son marzo y febrero seguidos de agosto y octubre, es decir, dos temporadas marcadas, la una por el auge de los visitantes nacionales y la otra por los extranjeros. 
En Chimborazo también se encuentra la Reserva de Producción de Fauna Chimborazo, un lugar para turistas que quieren conectarse con la naturaleza, el principal atractivo del parque es el volcán Chimborazo. Dentro de la reserva, se cuenta con ocho tipos de ecosistemas, existen varias rutas para caminatas como el templo Machay, un sitio ancestral de ofrenda al Chimborazo; el bosque Polylepis un terroso comunitario y enigmático; y la Chorrera, un gran cañón donde nace el río del mismo nombre que exhibe además un paisaje único compuesto por grandes rocas de cortes verticales y filudas de hasta 100 metros de altura (Ministerio de Turismo, 2018).

El turismo comunitario es algo que ya se toma en cuenta en los distintos programas de los gobiernos, ya se encuentran planteados por ejemplo en el Ordenamiento Territorial de Chimborazo. Según Gallegos (2016), se plantea que "el turismo constituye un sector con alto potencial de generación de empleo e ingresos en el corto y mediano plazo, puede aportar a dinamizar otros sectores antes, durante y después de ofertar el servicio".

En la provincia de Chimborazo, las distintas comunidades existentes han realizado proyectos lo cuales impulsaría la activad turística. Según Gallegos (2016), en estos proyectos a más de impulsar el turismo comunitario, se ha iniciado y consolidado emprendimientos productivos que a más de generar ingresos económicos adicionales a las comunidades han motivado la recuperación de técnicas ancestrales que estaban en desuso.

Una de las principales características de Chimborazo muy llamativa para el turismo es su gastronomía que considera cuatro principales platos típicos, como son: 1) El hornado en Riobamba es un plato que contiene carne de cerdo hornado, principalmente cocinado en leña, acompañado de motey lechuga enjugo avinagrado, papas horneadas con la carne de chancho, tajas de aguacate, y ají criollo; 2) El llapingacho de Alausí que son pequeñas tortillas 
asadas, hechas de papas cocidas y aplastadas, estos pueden ser servidos con chorizo, huevo frito, carne asada, lechuga, cebollas, arroz y aguacate; 3) Otro plato es el cuy con papas de Chunchi que consiste en un cuy lavado, aliñado y dorado por los dos lados al carbón, que se sirve acompañado de papas cocinadas bañadas en salsa de maní, con una ensalada de lechuga y ají, se lo puede servir también con arroz; y 4) la fritada de Guano, plato típico compuesto de carne de cerdo frita, chorizo, maduro, tostado y mote. La fritada de Guano es diferente a las que se preparan en otras ciudades del país, ya que contiene un adobo hecho con chicha de jora, bebida añeja, que se elabora con base en maíz germinado.

Todos estos platillos típicos son los preferidos por turistas o visitantes que concurren a estas ciudades ubicadas en la sierracentro, durante ciertas fechas festivas o feriados nacionales, gracias este gran consumo turístico en la gastronomía local, la economía de estas localidades tiende a crecer, incluso las fuentes de empleo aumentan en estas fechas gracias a la gran llegada de turistas.

Tabla 22: Arribo de visitantes a la reserva faunística Chimborazo, periodo 2012-2016.

\begin{tabular}{cccc} 
Año & Visitantes Extranjeros & Visitantes Nacionales & Total \\
\hline 2012 & 9.634 & 53.969 & 63.603 \\
2013 & 9.279 & 59.344 & 68.623 \\
\hline 2014 & 14.850 & 60.062 & 74.912 \\
\hline 2015 & 19.396 & 74.415 & 93.811 \\
\hline 2016 & 19.168 & 76.632 & 95.800 \\
\hline
\end{tabular}

Fuente: MINTUR (2018).

Elaboración: Autores. 
Gráfico 34. Arribo de visitantes a la reserva faunística Chimborazo, periodo 20122016.

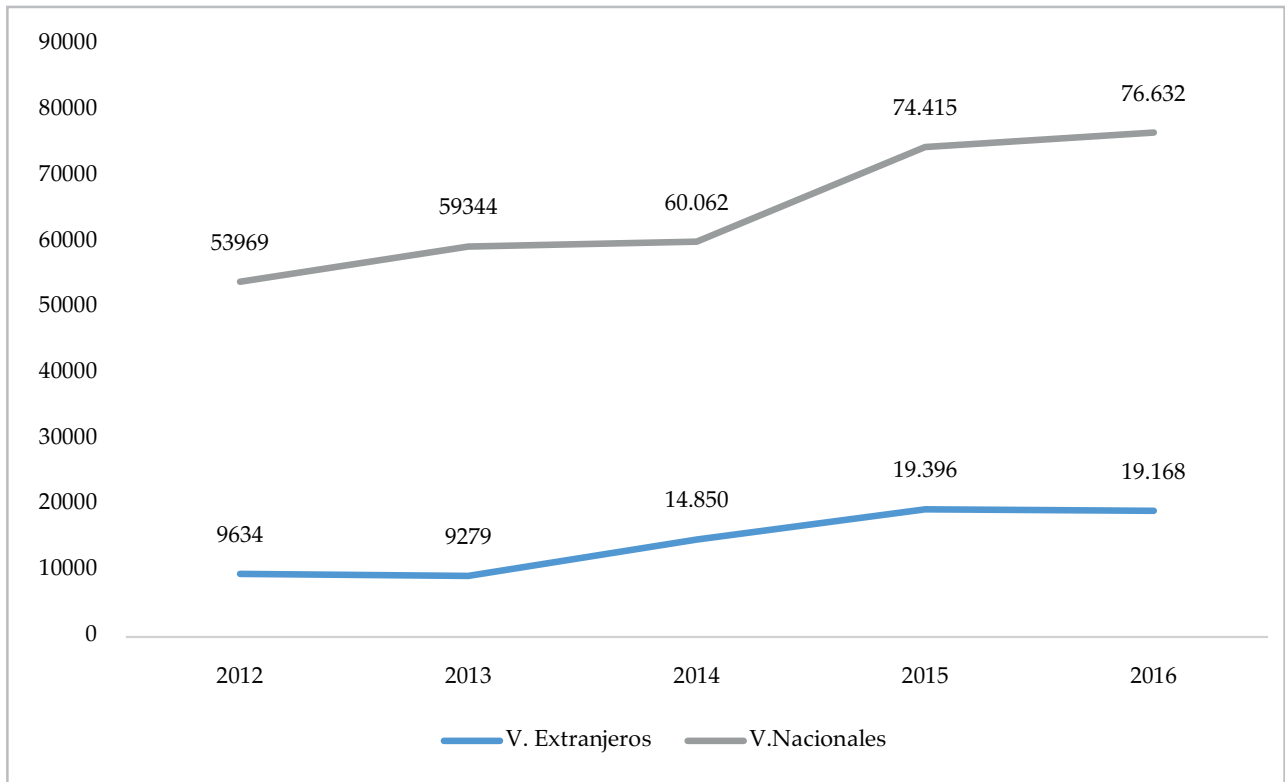

Fuente: MINTUR (2018).

Elaboración: Autores.

En el gráfico 34, se observa que en los arribos se destacan los turistas nacionales, pero en ambos casos se da a notar un crecimiento hasta el año 2016, las visitas de turistas extranjeros en el año 2012 son de 9634 y 19168 en el 2016, un crecimiento promedio de $24,74 \%$ para el periodo de análisis. Los visitantes nacionales pasaron de 53969 en el 2012 hasta 76632 en el 2016 teniendo una tasa promedio de 10,5\%, este crecimiento significó algo bueno para el sector turístico y todas las industrias que lo componen. 


\section{Capítulo 4}

\section{Turismo en Riobamba}




\subsection{Caracterización del sector turístico en la ciudad de Riobamba}

Con respecto al turismo, la Organización Mundial del Turismo (2018), lo define como una de las fuentes que genera mayores recursos económicos en el mundo, actividad que a través del tiempo ha crecido rápidamente y se relaciona de manera directa con el desarrollo, convirtiéndose en un punto clave para el desarrollo socioeconómico.

El Ministerio de Turismo (2018), coloca al turismo como la tercera actividad más importante dentro de la economía nacional. En primer lugar, se ubica el banano, que en 2016 generó ingresos de 2039 millones de dólares y en 2017 generó 2323 millones de dólares, seguido por el plátano y camarón, que generaron ingresos en el año 2016 de 1886.9 millones de dólares-y en el año 2017 de 2231.3 millones de dólares, y de ahí el turismo, que en 2016 generó 1075.5 millones de dólares y en 20171204.5 millones de dólares, teniendo un incremento de 129 millones de dólares entre en año 2016 y 2017.

Riobamba es la capital de la provincia de Chimborazo, situada en pleno centro del territorio ecuatoriano, se edificó en el año de 1799 luego de un terremoto devastador que destruyó la ciudad colonial, su construcción fue totalmente planificada, lo que le atribuyó el nombre de "Ciudad Bonita". Posee una extensión de 5.637 km2 está conformada por cinco parroquias urbanas y once rurales, la temperatura promedio es de $13^{\circ} \mathrm{C}$ y su altitud es de $2.754 \mathrm{msnm}$, Riobamba cuenta con 2 áreas protegidas: Parque Nacional Sangay y la Reserva de Producción de Fauna Chimborazo. ( Dirección de Gestión de Turismo del Gobierno Autónomo Descentralizado de Riobamba , 2019) 
La ciudad de Riobamba es un lugar con amplia gama de material turístico que sería la principal fuente de ingresos. Según Cangas y Romero (2014), el turismo constituye un sector económico de máxima importancia tanto por los ingresos de divisas que aporta como el considerable volumen de empleo directo e indirecto que genera. Debido a su peculiar belleza natural y arquitectónica, Riobamba es un atractivo turístico para visitantes locales y extranjeros.

El cantón Riobamba se encuentra ubicado al norte de la provincia Chimborazo, ocupa parte de la hoya del río Chambo y de las vertientes internas de las cordilleras Oriental y Occidental de los Andes, se encuentra limitado por el norte por los cantones Guano y Penipe; al sur los cantones Colta y Guamote; al este por el cantón Chambo y la provincia Morona Santiago; y al oeste por las provincias Bolívar y Guayas (Cangas \& Romero, 2014).

En Riobamba existen diversos lugares o centros turísticos en los cuales los viajeros pueden experimentar y divertirse, al igual que obtener conocimientos sobre la cultura e historia de los locales. Según Go Ecuador (s.f.), para ello la ciudad ofrece:

El museo del convento de la Concepción

Estación ferroviaria

Tren del hielo I

El nevado Chimborazo, etc.

Además de estos lugares que son característicos del turismo riobambeño, también esta ciudad brinda actividades que son propias culturales del pueblo, como son los pases del niño, la Dirección de Turismo hizo un estudio para determinar la cantidad de turistas que visitan la ciudad durante la temporada de pases del niño. En el 2017, por ejemplo, 37205 visitantes llegaron a la ciudad, 
y entre diciembre y enero se reportó un incremento del 3\% sobre el flujo normal.

La ciudad de Riobamba posee gran variedad de atractivos turísticos los cuales motivan al turismo inclusivo. Según Velasco (2017), para ampliar la visión de la situación actual de la oferta turística de Riobamba, con respecto a las personas con discapacidad se interactuó con varios actores: prestadores de servicio turístico, autoridades y estudiantes de la Unidad Educativa Especializada Sordos de Chimborazo y personas con discapacidad. En Riobamba se ha incrementado este tipo de turismo en un porcentaje bajo, esta modalidad es difícil de aplicar, ya que el del 37,5\% de los lugares visitados cumple parcialmente con las condiciones, y el $62.5 \%$ no lo hace.

En Riobamba existen distintas parroquias la cuales-brindan diversas actividades incentivadas por su cultura y la naturaleza que las rodea. Cacha es una parroquia que brinda cultura y muchos otros atractivos turísticos, ofrece a sus visitantes varias actividades entre las que se destaca el "Centro de Servicios Pukara Tambo" lugar donde se celebran ceremonias tradicionales, convivencia comunitaria para compartir su cultura, música, danza, gastronomía, tradiciones y leyendas, visita a microempresas entre otros.

Riobamba también es una ciudad rica en gastronomía, sus diversos platos hacen a los turistas querer permanecer el mayor tiempo posible en la ciudad, esta actividad tiene un gran aporte a la economía de la ciudad, dado que la existencia de diversos establecimientos ha sido fuente de empleo. 


\subsubsection{Establecimientos registrados}

Según el Ministerio de Turismo (2018), en la provincia de Chimborazo se cuenta con un total de 88 establecimientos registrados que brindan servicios de hospedaje a los turistas, con un equivalente de 1791 habitaciones y 3754 camas, las mismas que se encuentran aptas para cubrir con la demanda turística nacional e internacional.

Tabla 23: Establecimientos registrados en Chimborazo.

\begin{tabular}{cccc}
\hline Provincia & Registrado & Habitaciones & Camas \\
\hline Chimborazo & 88 & 1791 & 3754 \\
\hline
\end{tabular}

Fuente: Ministerio de Turismo (2018).

Elaboración: Autores.

En la Tabla 24, Riobamba tiene un total de 63 establecimientos registrados, siendo los hoteles y hostales los establecimientos más importantes para la ciudad, juntos suman 57 establecimientos que representan el 90,48\% del total. La disponibilidad de habitaciones es de 1408 y 2976 camas en total, que brindan confort a los turistas.

Tabla 24: Distribución por clase y categoría de establecimientos de alojamiento registrados del cantón Riobamba 2018.

\begin{tabular}{|cccc|}
\hline Clasificación & Registrado & Habitaciones & Camas \\
\hline Casa de Huéspedes & 2 & 9 & 14 \\
\hline Hostales & 30 & 627 & 1259 \\
\hline Hosterías & 3 & 89 & 279 \\
\hline Hoteles & 27 & 679 & 1416 \\
\hline Refugios & 1 & 4 & 8 \\
\hline Total & 63 & 1408 & 2976 \\
\hline
\end{tabular}

Fuente: Ministerio de Turismo (2018).

Elaboración: Autores. 


\subsubsection{Establecimientos de alimentos y bebidas}

En la ciudad de Riobamba también se encuentran establecimientos que brindan el servicio de alimentación y bebidas. Según el Ministerio de Turismo (2018), en el cantón Riobamba existe una oferta de 365 establecimientos registrados, con una disponibilidad de 4020 mesas para brindar un servicio de calidad y comodidad a los clientes.

Tabla 25: Establecimientos de alimentos y bebidas registrados del cantón Riobamba, año 2018.

\begin{tabular}{lcc} 
Clasificación & Registrado & Mesas \\
\hline Bares & 44 & 570 \\
Cafeterías & 50 & 419 \\
\hline Discotecas & 21 & 359 \\
\hline Fuentes de Soda & 31 & 206 \\
Restaurantes & 219 & 2466 \\
Total & 365 & 4020 \\
\hline
\end{tabular}

Fuente: Elaboración propia con base al Ministerio de Turismo (2018).

Elaboración: Autores.

En la Tabla 25, se muestra que existen un total de 365 establecimientos, de los cuales, los establecimientos con mayor número de registros y mesas son los restaurantes con 219 que representan el $60 \%$ del total, en segundo lugar, se encuentran las cafeterías con 50 establecimientos que representan el 13,70\% del total.

\subsubsection{Lugares turísticos de Riobamba}

Riobamba cuenta con hermosos atractivos turísticos naturales, culturales, gastronómicos que son visitados por los 
turistas nacionales y extranjeros. El GAD Municipal ha elaborado 10 rutas turísticas que pueden ser potenciadas por las autoridades y por el sector privado. En primer lugar, citamos la Ruta de las Iglesias de Riobamba, la belleza interior y exterior de sus iglesias es muy impresionante; en segundo lugar, está la Ruta Histórico Patrimoniales de Riobamba, donde se envuelve la historia y tradiciones, en tercer lugar, está la Ruta de los Museos. Riobamba tiene pequeños museos pero especializados e interesantes de conocer; en cuarto lugar tenemos la Ruta de Recreación Nocturna, donde las noches riobambeñas están llenas de diversión, hermosos paisajes urbanos y mucha gastronomía ( Dirección de Gestión de Turismo del Gobierno Autónomo Descentralizado de Riobamba , 2019).

En quinto lugar, está lo referente al turismo rural, Riobamba posee 11 parroquias rurales, cada una con diferentes atractivos turísticos, naturales y culturales, en sexto lugar está el Turismo Comunitario con 3 parroquias rurales, donde comunidades indígenas brindan a turistas nacionales y extranjeros la oportunidad de convivir y compartir su cultura y tradiciones. En séptimo lugar la Ruta de las Huecas, Riobamba es un destino gastronómico impresionante donde las huecas tradicionales que mantienen vivos los sabores. En octavo lugar están los parques y plazas patrimoniales, el Centro Histórico de Riobamba cuenta con una hermosa serie de plazas y parques patrimoniales, en noveno lugar están los parques recreativos y para deporte, que brindan una oportunidad de contacto con la naturaleza, en la última ruta constan las áreas protegidas, las mismas que se caracterizan por la belleza de flora y fauna que rodea la ciudad y la provincia, por ello existe el Parque Nacional Sangay y la Reserva de Producción de Fauna Chimborazo (Dirección de Gestión de Turismo del Gobierno Autónomo Descentralizado de Riobamba , 2019). 


\subsubsection{Transporte turístico}

Con base en el Ministerio de Turismo (2014), el transporte turístico hace referencia a la movilización de turistas o excursionistas, en transportes autorizados para dar dicho servicio. Según el Ministerio de Turismo (2018), en el cantón Riobamba existe un total de tres establecimientos registrados. En la Tabla 26 se aprecia que este servicio ha tenido un comportamiento decreciente desde el año 2015 al 2018, registrando una reducción del 50\% al pasar de seis empresas a tres, datos que explican el débil desarrollo del sector turístico en la zona.

Tabla 26: Servicio de transporte turístico en el cantón Riobamba, periodo 2015-2018

Años 2015 2016 2017 2018

\section{Servicio de Transporte Turístico}

6

6

3

Fuente: Ministerio de Turismo (2018).

Elaboración: Autores.

\subsubsection{Operación e intermediación turística de Riobamba}

Según el Ministerio de Turismo (2020), para la ejecución de las actividades de operación e intermediación turística se tiene la siguiente clasificación: a) Agencias de viajes mayoristas, las mismas que se encargan de elaborar, organizar y comercializar servicios y paquetes turísticos en el exterior y esto lo realizan a través de agencias de viajes internacionales o agencias de viajes duales. b) Las agencias de viajes internacionales son las que se encargan de comercializar los productos de las agencias mayoristas y del operador turístico a nivel nacional e internacional. c) El operador 
turístico, es el que se encarga de la ejecución directa de viajes y de las visitas turísticas. d) Las agencias de viajes duales, son las que se encargan de realizar en conjunto actividades de las agencias de viaje internacionales y del operador turístico. En Riobamba para el año 2015 se registraron 33 agencias de viajes y operadores turísticos, a partir del año 2016, se denota un decrecimiento hasta el año 2017 con 28 registros, evidenciándose una caída del 15,15\%. Para el año 2018 se observa un crecimiento del 21,43\%, lo que denota variabilidad en el sector turístico.

Tabla 27: Operación e intermediación turística de Riobamba, periodo 2015-2018

Años

2015

2016

2017

2018

\section{Agencias de viajes y operadores turísticos}

33

32

28

34

Fuente: Elaboración propia con base al Ministerio de Turismo (2020).

El GAD Municipal de la ciudad de Riobamba (2018), proporciona datos correspondientes a la ciudad, misma que también es conocida como la "Ciudad de las Primicias", ubicada al norte de la provincia de Chimborazo, su división política consta de 5 parroquias urbanas y 11 parroquias rurales, su extensión es de aproximadamente 40 $\mathrm{km} 2$, se destaca un paisaje único, lleno de gestas políticas, historias heroicas, cultura, religiosidad, tradiciones, costumbres, que en conjunto se convierte en identidad de los riobambeños. La ciudad cuenta con varias primicias dentro de la historia nacional, entre las más importantes, es la primera ciudad española en el país, asentada en el actual Colta antes del terremoto de 1797, cuenta con el primer escudo de armas, privilegio otorgado a muy pocas ciudades fundadas por españoles, el primer convento y la primera iglesia del país, entre otras. 
Su envolvente historia, va de la mano con varios atractivos turísticos, conjuntamente con su clima, al que favorece su ubicación en la sierra centro de Ecuador, atractivos que merecen ser promocionados, de manera que sea el turismo una de las principales actividades económicas de la ciudad.

Viajar es una de las actividades más placenteras para los seres humanos, permite conocer nuevos lugares, paisajes, culturas, religiones, y así combatir la rutina, viajes que por lo general se realizan en familia para fortalecer los lazos de unidad, sin contar con el gran beneficio que genera para las regiones atractivas para dichas actividades, sobre todo para aquellas en las que sus ingresos se fundamentan en el turismo.

Arroyo (2018), respecto al turismo local manifiesta que, con una buena planificación del turismo y el cuidado del entorno natural, se pudiera lograr plenamente el desarrollo turístico de una localidad; por lo que es necesario poner en práctica estrategias que comprometan al gobierno local y a la comunidad. Llegando a ser el principal aportador de ingresos económicos. En la actualidad, es una herramienta importante para el desarrollo socioeconómico del Ecuador, ya que genera crecimiento económico y desarrollo nacional, objetivos considerados dentro del Plan Nacional de Desarrollo, siendo el turismo local una fuente a explotar dentro de la ciudad de Riobamba.

La provincia de Chimborazo en general, con su capital Riobamba y sus 11 parroquias rurales, cuenta con mucha historia, lo que hace de todo el sector una zona turística y llamativa para turistas nacionales y extranjeros. Riobamba se ubica en los valles de la cordillera de los Andes, con un clima templado-frío y ofrece una variedad de atractivos turísticos propios de la Región Sierra ( Dirección de Gestión de Turismo del Gobierno Autónomo Descentralizado de Riobamba , 2019). 
Cuadro 2. Atractivos turísticos de Riobamba.

\begin{tabular}{|c|c|}
\hline Naturales & Culturales \\
\hline Nevado Chimborazo & Centro Histórico: edificaciones \\
Nevado Carihuariazo & arquitectónicas de la época de la \\
\hline Volcán Tungurahua (activo) & colonia, iglesias, museos, teatro. \\
Nevado El Altar & \\
Cadena montañosa Quilimas & \\
Cadena montañosa Cubillin & \\
\hline
\end{tabular}

Fuente: Modelo de gestión para el desarrollo sustentable del turismo en la ciudad de Riobamba (2017).

Elaboración: Autores. 


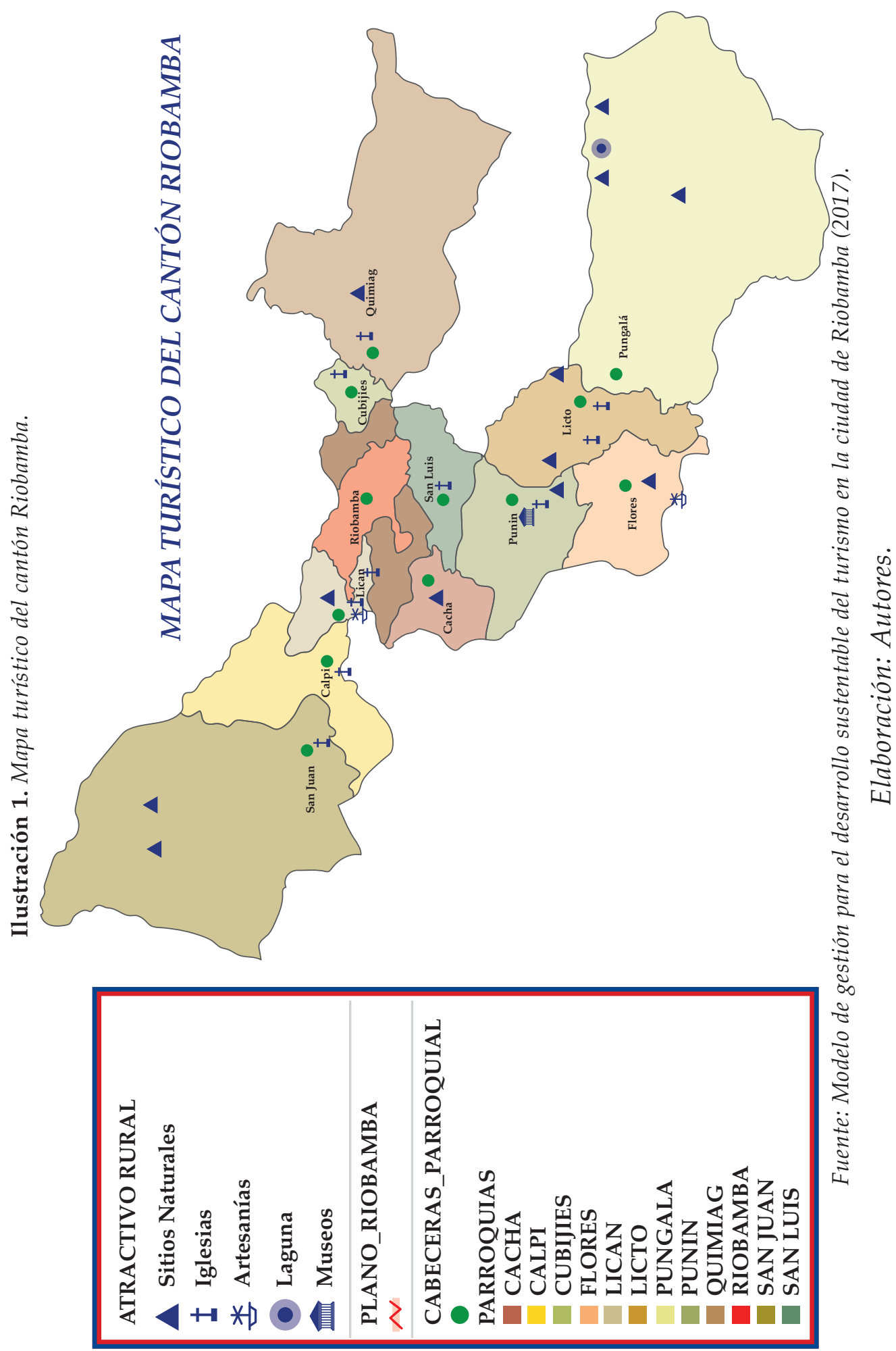


Dentro del mapa turístico de la ciudad de Riobamba, se observan los diferentes lugares turísticos como sitios naturales, iglesias, artesanías, lagunas y museos. Dentro de los sitios naturales constan las parroquias rurales de: San Juan, Químiag, Licto, Pungalá, Flores, Punín, Colta y San Luis. Respecto a iglesias, destacan las situadas en: Colta, San Juan, Calpi, Riobamba, San Luis, Cubijíes y Licto. Considerando las artesanías, acentúan lugares como Flores y Riobamba, considerando lagunas tenemos a Pungalá y Colta y respecto a museos, visitan Riobamba y Punín ( Dirección de Gestión de Turismo del Gobierno Autónomo Descentralizado de Riobamba , 2019).

\subsubsection{Distancia de Riobamba a otras ciudades del Ecuador}

A continuación, se destaca la distancia de Riobamba hacia ciudades consideradas como principales en Ecuador:

Tabla 28: Distancia de Riobamba a otras ciudades del Ecuador.

\begin{tabular}{cc} 
Ciudad & Distancia \\
\hline Guayaquil & $233 \mathrm{~km}$ \\
\hline Quito & $188 \mathrm{~km}$ \\
\hline Cuenca & $254 \mathrm{~km}$ \\
Baños & $74 \mathrm{~km}$ \\
\hline Esmeraldas & $442 \mathrm{~km}$ \\
\hline Ibarra & $303 \mathrm{~km}$ \\
\hline
\end{tabular}

Fuente: El Riobambeño (2018).

Elaboración: Autores.

En la Tabla 28, se detalla la distancia de Riobamba a ciudades consideradas como principales en Ecuador. En el trayecto de Riobamba a Guayaquil o Perla del Pacífico existen 233 km; a Quito o capital de Ecuador son 188 km; a Cuenca o Santa Ana de los 
cuatro ríos hay 254 km; a Baños de Ambato o Baños de Agua Santa, uno de los principales sitios turísticos a nivel internacional, existen 74 km; a Esmeraldas o San Mateo de las Esmeraldas, constan 442 km; y, a Ibarra o San Miguel de Ibarra existen 303 km.

\subsection{Perfil turístico de la ciudad de Riobamba}

El GAD Municipal del cantón Riobamba (2018), en sus boletines anuales respecto a la demanda turística del sector, detalla varios parámetros, dentro de los cuales se toma los datos más relevantes en los años 2016, 2017 y 2018.

\subsubsection{Género del turista}

Para el periodo 2018-2019 se cuenta con datos respecto al género del turista que viaja a la ciudad de Riobamba:

Tabla 29. Género del turista que visita a la ciudad de Riobamba (porcentaje).

\begin{tabular}{ccc}
\multirow{2}{*}{ Año } & \multicolumn{2}{c}{ Género } \\
& Femenino & Masculino \\
\hline 2018 & 48 & 52 \\
2019 & 49 & 51 \\
\hline
\end{tabular}

Nota: Los datos del año 2019 corresponden al periodo mayo-agosto 2019.

Fuente: GAD Municipal de Riobamba (2018) y (2019).

Elaboración: Autores.

Respecto al género de los turistas que viajan a la ciudad de Riobamba, se observa en la Tabla 29, que durante el año 2018 el género masculino representa el 52\% del total de turistas y para el año 2019 se registra una disminución del 1,92\% y un incremento de una tasa del 2,08\% para las visitas de género femenino, llegando a representar el $49 \%$ del total, esto se relaciona con la tendencia 
registrada a nivel nacional en la cual se destaca que en la actualidad las mujeres han incrementado sus viajes ya se para cumplir con sus obligaciones laborales o por placer.

\subsubsection{Arribo de visitantes a Riobamba.}

Tabla 30. Arribo de visitantes a Riobamba.

\begin{tabular}{cccc} 
Años & Nacionales & Extranjeros & Total \\
\hline 2016 & 77.658 & 14.714 & 92.372 \\
2017 & 71.999 & 12.314 & 84.313 \\
2018 & 73.401 & 16.246 & 89.647 \\
2019 & 59.530 & 16.158 & 75.688 \\
\hline
\end{tabular}

Los datos del 2019 comprenden el periodo enero-agosto de 2019

Fuente: GAD de Riobamba (2016-2019)

Elaboración: Autores.

Gráfico 35. Arribo de visitantes a Riobamba.

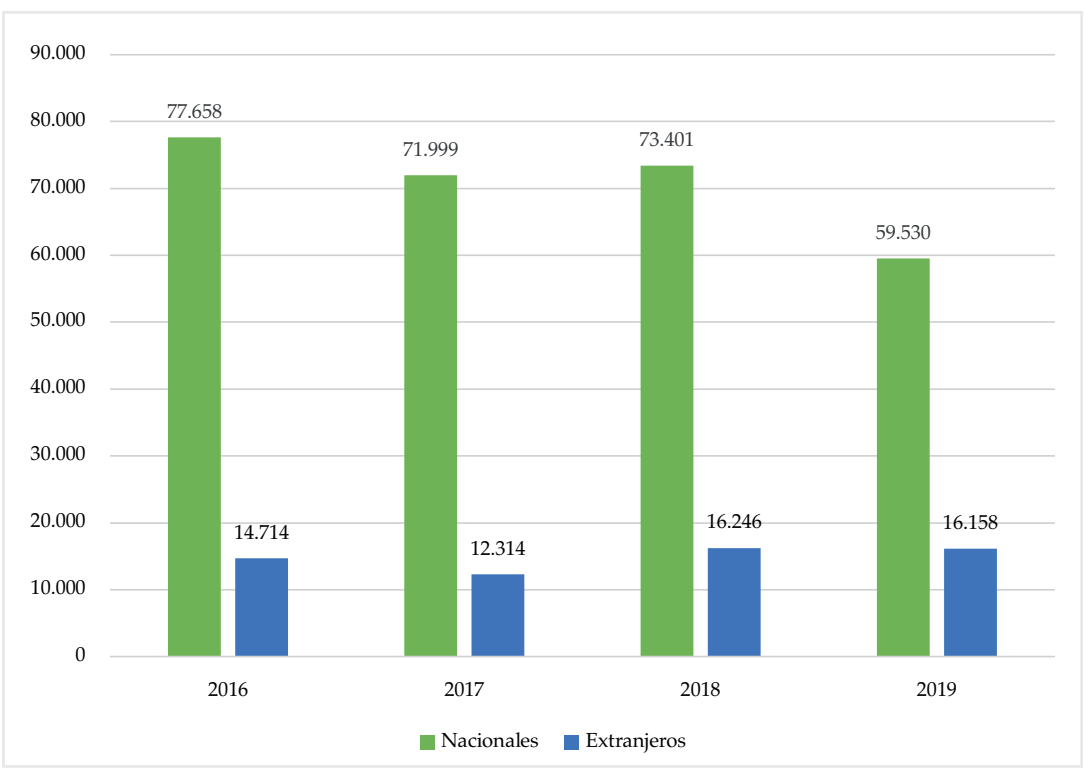

Los datos del 2019 comprenden el periodo enero-agosto de 2019

Fuente: GAD de Riobamba (2016-2019)

Elaboración: Autores. 
La mayor parte de visitantes que llegan a Riobamba son nacionales, los datos registrados muestran que durante el año 2016 se registraron 77.658 visitantes, para el año 2018 se evidencia un decrecimiento del $5,48 \%$, esto se debe a la falta de políticas emprendidas por las autoridades locales, como también por los empresarios turísticos para incentivar el turismo interno. Sin embargo, a nivel nacional el Ministerio de Turismo ha motivado mediante políticas para la promoción entre las cuales se destaca el traspaso de días feriados a fines de semana, el cambio de cultura de los viajeros ecuatorianos, y el aumento de la calidad de la oferta turística.

En lo referente a los turistas extranjeros para el año 2016 se registraron 14.714 visitantes y para el año 2017 se evidencia un decrecimiento del 16,31\% sin embargo para el año 2018 se denota un crecimiento del 31,93\% llegando a registrar 16.246 visitantes, esto concuerda con las estadísticas nacionales en las cuales se expresa un crecimiento del $4 \%$ en la llegada de turistas extranjeros para el mismo año (Ministerio de Turismo, 2019). Esta variabilidad en los visitantes internacionales, muestra que Riobamba no constituye todavía un destino turístico permanente para extranjeros.

\subsubsection{Meses de afluencia turística}

Dentro del perfil del turista, se toma en cuenta a viajeros nacionales y extranjeros mediante un detalle minucioso por meses de afluencia a la ciudad de Riobamba. 


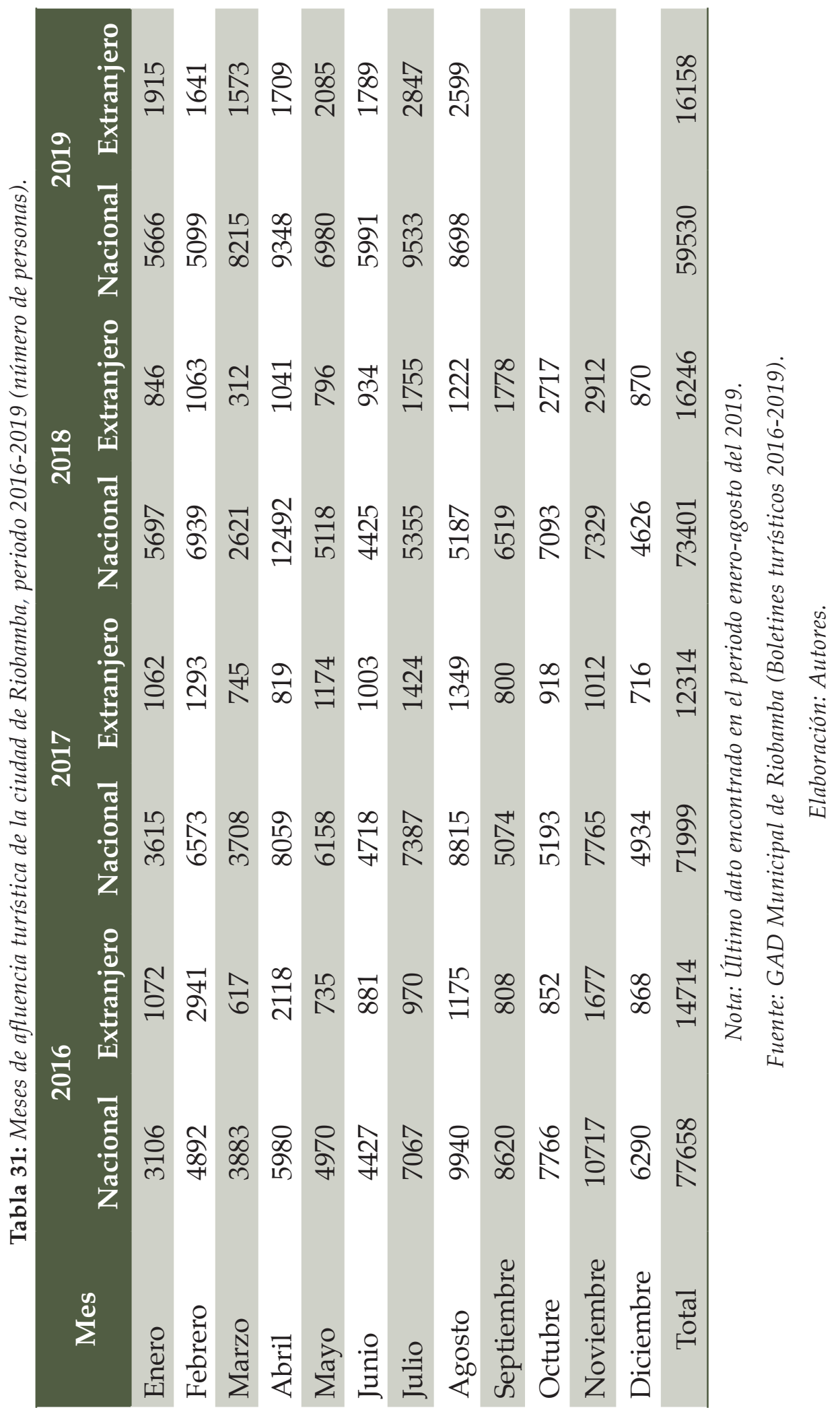


En la Tabla 31, se observa que, durante el año 2016, los meses de mayor afluencia de turistas nacionales son agosto, septiembre y noviembre. En el año 2017 los meses de mayor afluencia son abril, agosto y noviembre. Para el año 2018 se denota que los meses de mayor afluencia turística son abril, octubre y noviembre. Finalmente, para el año 2019 se muestra que los meses que se destacan son abril, julio y agosto.

En lo referente a las visitas efectuadas por turistas extranjeros se denota que durante el año 2016 los meses de mayor afluencia son febrero, abril y noviembre. Durante el año 2017 los meses que se destacan son febrero, julio y agosto. Para el año 2018 la mayor afluencia turística se concentra en los meses de septiembre, octubre y noviembre. Finalmente, para el año 2019, se denota que los meses con mayor afluencia turística son mayo, julio y agosto.

\subsubsection{Tiempo de estadía}

En lo concerniente al análisis del tiempo de estadía, a continuación, se describe el número de noches que los turistas permanecen en la ciudad. Durante el año 2016 se En ese sentido, se tiene que el rango de un día, de dos a tres días, de cuatro a cinco días y de seis a más días, diferenciando de igual manera, entre el año 2016, 2017, 2018 y 2019, para comparar resultados y determinar el tiempo promedio de estadía de turistas en la ciudad. 
Tabla 32: Tiempo de estadía (número de turistas) periodo 2016-2019.

\begin{tabular}{ccccc}
\hline Tiempo de estadía & $\mathbf{2 0 1 6}$ & $\mathbf{2 0 1 7}$ & $\mathbf{2 0 1 8}$ & ${ }^{*} \mathbf{2 0 1 9}$ \\
\hline Un día & 83320 & 24451 & 38548 & 66908 \\
\hline Dos a tres días & 6466 & 42157 & 36755 & 7493 \\
\hline Cuatro a cinco días & 1847 & 5059 & 5379 & 530 \\
\hline Seis días a más & 739 & 12647 & 8965 & 757 \\
\hline Total & $\mathbf{9 2 3 7 2}$ & $\mathbf{8 4 3 1 3}$ & $\mathbf{8 9 6 4 7}$ & $\mathbf{7 5 6 8 8}$ \\
\hline
\end{tabular}

*Los datos del 2019 comprenden el periodo mayo-agosto de 2019

Fuente: GAD Municipal de Riobamba (2019).

Elaboración: Autores.

Como se observa en la Tabla 32, respecto al tiempo de estadía durante el año 2016, se evidencia que los turistas que optaron por quedarse un día en la ciudad representan el 90,20\%, en cambió, se muestra que los turistas que se quedaron más de seis días son 739 personas que representa el 0,8\% del total. En el año 2017 el mayor porcentaje se encuentra en el rango de dos a tres días con el 50\%, en este año existe un incremento sustancial en el tiempo de estadía de los turistas que permanecen más de un día. Para los años 2018 y 2019 el mayor tiempo de estadía se encuentra en un día con 43,00\% y $88,40 \%$ respectivamente, notándose un descenso en el tiempo de estadía de los visitantes a Riobamba.

\subsubsection{Principales atractivos}

En lo referente a los principales atractivos visitados por parte de los turistas, considerando los tres principales lugares visitados, datos obtenidos por el Boletín de Demanda Turística del GAD Municipal de Riobamba (2018). 
Tabla 33: Principales atractivos (porcentaje).

\begin{tabular}{lccc} 
Atractivo & $\mathbf{2 0 1 7}$ & $\mathbf{2 0 1 8}$ & ${ }^{*} \mathbf{2 0 1 9}$ \\
\hline Riobamba & 84313 & 89647 & 75688 \\
$\begin{array}{l}\text { Reserva de Producción de Fauna } \\
\text { Chimborazo }\end{array}$ & 56878 & 68834 & 55057 \\
\hline $\begin{array}{l}\text { Parque Nacional Sangay } \\
\text { Total }\end{array}$ & 10962 & 9768 & 6169 \\
\hline
\end{tabular}

*Datos de enero a mayo de 2019.

Fuente: Elaboración propia con base al GAD Municipal de Riobamba (2017-2019) Elaboración: Autores.

Los tres principales atractivos considerados son: Riobamba, la Reserva de Producción de Fauna Chimborazo y el Parque Nacional Sangay. En el año 2017, de un total de 154170 turistas registrados el 54,68\% visitó Riobamba, un 36,89\%, la Reserva de Producción de Fauna Chimborazo y el 7,1\% visitaron el Parque Nacional Sangay. Para el año 2018, Riobamba recibió, el 52,65\%, la Reserva de Producción de Fauna Chimborazo recibió el 40,43\% y el Parque Nacional Sangay el 5,74\% del total de visitantes.

\section{Procedencia turística extranjera}

Durante el periodo 2017-2019 se registran los siguientes datos respecto a la procedencia de turistas extranjeros:

Tabla 34: Procedencia de turistas extranjeros a la ciudad de Riobamba, periodo 20172019.

\begin{tabular}{|cccc|}
\hline País & $\mathbf{2 0 1 7}$ & $\mathbf{2 0 1 8}$ & $\mathbf{2 0 1 9}$ \\
\hline Colombia & $35 \%$ & $2 \%$ & $6 \%$ \\
\hline Alemania & $15 \%$ & $36 \%$ & $21 \%$ \\
\hline Francia & $14 \%$ & $5 \%$ & $8 \%$ \\
\hline
\end{tabular}




\begin{tabular}{cccc} 
Estados Unidos & $11 \%$ & $11 \%$ & $15 \%$ \\
\hline España & $8 \%$ & $6 \%$ & $3 \%$ \\
Resto del Mundo & $17 \%$ & $40 \%$ & $47 \%$ \\
\hline Total & $100 \%$ & $100 \%$ & $100 \%$ \\
\hline
\end{tabular}

Nota: Último dato encontrado en el periodo mayo-agosto del 2019.

Fuente: GAD Municipal de Riobamba (Boletines turísticos 2016-2019).

Elaborado por: Autores

Gráfico 36. Procedencia de turistas extranjeros a la ciudad de Riobamba, periodo 2017-2019.

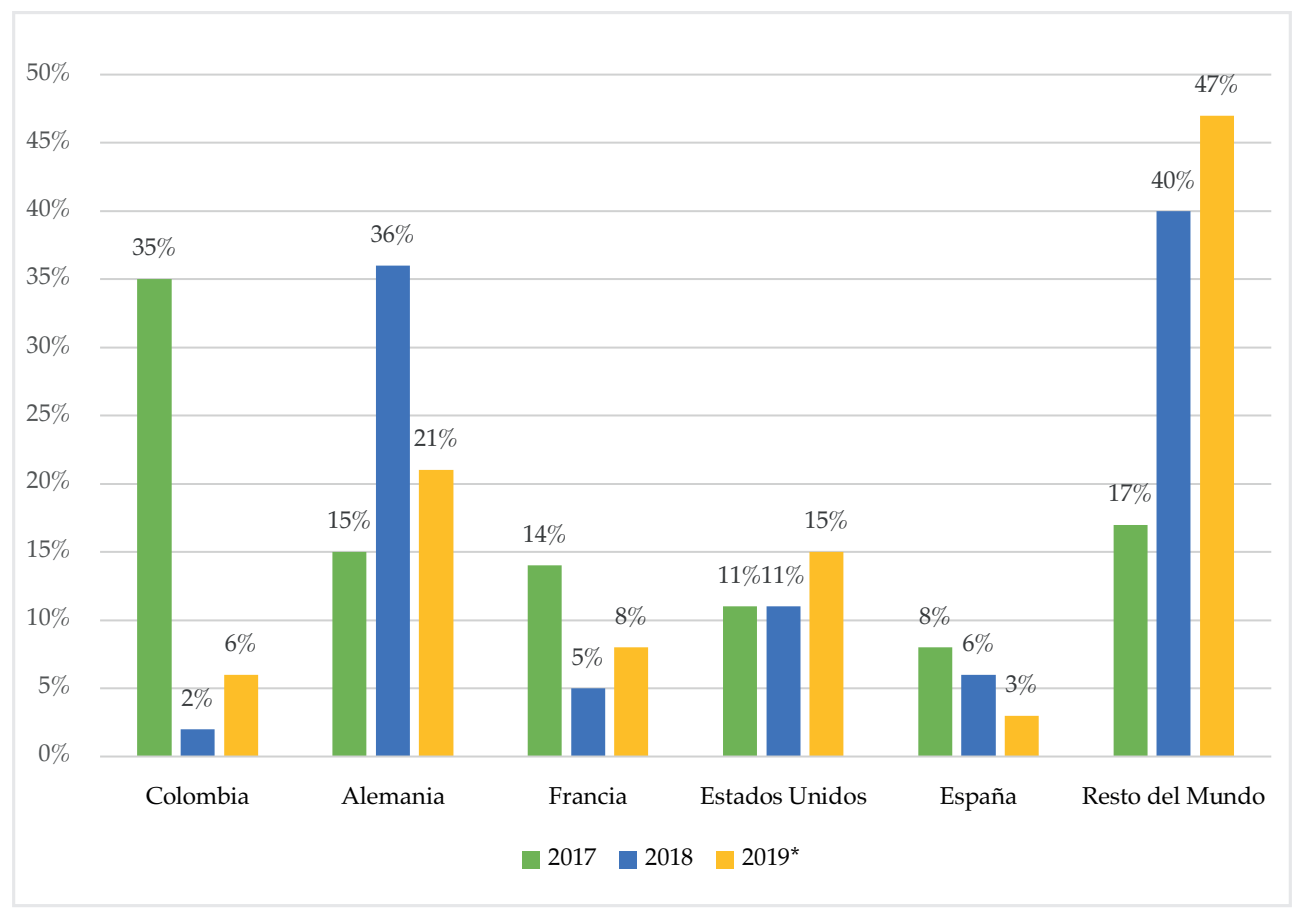

Nota: Último dato encontrado es del periodo mayo-agosto del 2019.

Fuente: GAD Municipal de Riobamba (Boletines turísticos 2016-2019).

Elaborado por: Autores.

Se muestra en el gráfico 36 , la procedencia de los turistas extranjeros que visitan la ciudad de Riobamba, en el año 2017, 
Colombia representa el 35\% de los turistas, esta tendencia para el año 2018 decae a 2\% y para el año 2019 se registra una participación del $6 \%$, indicando que para el periodo se registra una caída del $82,86 \%$. En el contexto de Alemania, se denota que durante el año 2017 este país registró una participación del 15\%, para el año 2018 se evidencia una participación del 36\%, y para el año 2019 llega al $21 \%$ es decir se registra una tasa de crecimiento del $40 \%$. Para Francia, en el año 2017 la participación es de 14\%, en el año 2018 llega solo a un 5\%, y para el año 2019 se registra un 8\% de participación, es decir una tasa decreciente del 42,86\%. En el caso de Estados Unidos se denota una tendencia constante durante los años 2017 y 2018 con una participación del 11\%, para el año 2019 se denota una tendencia creciente llegando su participación del $15 \%$, siendo la tasa de crecimiento del 36,36\%. En España se denota una tendencia decreciente durante el periodo, al pasar de $8 \%$ en el 2017 a 3\% en el año 2019 con una caída del 62,5\%. En el caso del Resto del mundo, se registra una tendencia creciente, con una tasa del 176,47\% entre los países que se destacan dentro de este grupo están: Venezuela, Suiza, Argentina, Canadá, Perú, Brasil, Austria, Reino Unido, Bélgica, Italia, entre otros.

Tabla 35: Procedencia Turística Nacional 2017-2019 (porcentaje).

\begin{tabular}{cccc} 
Ciudad & $\mathbf{2 0 1 7}$ & $\mathbf{2 0 1 8}$ & ${ }^{*} \mathbf{2 0 1 9}$ \\
\hline Quito & $54 \%$ & $34 \%$ & $42 \%$ \\
Guayaquil & $21 \%$ & $21 \%$ & $18 \%$ \\
Cuenca & $0 \%$ & $6 \%$ & $7 \%$ \\
Puyo & $0 \%$ & $2 \%$ & $3 \%$ \\
Ambato & $0 \%$ & $3 \%$ & $2 \%$ \\
Resto del país & $25 \%$ & $34 \%$ & $28 \%$ \\
\hline Total & $100 \%$ & $100 \%$ & $100 \%$ \\
\hline
\end{tabular}

Nota: Último dato encontrado en el periodo mayo-agosto del 2019. Fuente: GAD Municipal de Riobamba (Boletines turísticos 2016-2019). 


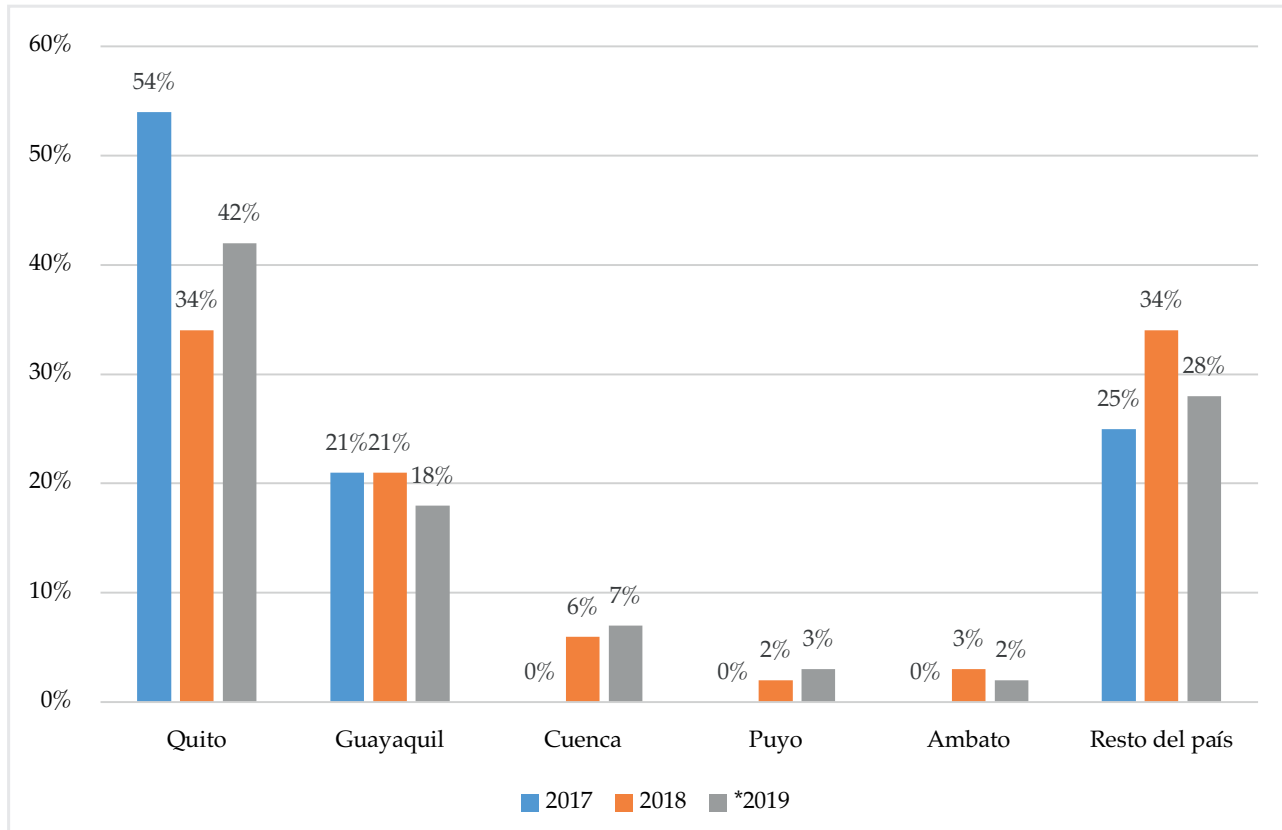

Nota: Último dato encontrado en el periodo mayo-agosto del 2019.

Fuente: GAD Municipal de Riobamba (Boletines turísticos 2016-2019).

Elaborado por: Autores

Se muestra en el gráfico 37, la procedencia de los turistas nacionales que visitan la ciudad de Riobamba, en el año 2017, Quito representa el 54\% de los turistas, esta tendencia para el año 2018 decae a $34 \%$ y para el año 2019 se registra una participación del $42 \%$, indicando que para el periodo se registra una caída del $22,22 \% \%$. En el contexto de Guayaquil, se denota que durante el año 2017 y 2018 esta ciudad registró una participación del 21\%, y para el año 2019 llega al 18\% es decir se registra un decrecimiento del 14,29\%. Para el resto del país, en el año 2017 la participación es de 25\%, en el año 2018 llega a un 34\%, y para el año 2019 se registra un $28 \%$ de participación, es decir se registra un crecimiento del $12 \%$. Otras ciudad que han tomado importancia para el año 2018 y 2019 son Cuenca, Puyo, y Ambato. 


\subsubsection{Canales informativos para visitar Riobamba}

En lo referente a los medios por los cuales se informaron los turistas respecto a Riobamba como destino turístico, consolidando los tres años se observa los siguientes resultados:

Tabla 36: Canales informativos para visitar Riobamba

\begin{tabular}{|l|c|c|c|}
\hline Medio & $\mathbf{2 0 1 6}$ & $\mathbf{2 0 1 7}$ & $\mathbf{2 0 1 8}$ \\
\hline Recomendación & $26 \%$ & $18 \%$ & $22 \%$ \\
\hline Agencia de Viaje & $22 \%$ & $44 \%$ & $3 \%$ \\
\hline Internet & $39 \%$ & $26 \%$ & $41 \%$ \\
\hline Revistas & $7 \%$ & $3 \%$ & $6 \%$ \\
\hline Otros & $6 \%$ & $9 \%$ & $28 \%$ \\
\hline Total & $100 \%$ & $100 \%$ & $100 \%$ \\
\hline
\end{tabular}

Nota: Último dato encontrado año 2018.

Fuente: GAD Municipal de Riobamba (2018).

Elaborado por: Autores.

Gráfico 38. Canales informativos para visitar Riobamba

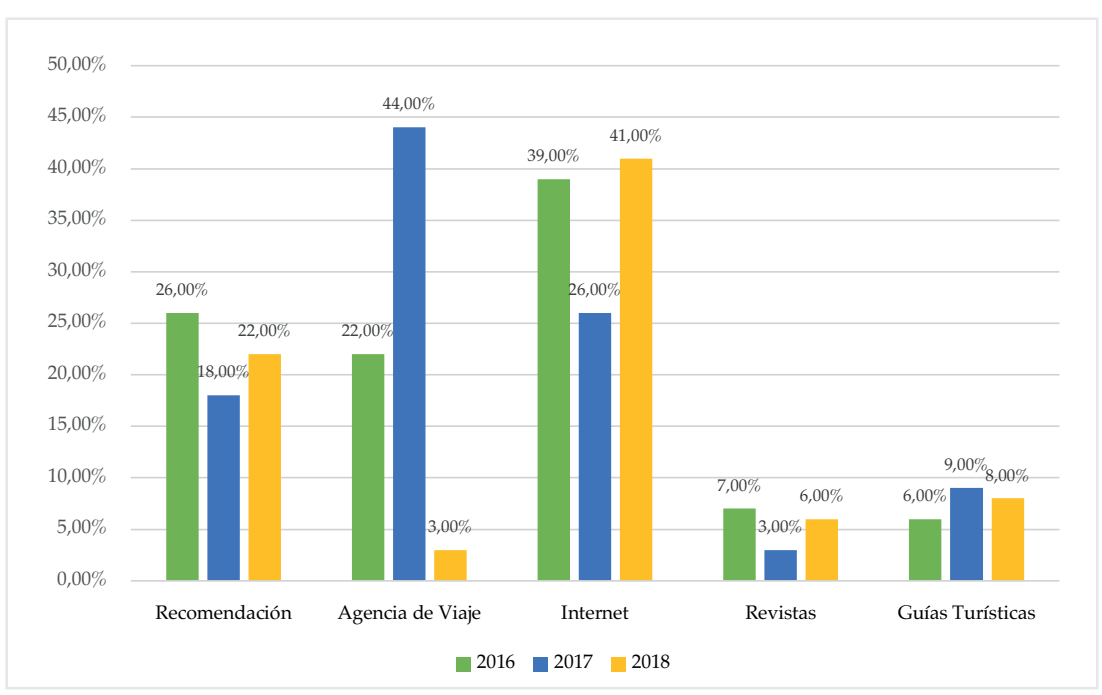

Nota: Último dato encontrado año 2018.

Fuente: GAD Municipal de Riobamba (2018).

Elaborado por: Autores. 
En la Tabla 36 se muestran los porcentajes de los medios por los cuales los turistas se informaron respecto a Riobamba como destino turístico, en la misma se puede apreciar que el internet constituye el principal medio informativo con un promedio para el periodo de estudio del 35,33\%, en segundo lugar figuran agencias de viaje con el $23 \%$ en promedio y en tercer lugar se encuentras las recomendaciones con un promedio del $22 \%$, en cuarto lugar se encuentran las revistas con un promedio del 5,33\%, y finamente otros medios como guías turísticas, radio y televisión con un promedio de 14,33 durante el período.

La tecnología tiene un impacto transversal en todos los formatos de la comunicación influyendo continuamente en el panorama mediático, en este sentido el turismo es uno de los principales sectores que debe ser protagonista en el entorno de los nuevos medios de comunicación. Lo que implica que las políticas de promoción se deben orientar al internet, entendiendo que este es el principal medio informativo.

\section{Tipo de turismo}

Otra de las variables a considerar es el tipo de turismo que se realiza, dentro de los cuales tenemos el turismo de aventura, naturaleza, comunitario, cultural, religioso y otros.

Tabla 37: Tipo de turismo (porcentual).

\begin{tabular}{lccc} 
Tipo de turismo & $\mathbf{2 0 1 6}$ & $\mathbf{2 0 1 7}$ & $\mathbf{2 0 1 8}$ \\
\hline Aventura & $37,00 \%$ & $24,00 \%$ & $20,00 \%$ \\
\hline Naturaleza & $24,00 \%$ & $16,00 \%$ & $27,00 \%$ \\
\hline Comunitario & $9,00 \%$ & $11,00 \%$ & $10,00 \%$ \\
\hline Cultura & $20,00 \%$ & $32,00 \%$ & $30,00 \%$ \\
\hline Religioso & $9,00 \%$ & $17,00 \%$ & $13,00 \%$ \\
\hline Otros & $1,00 \%$ & $0,00 \%$ & $0,00 \%$
\end{tabular}


Nota: Último dato encontrado en el año 2018.

Fuente: GAD Municipal de Riobamba (2018).

Elaborado por: Autores.

En la Tabla 37, el turismo de aventura ha sido el predominante en el año 2016, con un 37\%, luego le sigue el turismo de naturaleza con un $24 \%$, seguido de turismo cultural con un $20 \%$, de ahí el turismo comunitario y religioso con un $9 \%$ cada uno y al final otro tipo de turismo con un $1 \%$. Analizando de la misma manera para el año 2017, el tipo de turismo esta de la siguiente manera: cultural, aventura, religioso, naturaleza, comunitario sin presentar datos para otros tipos de turismo, con porcentajes de 32\%, 24\%, 17\%, $16 \%$ y $11 \%$ respectivamente.

Respecto a los datos del año 2018, el predominante es el turismo cultural con un $30 \%$, luego el turismo de naturaleza con un $27 \%$, el turismo de aventura con un $20 \%$, el turismo religioso con un $13 \%$ y el turismo comunitario con un $10 \%$, sin presentar datos para otros tipos de turismo.

\subsubsection{Motivo de la visita}

Tabla 38: Motivo de la visita (porcentaje).

\section{Motivo de la visita}

2017

2018

2019

Familiares y amigos

$14,00 \%$

\begin{tabular}{lccc} 
Negocios & $20,00 \%$ & $32,00 \%$ & $17,00 \%$ \\
\hline Vacaciones, recreación y ocio & $61,00 \%$ & $45,00 \%$ & $77,00 \%$ \\
\hline Otros & $5,00 \%$ & $23,00 \%$ & $6,00 \%$ \\
\hline Total & $100,00 \%$ & $100,00 \%$ & $100,00 \%$ \\
\hline
\end{tabular}

Fuente: GAD Municipal de Riobamba (2019).

Elaborado por: Autores. 
Como se observa en la Tabla 38 respecto al motivo de la visita, tanto en el año 2017 como en el año 2018, el principal motivo de visita fue vacaciones, recreación y ocio, de ahí en el año 2017 los viajes por negocios corresponden al $20 \%$, visitas a familiares y amigos el 14\%, por motivos profesionales el $3 \%$ y con el $1 \%$ corresponde a educación y formación y a otros motivos. En el año 2018 varía el orden, siendo los viajes por negocios el 32\% del total y por otros motivos el 23\%. Para el año 2019 comprendido en el periodo de mayo-agosto, el principal motivo es de vacaciones, recreación y ocio con el $77,00 \%$ seguido del motivo de negocios con un $17 \%$.

\subsubsection{Servicios que utilizaron los turistas}

Los servicios que se utilizaron también son de gran importancia al momento de analizar el perfil del turista:

Tabla 39: Servicios que utilizaron los turistas (porcentaje).

\begin{tabular}{|c|c|c|}
\hline Servicios & 2017 & 2018 \\
\hline Alimentación & $61,00 \%$ & $34,00 \%$ \\
\hline Entretenimiento / información turística & $20,00 \%$ & $9,00 \%$ \\
\hline Alojamiento & $12,00 \%$ & $28,00 \%$ \\
\hline Operación & $6,00 \%$ & $0,00 \%$ \\
\hline Transporte & $1,00 \%$ & $26,00 \%$ \\
\hline Guianza & $0,00 \%$ & $2,00 \%$ \\
\hline Agencia de viajes & $0,00 \%$ & $1,00 \%$ \\
\hline Total & $100,00 \%$ & $100,00 \%$ \\
\hline
\end{tabular}

Nota: Último dato encontrado en el año 2018.

Fuente: GAD Municipal de Riobamba (2018).

Elaborado por: Autores. 
En la Tabla 39 se detalla los servicios que utilizaron tanto para el año 2017 y 2018, en el año 2017 se han detallado los servicios como alimentación, entretenimiento, alojamiento, operación y transporte con el $61 \%, 20 \%, 12 \%, 6 \%$ y $1 \%$ respectivamente. Y para el año 2018, al servicio de alimentación le corresponde el $34 \%$ alojamiento el $28 \%$, transporte el $26 \%$, entretenimiento e información turística el 9\%, guianza el $2 \%$ y agencia de viajes el $1 \%$.

\subsubsection{Gasto promedio}

Gráfico 39. Gasto promedio diario de los turistas en la ciudad de Riobamba año 2018 (rangos)

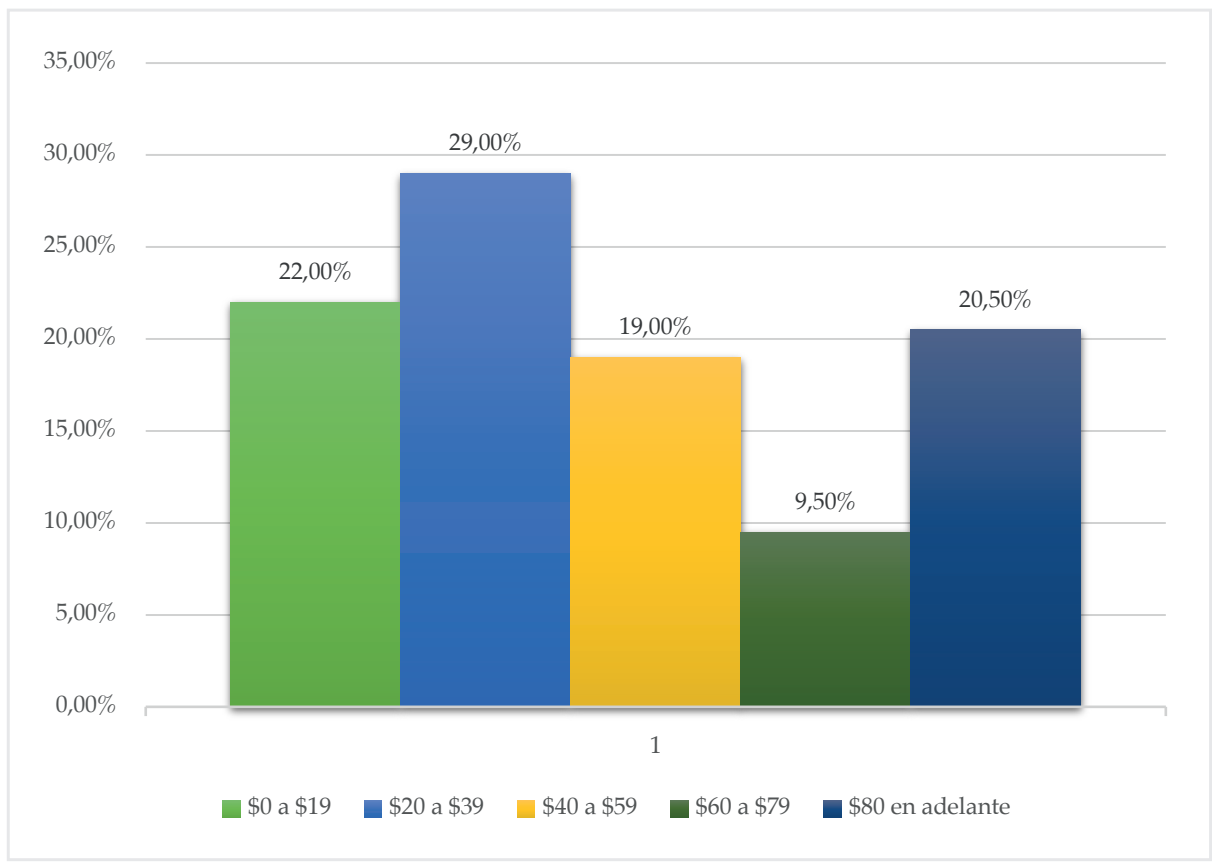

Fuente: GAD Municipal de Riobamba (2018).

Elaborado por: Autores.

En relación a los ingresos que deja un turista en la ciudad de Riobamba, se ha logrado establecer que el $29 \%$ gasta entre 20 y 
39 dólares diarios, el 22\%entre 0 y 19 dólares y el 20,50\% destina más de 80 dólares diariamente. Estos datos son inferiores a lo que reporta el el boletín turístico del Distrito Metropolitano de Quito (2012), en el que se señala que los turistas gastan un promedio diario de \$59,6 en la ciudad de Quito. Esto indica que el visitante de la ciudad de Riobamba tiene una estancia transitoria. 



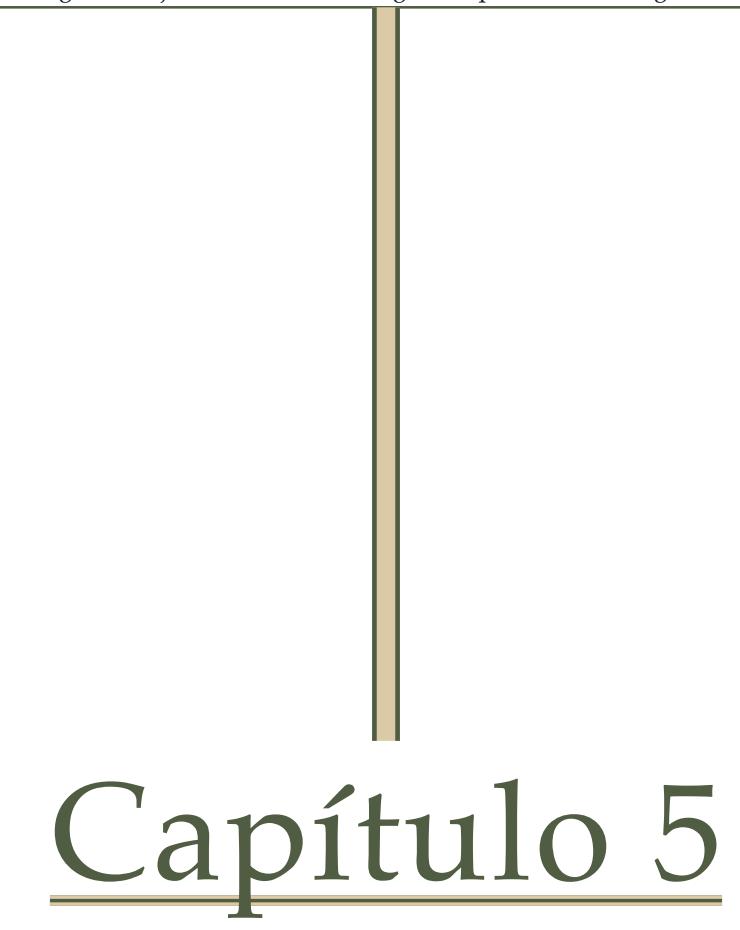

\section{Eficiencia del sector hotelero de la ciudad de Riobamba}




\section{Eficiencia del sector hotelero de la ciudad de Riobamba}

Este capítulo se centra en el análisis de la eficiencia del sector hotelero de la ciudad de Riobamba para el año 2018, para lo cual se utilizan variables como el ingreso medio por ocupación habitacional, gasto medio en servicios públicos y mantenimiento, empleados permanentes y ocasionales, servicios que presta, entre otros. Utilizando un análisis envolvente de datos, con el fin de calcular y verificar el nivel de eficiencia con el que trabajan los diferentes hoteles tanto de primera, segunda y tercera categoría en el cantón Riobamba.

\subsection{Elementos teóricos}

El sector hotelero es una fuente dinamizadora de la economía, siendo un recurso fundamental para el impulso del turismo. El Ecuador cuenta con una ventaja absoluta en biodiversidad y fauna natural lo que motiva a los diferentes turistas nacionales e internacionales a visitar y disfrutar de los centros y atracciones turísticas que el país ofrece. Por otra parte, la ciudad de Riobamba constituye un atractivo turístico rico en edificaciones coloniales y múltiples nevados, tales como el Chimborazo, Altar, etc. Debido a esto múltiples emprendedores han invertido en la construcción de distintos hoteles, con sus respectivas comodidades para brindar servicios de alojamiento de acuerdo a la demanda turística (Quinllín, 2018).

El turismo durante los últimos años se ha transformado en una fuente generadora de ingresos, puesto que los beneficios financieros que esta actividad genera han promovido un interesante crecimiento económico de este sector. En ese contexto, la ciudad Riobamba es un punto fundamental para conocer el centro, sur y 
norte del país, ya que debido a su ubicación estratégica se puede direccionar hacia otros destinos del Ecuador. Además de ello la ciudad cuenta con excelente infraestructura hotelera, gastronómica y de transporte lo cual debe aprovecharse para convertirlo en un referente turístico (Tene, 2018).

\subsubsection{Sector hotelero}

El sector hotelero, lo conforman todas las entidades que prestan servicios de alojamiento y demás servicios mediante diferentes estructuras y calidades que van desde hoteles considerados de primera o de lujo hasta hostales cuyos servicios son limitados y básicos, en función a precios que son fijados con anterioridad (Zaldivar, 2016).

Por otra parte, Lara (2016) señala que el sector hotelero es una parte del turismo, en la cual se proporciona servicio de alojamiento a turistas nacionales y extranjeros. Este tiene diferentes categorizaciones, dependiendo de la comodidad y su ubicación. Cada unidad hotelera posee características únicas que la distinguen. El sector hotelero es fundamental para el sector turístico ya que brinda una experiencia única para el turista.

\subsubsection{Sector hotelero de la ciudad de Riobamba}

En lo referente al sector hotelero de la ciudad de Riobamba, existen 66 establecimientos de hospedaje en diferentes categorías y una oferta total de 1423 habitaciones y una disponibilidad de 3008 camas.

Los establecimientos de alojamiento se distribuyen por categorías de la siguiente manera: 1 estrella 22 establecimientos, con 2 estrellas están registrados 25 establecimientos, 3 estrellas se encuentran 
registrados 11 establecimientos, 4 estrellas se encuentran registrados 2 establecimientos y en la categoría única se encuentran registrados 6 establecimientos (Ministerio de Turismo, 2018).

Los visitantes que acuden a la ciudad de Riobamba lo hacen en fechas festivas para la localidad, esto hace que la actividad económica se incremente, especialmente el sector hotelero. Según El Telegrafo (2017), el movimiento de ingresos aumenta en estas fechas, pero se mantiene bajo el resto del año porque el sector turístico de Riobamba no ha mostrado un crecimiento elevado. Según el presidente de asociación de hoteleros de la ciudad menciona que el aumento en la demanda de hospedaje sería del $80 \%$ para los días festivos.

En este contexto, para el feriado de carnaval la provincia de Chimborazo durante el periodo 2017-2019, tuvo una participación promedio del 2,7\%, En cambio para el feriado de Semana Santa la participación promedio fue de 1,90\% y para el feriado del 2 y 3 de noviembre al 2,38\%, y para el feriado de fin de año 1,49\% (Ministerio de Turismo, 2019).

Para el año 2007, el sector hotelero y de restaurantes estaba ubicado en el puesto número 12 con 16,9 millones de dólares que representa el 0,96\% del PNB provincial 784.573, por lo que estaba debajo de las actividades de construcción que tiene un 16,5\%, agricultura, ganadería, $14.09 \%$, transporte, almacenamiento y comunicaciones $13,61 \%$ y comercio al por mayor y menor $13,35 \%$, lo que representa el relativo bajo impacto de las actividades vinculadas con el turismo en la provincia (Cangas \& Romero, 2014).

En lo que respecta a la recaudación tributaria que proviene de actividades turísticas, se registra USD 150.944.484 que corresponde a las actividades de hoteles y restaurantes, con un aporte signi- 
ficativo de la provincia de Pichincha, representado en el 54,1\% en el año 2016, seguido de la provincia de Guayas con el 25,3\%, entre otras provincias que presentan un menor aporte (Ministerio de Turismo, 2019).

El sector hotelero es de gran importancia para la economía del país ya que genera una diversidad de consumo interno, a diciembre de 2018 generó 131.630 fuentes de empleo en la industria de alojamiento y servicios de comida según encuesta ENEMDU. Además, el $46.72 \%$ de los empleos por turismo corresponde a mujeres (Ministerio de Turismo, 2018).

Lo anteriormente mencionado destaca la importancia del sector turístico, es así que este tiene un efecto multiplicador de 1.6\% para el año 2018 en la economía nacional, la contribución total del turismo al PIB alcanza el 5.51\% de los cuales el $2.28 \%$ es de tipo directo, así mismo se contabilizaron 24.720 establecimientos turísticos (Ministerio de Turismo, 2018).

La ocupación hotelera del Ecuador en 2015 fue de 65,6\% y hasta abril de 2016 bajó a 57,2\%, lo que significa que un poco más de cuatro de cada diez camas existentes están vacías. Entre los motivos para esta caída se incluyen la apreciación del dólar que convierte al país en un destino más costoso frente a países vecinos, y la tendencia de alojamiento alternativo en casas y departamentos (Romero, 2015). Es solo cuestión de tiempo para que el sector del turismo y el hotelería puedan reemplazar al sector petrolero. Lo positivo de esto es que el turismo no es más que la exportación de recuerdo y momentos, y el gobierno debería impulsar este sector. Debemos aprender de países como México, España y Francia, y esto solo se logrará generando confianza con inversionistas locales, además de reformar todo el sistema de promoción y leyes para atraer la inversión extranjera (Mayorista de Turismo, 2017). 
Los hoteles se categorizan según su calidad de servicio, calidad de infraestructura y de más, en Ecuador estas características ayudan a fijar precios del servicio que se brinda a los viajeros o turistas. Según Hoteles Ecuador (2019), La gran mayoría de hoteles cobra alrededor de los 15 a 70 dólares. Estos lugares tienen mejor categoría y la comodidad está asegurada. También hay hoteles de lujo, que van desde los 70 dólares hacia arriba.

\subsubsection{Eficiencia}

En lo referente a eficiencia, Pérez (2017) explica la utilización racional de los medios disponibles para alcanzar un objetivo, esto implica que dicho objetivo se logre con el menor tiempo y recursos posibles.

Por otra parte, García (2012) manifiesta que la eficiencia muestra la concordancia existente entre los insumos utilizados y los resultados obtenidos en un proceso productivo. En este sentido, lo importante es conseguir un objetivo con la menor cantidad de recursos disponibles.

\subsubsection{Base legal del sector hotelero}

Toledo (2015), afirma que en el país el marco que rige el comportamiento de la sociedad es la Constitución de la República del Ecuador, con base en dicha normativa se citan los siguientes artículos que hacer referencia al turismo. 


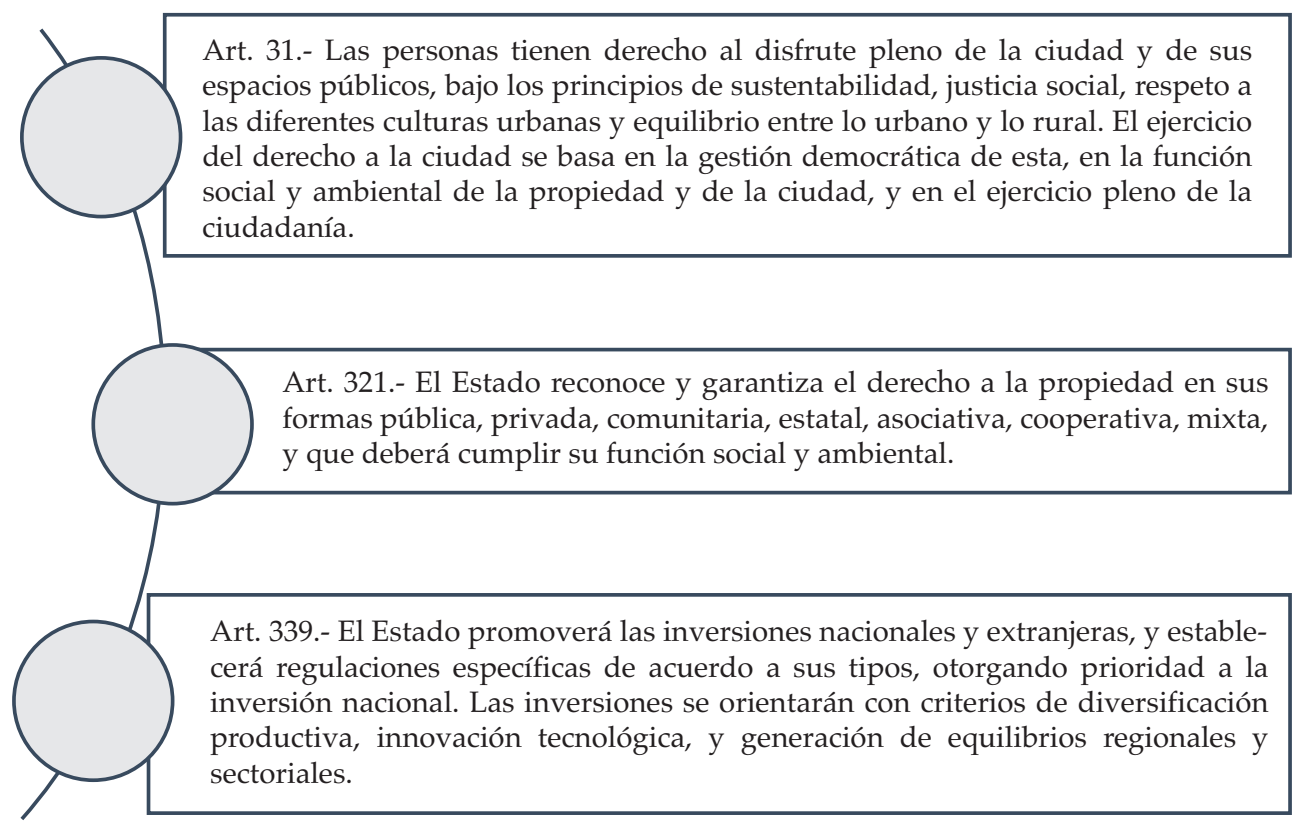

Figura 3. Base legal del turismo en el Ecuador

Fuente: Constitución de la República del Ecuador (2008); (p.7-8).

Elaborado por: Autores.

\subsection{Metodología}

En cuanto a la metodología aplicada para el análisis y recolección de datos se ha utilizado el análisis envolvente de datos también conocido como (DEA), el cual se utiliza principalmente para el cálculo de la estimación de la eficiencia relativa para un grupo de entidades dedicadas a la producción, tal como Somarriba (2015) señala que la metodología DEA constituye un método para la cuantificación de la eficiencia a través de la obtención de una frontera de eficiencia con base a un conjunto de datos, tomando en consideración "inputs" y "outputs". 


\subsubsection{Estudios previos DEA.}

En un trabajo realizado por Alberca y Parte (2013), en el cual se analiza la eficiencia nacional, regional y la producción total de factores de los hoteles españoles, la metodología de análisis envolvente de datos, fue empleada para dicha medición y también los índices de Malmquist, los cuales sirvieron para estimar el cambio productivo en el periodo 2001-2008.

Se obtuvo como resultado que las empresas ubicadas en las Comunidades Autónomas de España (CCAA) de Madrid, país Vasco y Cataluña, orientadas a un turismo diversificado, resultan ser más competitivas al obtener mayores índices de eficiencia. Por el contrario, las CCAA con empresas menos competitivas que muestran un comportamiento menor en niveles de eficiencia media en el año 2008 fueron: Galicia, Castilla- La Mancha y Murcia (Alberca \& Parte, 2013).

También el modelo DEA, fue aplicado en un estudio realizado en Colombia por Carrillo y Gómez (2017), quien para la medición de la eficiencia del sector hotelero en la ciudad de Bucaramanga en el año 2013 analizó 15 hoteles, las variables fueron tomadas de los estados financieros tales como variables de entrada gastos de personal, inventarios y propiedad planta y equipo y variables de salida como los ingresos.

Los resultados obtenidos según los autores antes citados fueron una falta de uniformidad en los formatos de registro de los estados financieros que se mantienen en la Cámara de comercio de la ciudad estudiada. Por lo tanto esto dificulta la realización de los análisis comparativos por parte de entidades externas así como también la generación de diagnósticos apropiados (Carrillo \& Gómez, 2017). 
De igual manera el método antes mencionado ha sido aplicado en la ciudad de Cartagena (Colombia) en el periodo 2007-2008, con 21 hoteles de los cuales uno se excluyó por razones de su composición de activo, por lo tanto, las muestras a trabajarse fueron de 20 hoteles de tres categorías: cinco, cuatro y tres estrellas. Los resultados que se obtuvieron con respecto a la eficiencia fueron que para el año 2007 del total de la muestra analizada el promedio de eficiencia fue de $97.28 \%$, donde solo cuatro hoteles obtuvieron un nivel de eficiencia por debajo de la media observada. El hotel que presentó menor eficiencia en el año 2007, fue el hotel El Dorado, y para el año 2008 fue el hotel El Pueblito (Maldonado, 2009).

\subsubsection{Análisis envolvente de datos (DEA)}

Rivera (2015) señala que la DEA es una técnica de medición de la capacidad de lograr el máximo producto con el mínimo de recursos, para lo cual se basa en una frontera de eficiencia a partir de un número de variables de entrada (inputs) para obtener un número de variables de salida (outputs) sin necesidad de conocer una relación funcional específica.

La metodología DEA es en definitiva una alternativa para extraer información de observaciones frente a los métodos paramétricos cuyo objetivo es la obtención de un hiperplano que se ajuste lo mejor posible al conjunto de observaciones. Es así que esta se trata de optimizar la medida de eficiencia de cada unidad analizada para crear una frontera eficiente. Por otra parte, Charnes (1997) explica que es necesario construir en primera instancia una frontera de producción empírica y posteriormente evaluar la eficiencia de cada observación que no sea parte de la frontera de eficiencia.

Inicialmente dicho modelo fue propuesto por Rhodes (1978) y posteriormente publicado por Charnes et alter (1978). Rivera 
(2015) señala que la eficiencia vincula la sumatoria en función de su participación de los inputs con la de outputs de cada ente de decisión y diseñó programas de optimización lineal para estimar las ponderaciones, sin embargo en el modelo inicial no era lineal.

$$
\begin{aligned}
& \text { ho }=\frac{\sum_{\mathrm{r}=1}^{\mathrm{s}} \mathrm{Ur}^{*} Y \text { ro }}{\sum_{\mathrm{i}=1}^{\mathrm{m}} \mathrm{Vi}^{*} X i o} \\
& \frac{\sum_{\mathrm{r}=1}^{\mathrm{s}} \mathrm{Ur}^{\star} Y \mathrm{rj}}{\sum_{\mathrm{i}=1}^{\mathrm{m}} \mathrm{Vi}^{\star} X_{\mathrm{ij}}} \leq 1 \forall \mathrm{j}: 1 . . \mathrm{n} \\
& \mathrm{U} \mathrm{r}, \mathrm{V} \mathrm{i} \geq 0 \mathrm{~s} \quad \forall \mathrm{r}: 1 \ldots \forall \mathrm{i}: 1 \ldots \mathrm{m}
\end{aligned}
$$

\section{Donde:}

ho: función objetivo. Medida de la eficiencia.

Yrj: output i-ésimo de la DMU j-ésima.

Xij: input i-ésimo de la DMU j-ésima. Vi,

Ur: ponderaciones de inputs y outputs respectivamente (soluciones del programa).

\subsubsection{Modificaciones del modelo básico}

Rivera (2015) explica que el diseño original del modelo fue cambiado posteriormente por su mismo autor Charnes et alter en el año de 1979 con la finalidad que las ponderaciones logren números positivos.

$\operatorname{Max} \phi o, \lambda, S i-, S r+\phi o+\varepsilon\left(\sum_{\mathrm{i}=1}^{\mathrm{m}} S 1-+\sum_{\mathrm{r}=1}^{\mathrm{s}} S r+\right)$

S. A.

$$
\begin{aligned}
& \sum_{\mathrm{i}=1}^{\mathrm{n}} \mathcal{\lambda} \mathrm{j}^{*} \mathrm{X} \mathrm{ij}+\mathrm{S} \mathrm{i}=\mathrm{X} \text { io } \quad \forall \mathrm{i}: 1 \ldots \mathrm{m} \\
& \sum_{\mathrm{j}=1}^{\mathrm{\lambda}} \boldsymbol{\lambda} \mathrm{j}^{*} \text { Yrn }-S \mathrm{r}=\varphi \mathrm{o}{ }^{*} \text { Y ro } \forall \mathrm{i}: 1 \ldots \mathrm{S}
\end{aligned}
$$




\section{$\lambda \mathrm{j}, \mathrm{S} \mathrm{i}-, \mathrm{S} \mathrm{r}+\geq 0$}

Donde:

$\varphi 0$ : parámetro que mide la eficiencia de la unidad evaluada.

$\lambda \mathbf{j}$ : ponderaciones obtenidas como solución del programa. Expresan el peso que posee cada DMU dentro del grupo de comparación (peer group) de la DMUo.

Si -, $\mathbf{S r}+$ : variables de holgura de inputs y outputs respectivamente. Transforman las restricciones de desigualdad en igualdades.

Rivera (2015) menciona que el método M.3 investiga una relación ponderada de elemento tal que para cada variable de entrada, su mezcla de componentes más la variable de holgura sea igual que los insumos gastados.

\section{Metodología}

Con el desarrollo de la industria turística en el Ecuador en la última década, ha existido un creciente interés por evaluar su eficiencia desde una perspectiva local. En este sentido, se presentan los resultados preliminares de un estudio sobre el rendimiento de la industria hotelera en la ciudad de Riobamba. Sobre una muestra de 42 hoteles ( 14 de $1^{\text {a }}$ estrella, 18 de 2 estrellas, y 10 de 3 estrellas) de una población de 62 , se calcula el nivel de eficiencia técnica de estos.

Para la presente investigación se aplicó un análisis envolvente de datos (DEA), la información se obtuvo a través de encuestas dirigidas a los hoteles de la ciudad de Riobamba, Estas se realizaron a través de una muestra estratificada aleatoria con la finalidad de tener estratos homogéneos con características similares. La información que se obtuvo se relaciona con gastos de mantenimiento, servicios básicos, número de empleados permanentes y ocasionales, años de funcionamiento, capacidad 
máxima de ocupación, porcentaje de ocupación, tarifa por habitación, con el fin de poder determinar los inputs y outputs, insumos necesarios para la aplicación de la metodología DEA.

\subsection{Resultados}

A medida que aumenta la calidad y el número de servicios con el que cuentan los hoteles también aumenta sus costos de operación, por lo que el precio por los servicios brindados también aumentará. Tomando en consideración el nivel de competencia en el que se encuentra el sector hotelero esto podría resultar en posibles obstáculos que los hoteles deberán enfrentar en el largo plazo.

A partir de la encuesta aplicada a los hoteles de la ciudad de Riobamba, se obtuvieron los siguientes resultados:

Gráfico 40. Ingreso medio por ocupación habitacional (mensual - dólares)

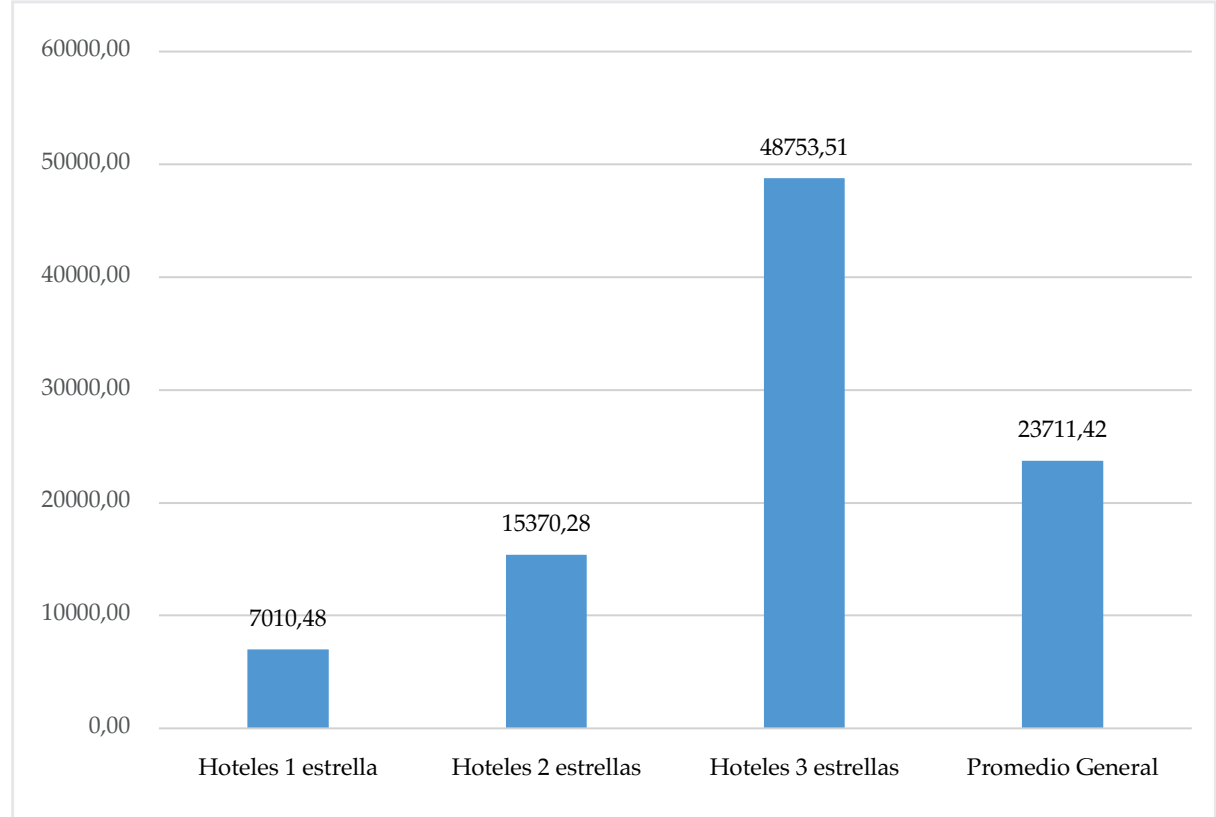

Fuente: Cálculos propios sobre información suministrada por los establecimientos hoteleros (2018)

Elaborado por: Autores. 
En el gráfico 40, se aprecia que los ingresos mensuales para los hoteles de una estrella apenas superan los 5000 dólares, los de dos estrellas llegan a los 15000 dólares y los de tres estrellas superan los 45000 dólares. Mientras que en conjunto los hoteles de la ciudad de Riobamba tienen un ingreso medio de 20000 dólares al mes. Esto indica que los hoteles que se encuentran en la categoría tres son los que tienen la mejor relación entre servicios que prestan y precio de habitación, en este sentido son los que tienen la mayor rentabilidad con respecto a la inversión realizada.

Gráfico 41. Gasto medio en servicios públicos y mantenimiento (mensual - dólares).

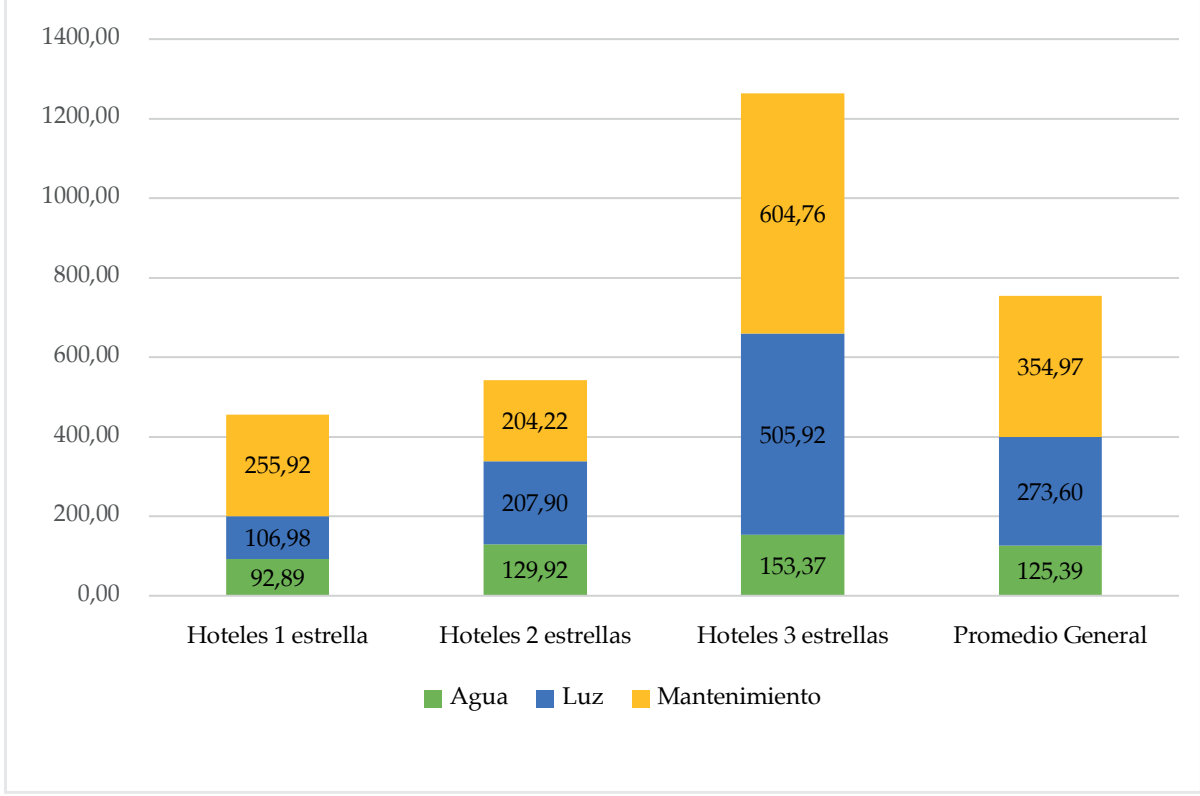

Nota: Gasto en mantenimiento se refiere a los costos por arreglos locativos, servicio de limpieza y reposición de capital físico.

Fuente: Cálculos propios sobre información suministrada por los establecimientos hoteleros (2018)

Elaborado por: Autores.

En el gráfico 40, se muestra que los costos medios en servicios públicos y mantenimiento mensual para hoteles de una estrella 
son 400 , dos estrellas 500, tres estrellas 1200 y en conjunto medio unos 700. Cuyos gastos son: agua, luz y mantenimiento.

Gráfico 42. Empleados permanentes y ocasionales (media simple).

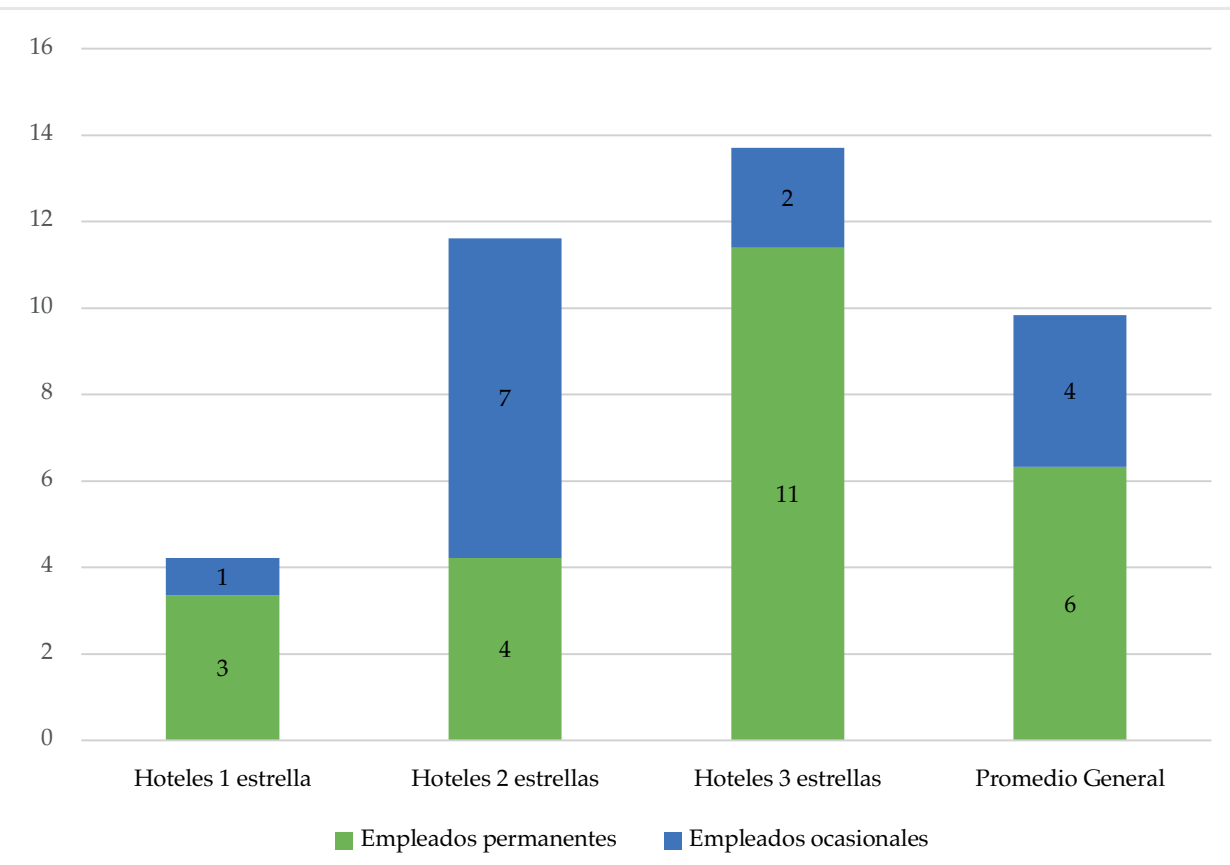

Fuente: Cálculos propios sobre información suministrada por los establecimientos hoteleros (2018)

Elaborado por: Autores.

En el gráfico 42, se muestra que los hoteles de una estrella cuentan con 4 empleados de los cuales 3 son permanentes, los de dos estrellas cuentan con 11 trabajadores de los que 4 son permanentes y los hoteles de tres estrellas cuentan con 14 trabajadores de los cuales 11 son permanentes. 
Gráfico 43. Servicios que presta (media simple).

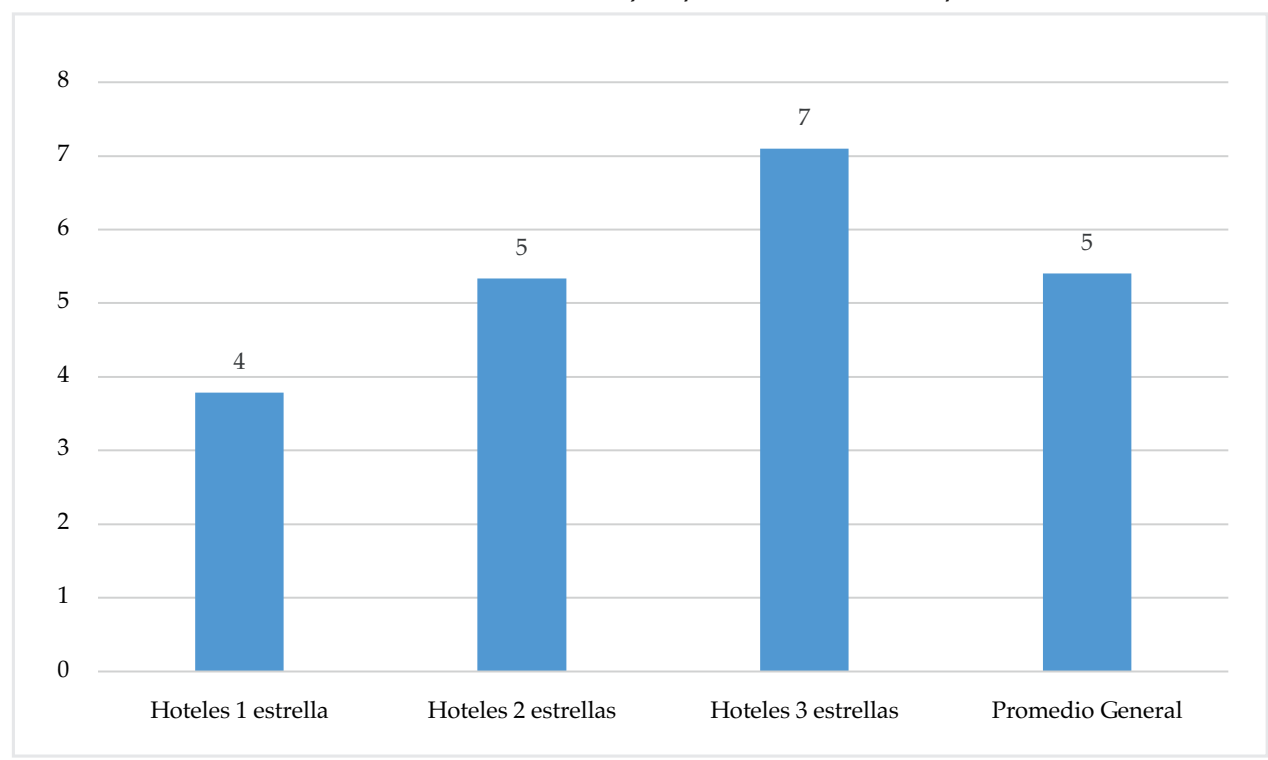

Fuente: Cálculos propios sobre información suministrada por los establecimientos hoteleros (2018)

Elaborado por: Autores

En el gráfico 43, se muestra que para que un hotel sea de una estrella debe tener 4 servicios, los de dos estrellas deben tener 5 servicios y los hoteles de tres estrellas cuentan con hasta 7 servicios, mientras que en conjunto medio los hoteles presentan 5 servicios adicionales que por lo general son: internet, cafetería, tv cable, etc. 
Gráfico 44. Años de funcionamiento (media simple).

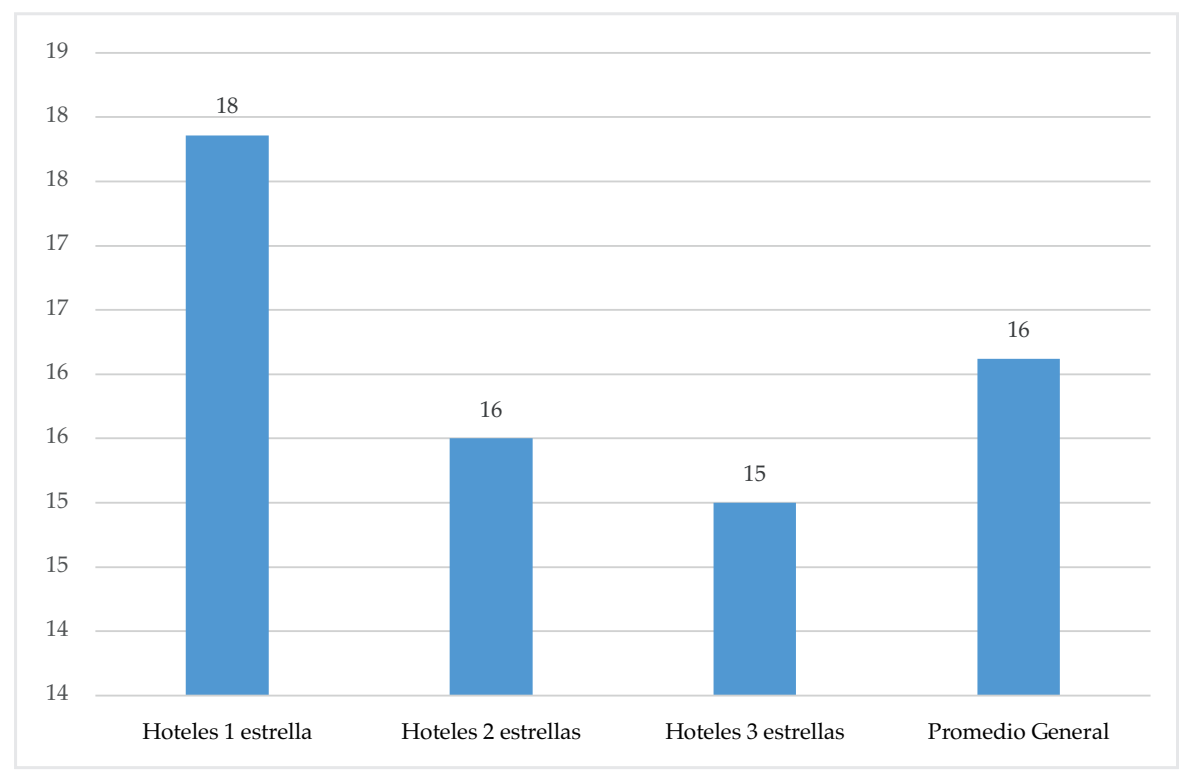

Fuente: cálculos propios sobre información suministrada por los establecimientos hoteleros (2018)

Elaborado por: Autores

En el gráfico 44, se muestra que los hoteles de 1 estrella tienen hasta 17 años de funcionamiento, los de dos estrellas tienen 15 años de funcionamiento, los de tres estrellas 15 años y en conjunto en promedio los hoteles llevan 16 años funcionando en Riobamba.

Para desarrollo del DEA el output son los ingresos y como variables inputs es decir los recursos que se utilizan para generar el output tenemos a las variables años de funcionamiento, categoría, número de empleados, número de servicios y costo de mantenimiento (luz, agua y mantenimiento).

Las estimaciones muestran un grado considerable de ineficiencia, sin que se identifique un efecto significativo de dos variables explicativas consideradas (categoría y años de funcionamiento), 
estas variables consideramos que eran importantes para determinar un mayor grado de eficiencia.

Gráfico 45. Nivel de eficiencia del sector hotelero, ocupación habitacional, media simple.

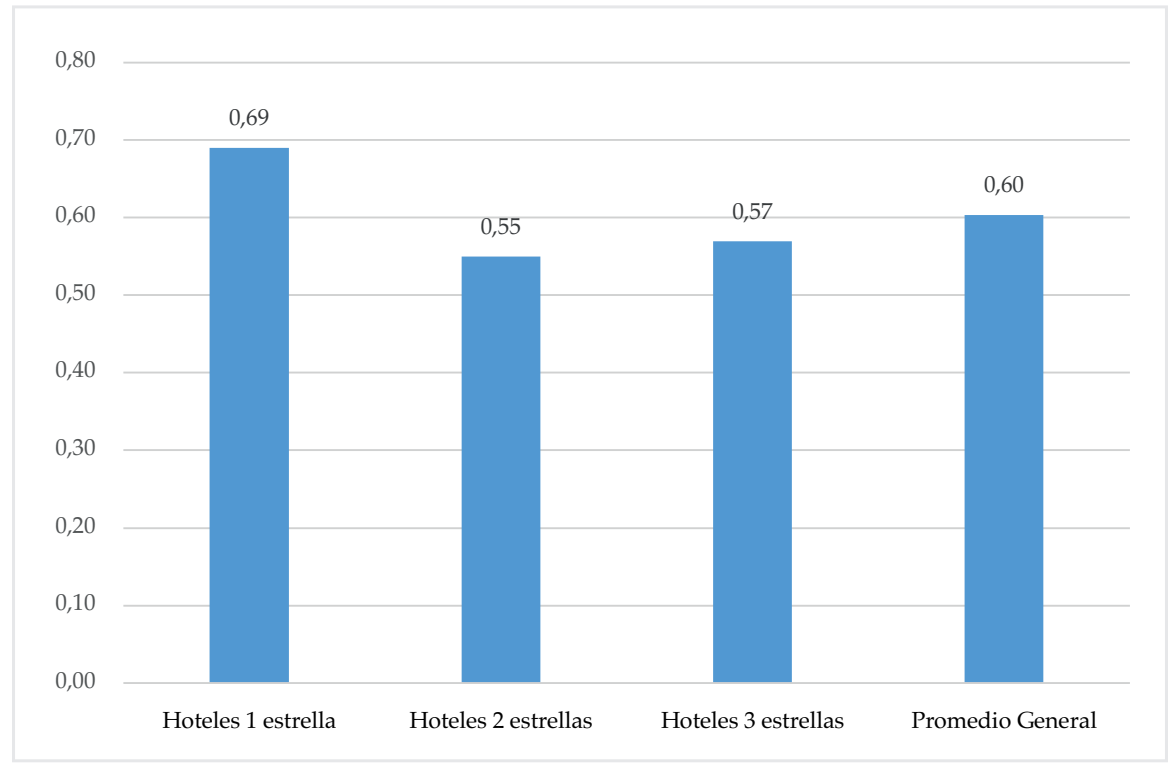

Fuente: cálculos propios sobre información suministrada por los establecimientos hoteleros (2018)

Elaborado por: Autores

En el gráfico 45, se presenta el cálculo de la eficiencia técnica con base en un análisis envolvente de datos (DEA), donde uno es el nivel máximo de eficiencia, sobre una muestra de 42 establecimientos (14 de una estrella, 18 de dos estrellas, y 10 de tres estrellas). Los de una estrella tienen un $69 \%$ de eficiencia, los de dos estrellas tienen un 55\%, los de tres estrellas tienen un 57\% y en conjunto los hoteles de la ciudad de Riobamba presentan una eficiencia de $60 \%$. 
Gráfico 46. Frontera de eficiencia del sector hotelero en la ciudad de Riobamba (por categorías).

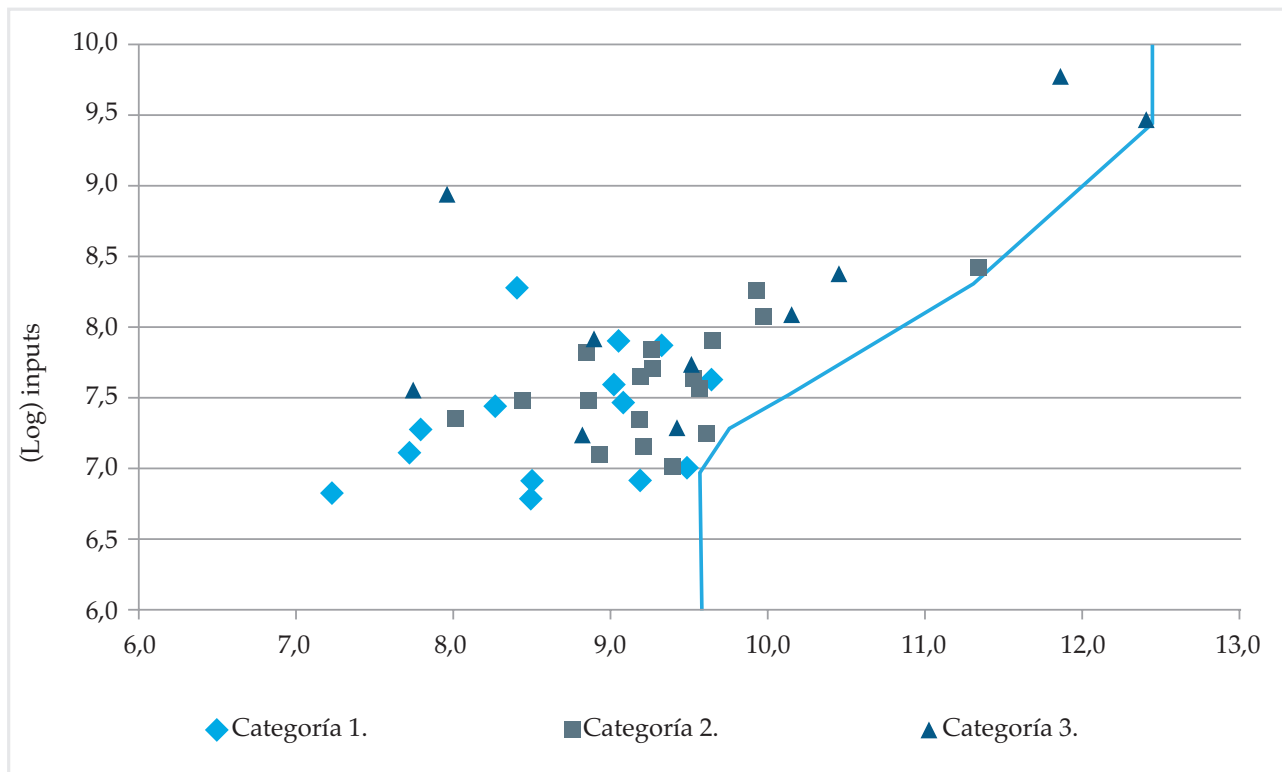

Nota: categoría 1 equivale a 1 estrella, categoría 2 equivale a 2 estrellas, categoría 3 equivale a 3 estrellas.

Fuente: cálculos propios sobre información suministrada por los establecimientos hoteleros (2018).

Elaborado por: Autores

Según el gráfico 46, referente a la frontera de eficiencia del sector hotelero en la ciudad de Riobamba. Tan solo un hotel de tres estrellas es eficiente, un hotel de categoría 2 es eficiente, mientras que los hoteles de 1 categoría apenas se acercan a la frontera de eficiencia técnica; mientras que, los demás hoteles de la muestra que fueron seleccionados para el estudio no cumplen con el nivel de eficiencia adecuado. 


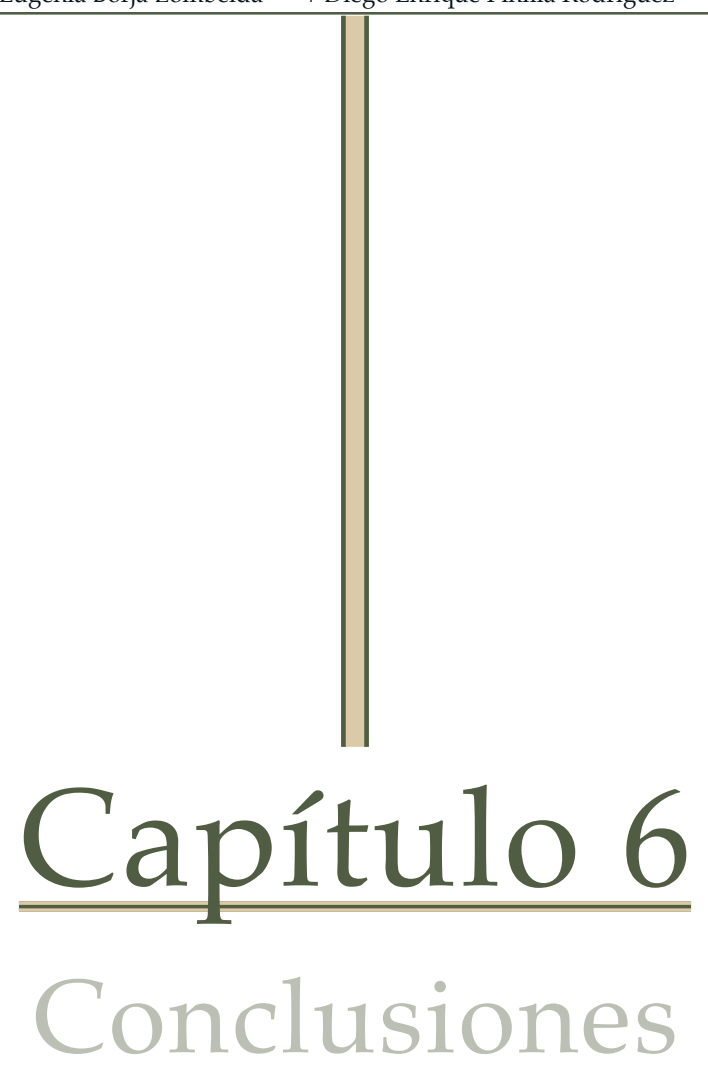




\section{Conclusiones}

El producto interno bruto del sector turístico durante el periodo 2000-2018 ha presentado un crecimiento promedio de 8.38\% y se observa que la participación en el PIB global se ha mantenido alrededor del $1,4 \%$, esto indica que el sector no ha logrado despegar completamente y se ha mantenido a la par del crecimiento de la economía.

El empleo generado por el sector turístico experimenta un crecimiento significativo alcanzando un total de 522.508 empleados para el tercer trimestre del 2019, esto se relaciona con el valor agregado bruto directo turístico que durante el periodo de estudio presenta una tasa de crecimiento promedio de $4,1 \%$.

Los turistas que visitan Ecuador durante el periodo 20122016 provienen de Estados Unidos, Colombia, Venezuela, Perú y España, siendo Colombia el país que más emisión de turistas genera hacia Ecuador, con 344.363 personas, seguido por Estados Unidos con 250.785, Perú con 150.805 y España con 65.245

El turismo se consolida como la tercera actividad más importante dentro de la economía nacional. En primer lugar, se ubica el banano, que en 2016 generó ingresos de 2039 millones de dólares y en 2017 generó 2323 millones de dólares, seguido por el plátano y camarón, que generaron ingresos en el año 2016 de 1886.9 millones de dólares y en el año 2017 de 2231.3 millones de dólares, y de ahí el turismo, que en 2016 generó 1075.5 millones de dólares y en 20171204.5 millones de dólares, teniendo un incremento de 129 millones de dólares entre en año 2016 y 2017.

En lo referente al aporte del sector turístico en el crecimiento económico del país, medido a través de la aplicación del método 
de mínimos cuadrados, se denota que las variables tienen el signo esperado, es decir, hay una relación positiva indicando que tanto los ingresos del sector turístico como la formación bruta de capital fijo afectan de manera importante en el crecimiento económico.

En cuanto al modelo econométrico, el coeficiente de los ingresos del sector turístico tiene un valor de 0.193070, lo que indica que por cada uno por ciento que aumente, el PIB aumentará en $0,19 \%$ y el valor del coeficiente de la formación bruta de capital fijo es de 0.281245 , lo que representa que por cada uno por ciento que aumente, la economía crecerá en 0,28\%.

Para determinar la relación de equilibrio de largo plazo se utilizó el test de Johansen, con el cual se encuentra certeza de cointegración entre las variables de estudio, por lo que contribuyen para una relación de equilibrio a largo plazo.

El estudio de la descomposición de la varianza que facilita medir el efecto porcentual de cada shock para explicar la variación en la variable dependiente refleja la siguiente información, que un shock en el ingreso de divisas del sector turístico contribuiría en $1,57 \%$ en el corto plazo y 6,78\% a la fluctuación del PIB en el largo plazo, mientras que la FBKF contribuiría en $34,50 \%$ en el corto plazo y en $23,67 \%$ a largo plazo.

En lo referente al valor agregado bruto del sector alojamiento y servicios de comida de la provincia de Chimborazo, periodo 2007-2017 se muestra una tendencia irregular, marcando una mayor tasa de crecimiento en el año 2012 del 34,4\% debido al proyecto de Fortalecimiento de la Red Social de Turismo Sostenible de la provincia de Chimborazo, donde el objetivo fue mejorar las condiciones de desarrollo social con base en la regulación de actividades de turismo sostenible en la provincia. 
Con respecto a la recaudación tributaria de hoteles y restaurantes en la zona 3, durante el periodo 2012-2016. Se observa que la provincia de Tungurahua presenta una mayor recaudación tributaria, la cual en promedio durante el periodo de estudio ha recaudado $\$ 3.237 .013$,4 debido a la gran acogida turística que tiene esta provincia. Por otra parte, la provincia de Chimborazo presenta una recaudación tributaria promedio durante el periodo de estudio de $\$ 1.482 .632,4$. Cotopaxi se encuentra en tercer lugar con un ingreso promedio de recaudación de $\$ 1.017 .628,8$, y finalmente Pastaza con \$277.322,0

El personal ocupado en los establecimientos registrados en el Ministerio de Turismo zona 3, año 2016. Tungurahua tiene una participación de $55 \%$, siendo esta la más alta, debido al incremento de turistas, lo que genera empleos ocasionales o permanentes dependiendo la época de año. La provincia de Chimborazo presenta una participación del $22 \%$ en la generación de empleo ocupando el segundo lugar. En tercer lugar, se encuentra Cotopaxí con una participación del 15,77\%, y finalmente, Pastaza con el 7,70\%.

Para el año 2018, Riobamba tiene un total de 63 establecimientos de alojamiento registrados, siendo los hoteles y hostales los más importantes, juntos suman 57 empresas que representan el 90,48\% del total. La disponibilidad de habitaciones y camas de todos los establecimientos registrados es de 1408 y 2976 respectivamente.

En Riobamba para el año 2015 se registraron 33 agencias de viajes y operadores turísticos, a partir del año 2016, se denota un decrecimiento hasta el año 2017 con 28 registros, evidenciándose una caída del 15,15\%. Para el año 2018 se registran 34 agencias notándose crecimiento del 21,43\%, con respecto al año 2017, lo que denota variabilidad en el sector turístico. 
Respecto al género de los turistas que viajan a la ciudad de Riobamba, se observa que durante el año 2018 el género masculino representa el 52\% y las mujeres el 48\%, para el año 2019 se registra una disminución del 1,92\% en los hombres y un incremento de una tasa del 2,08\% para las visitas de género femenino llegando a representar el $49 \%$ del total, esto se relaciona con la tendencia registrada a nivel nacional en la cual se destaca que en la actualidad las mujeres han incrementado sus viajes ya sea para cumplir con sus obligaciones laborales o por placer.

La mayor parte de visitantes que llegan a Riobamba son nacionales, los datos registrados muestran que durante el año 2016 se registraron 77.658 visitantes, para el año 2018 se evidencia un decrecimiento del $5,48 \%$, esto se debe a la falta de políticas emprendidas por las autoridades locales, como también por los empresarios turísticos para incentivar el turismo interno. Sin embargo, a nivel nacional el Ministerio de Turismo ha motivado mediante políticas para la promoción entre las cuales se destaca el traspaso de días feriados a fines de semana, el cambio de cultura de los viajeros ecuatorianos, y el aumento de la calidad de la oferta turística.

En lo concerniente a los turistas extranjeros para el año 2016 se registraron 14.714 visitantes y para el año 2017 se evidencia un decrecimiento del 16,31\% sin embargo para el año 2018 se denota un crecimiento del 31,93\% llegando a registrar 16.246 visitantes, esto concuerda con las estadísticas nacionales en las cuales se expresa un crecimiento del $4 \%$ en la llegada de turistas extranjeros para el mismo año. Esta variabilidad en los visitantes internacionales, muestra que Riobamba no constituye todavía un destino turístico permanente para extranjeros.

En Riobamba, durante el año 2016, los meses de mayor afluencia de turistas nacionales son agosto, septiembre y noviembre. En el año 2017 los meses de mayor afluencia son abril, agosto y 
noviembre. Para el año 2018 se denota que los meses de mayor afluencia turística son abril, octubre y noviembre. Finalmente, para el año 2019 se muestra que los meses que se destacan son abril, julio y agosto.

Los meses de mayor afluencia de visitas de turistas extranjeros a Riobamba para el año 2016 fueron febrero, abril y noviembre. Durante el año 2017 los meses que se destacan son febrero, julio y agosto. Para el año 2018 la mayor afluencia turística se concentra en los meses de septiembre, octubre y noviembre. Finalmente, para el año 2019, se denota que los meses con mayor afluencia turística son mayo, julio y agosto.

Respecto al tiempo de estadía durante el año 2016, se evidencia que los turistas que optaron por quedarse un día en la ciudad de Riobamba representan el 90,20\%, en cambió se muestra que los turistas que se quedaron más de seis días son 739 personas que representa el 0,8\% del total. En el año 2017 el mayor porcentaje se encuentra en el rango de dos a tres días con el $50 \%$, en este año existe un incremento sustancial en el tiempo de estadía de los turistas que permanecen más de un día. Para los años 2018 y 2019 el mayor tiempo de estadía se encuentra en un día con $43,00 \%$ y $88,40 \%$ respectivamente, notándose un descenso en el tiempo de estadía de los visitantes a Riobamba.

Los tres principales atractivos considerados son: Riobamba (zona urbana), la Reserva de Producción de Fauna Chimborazo y el Parque Nacional Sangay. En el año 2017, de un total de 154170 turistas registrados, el 54,68\% visitó Riobamba; un 36,89\% la Reserva de Producción de Fauna Chimborazo y el 7,1\% visitaron el Parque Nacional Sangay. Para el año 2018, Riobamba recibió 
52,65\% de turistas, la Reserva de Producción de Fauna Chimborazo albergó a 40,43\% y el Parque Nacional Sangay acogió 5,74\% del total de visitantes.

Los turistas extranjeros que visitaron la ciudad de Riobamba, para el periodo 2017-2019, procedieron de los países: Colombia, Alemania, Francia, España y en el caso del resto del mundo, se destacan: Venezuela, Suiza, Argentina, Canadá, Perú, Brasil, Austria, Reino Unido, Bélgica, Italia, entre otros.

Los turistas nacionales que visitan la ciudad de Riobamba, para el periodo 2017-2019 provienen de Quito, Guayaquil, y otras ciudades que han tomado importancia para el año 2018 y 2019 son Cuenca, Puyo y Ambato.

Los medios por los cuales los turistas se informaron respecto a Riobamba como destino turístico, están el internet que es el principal medio informativo con un promedio para el periodo de estudio del 35,33\%, en segundo lugar figuran agencias de viaje con el $23 \%$ en promedio y en tercer lugar se encuentran las recomendaciones con un promedio del $22 \%$, en cuarto lugar se encuentran las revistas con un promedio del 5,33\%, y finamente otros medios como guías turísticas, radio y televisión con un promedio de $14,33 \%$.

En cuanto al tipo de turismo que existe en Riobamba se destaca el turismo de aventura el cual ha sido el predominante en el año 2016, con un 37\%, luego le sigue el turismo de naturaleza con un $24 \%$, seguido de turismo cultural con un $20 \%$, de ahí el turismo comunitario y religioso con un $9 \%$ cada uno y al final otro tipo de turismo con el 1\%. Respecto a los datos del año 2018, el predominante es el turismo cultural con un $30 \%$, luego el turismo de naturaleza con un $27 \%$, el turismo de aventura con un $20 \%$, el 
turismo religioso con un $13 \%$ y el turismo comunitario con un $10 \%$, sin presentar datos para otros tipos de turismo.

En relación a los ingresos que deja un turista en la ciudad de Riobamba, se ha logrado establecer que el 29\% gasta entre 20 y 39 dólares diarios, el 22\% entre 0 y 19 dólares y el 20,50\% destina más de 80 dólares diariamente. Estos datos son inferiores a lo registrado por la ciudad de Quito que gastan un promedio diario de $\$ 59,6$. Esto implica que el visitante de la ciudad de Riobamba tiene una estancia transitoria.

En el año 2018 los empresarios hoteleros de la ciudad de Riobamba no cuentan con un nivel óptimo de eficiencia, los hoteles de una estrella tienen el 69\% de eficiencia, los de dos estrellas el $55 \%$ y los de tres estrellas un 57\%, sin embargo, en una media de todos los hoteles estudiados, estos apenas llegan a un nivel de eficiencia del $60 \%$.

En el año 2018, el ingreso promedio mensual de los hoteles de Riobamba, son los siguientes: de una estrella 7010,48 dólares, los de dos estrellas llegan a los 15370,28 dólares y los de tres estrellas registran 48753,51 dólares. Esto indica que los hoteles que se encuentran en la categoría tres son los que tienen la mejor relación entre servicios que prestan y precio de habitación, en este sentido son los que tienen la mayor rentabilidad con respecto a la inversión realizada.

Los costos medios mensuales para el año 2018 de los servicios públicos y mantenimiento de los hoteles de una estrella son 400 dólares, dos estrellas 500 dólares, tres estrellas 1200 dólares, referente a servicios básicos de agua, luz y mantenimiento.

En cuanto al número de empleados, los hoteles de una estrella cuentan con 4 trabajadores de los cuales 3 son permanentes, los hospedajes de dos estrellas cuentan con 11 empleados, 4 son 
permanentes, mientras que, los hoteles de tres estrellas poseen 14 personas de ellos, 11 son permanentes. 


\section{Bibliografía}

Altamira, R., \& Muñoz, X. (2007). El turismo como motor de crecimiento.

Altamirano , F. (10 de Enero de 2016). El Telégrafo. Obtenido de https: / / www.eltelegrafo.com.ec/noticias/buen/1/el-ano-pasado-elturismo-interno-en-ecuador-movio-1-7-millones-diarios

Anuario Jurídico y Económico Escurialense, 677-710.

Arroyo, M. (18 de 04 de 2018). Revista Electrónica Cooperación Universidad Sociedad. Obtenido de file://C:/Users/CTE/ Downloads / 1284-25-3236-2-10-20180719.pdf

Aye Carrera, E. (2018). Ecuador Explorer. Obtenido de La Sierra Ecuatoriana: http://www.ecuadorexplorer.com/es/html/lasierra-ecuatoriana.html

Banco Central del Ecuador. (11 de Diciembre de 2014). Obtenido de https: / / www.bce.fin.ec/index.php/boletines-de-prensa-archivo/ item / 728-inversi\%C3\%B3n-formaci\%C3\%B3n-bruta-de-capitalfijo-privada-y-p\%C3\%BAblica

Banco Central del Ecuador. (enero de 2020). Banco Central del Ecuador.

Banco Mundial. (2018).

Banco Mundial. (2018). Obtenido de https: / / datos.bancomundial.org/ indicador $/$ NY.GDP.MKTP.CD?locations=EC

Bayas, F. (Octubre de 2017). Universidad Técnica de Ambato. Obtenido de http://repositorio.uta.edu.ec/jspui/ bitstream/123456789/26569/1/405\%20o.e..pdf

Brida, J., London, S., \& Rojas, M. (Julio - Septiembre de 2014). El turismo como fuente de crecimiento económico: impacto de las preferencias intertemporales de los agentes. Elsevier, 73(289), 59-77 . 
Brida, J., Monterubbianesi, P., \& Aguirre, S. (2011). Impactos del turismo sobre el crecimiento económico y el desarrollo. El caso de los principales destinos turísticos de Colombia. Pasos, Vol. 9 ( $\mathrm{N}^{\mathrm{o}} 2$ ), págs. 291-159.

Brida, J., Pereyra, G., \& Such, J. (2008). La contribución del turismo al crecimiento económico. . Cuadernos De Turismo(22), 35-46.

Buenos Aires: Pearson.

Caguana, K., \& Janeta, J. (2016). Análisis e impacto del turismo en el crecimiento económico del Ecuador período 2000 - 2014. Obtenido de shorturl.at/uAFY9

Caiza, R., \& Molina, E. (2012). Análisis histórico de la evolución del turismo en territorio ecuatoriano. 6-24.

Calderón, F. (2018).El sector turístico en el país . Economía e Investigación

Cangas, L., \& Romero, A. (2014). Desarrollo de la Hotelería y el turismo en el cantón Riobamba, Chimborazo, Ecuador. Retos Turísticos, 8-13.

Carrillo, E., \& Gómez , Y. (2017). Medición de la eficiencia de hoteles: caso de estudio en Colombia. Revista Virtual Universidad Católica del norte, 7. Obtenido de https://www.redalyc.org/ pdf/1942/194252398010.pdf

Charnes, K. (1997). Analisis Emvolvene de Datos. Scielo, 8490. Obtenido de http://scielo.sld.cu/scielo.php?script=sci_ arttext\&pid=S1561-30032009000200009

Chávez, N., Fernandez, J., \& Gómez, G. (09 de 2017). Actualidad y proyecciones de desarrollo del turismo. Revista UNIANDES Episteme, 276-287. 
Coordinación General de Estadística e Investigación del MINTUR. (2018). Obtenido de El turismo ecuatoriano creció un $11 \%$ en 2018 de http:// dspace.unach.edu.ec/bitstream/51000/4254/1/ UNACH-EC-ING-GEST-TUR-2017-0033.pdf de https:/ / servicios. turismo.gob.ec/index.php/turismo- cifras/2018-09-18-21-11-17/ establecimientos-registrados.

Dirección de Gestión de Turismo del Gobierno Autónomo Descentralizado de Riobamba . (2019). Obtenido de https:// riobamba.com.ec/es-ec/chimborazo/riobamba/rutas-paseos / lugares-turisticos-riobamba-a1ldysrfx.

Distrito Metroppolitano de Quito. (2012). Quito Turismo. Obtenido de https://www.nlarenas.com/2019/01/estadisticas-de-turistasextranjeros-en-ecuador-2018/

Dornbusch, R., Fischer, S., \& Startz, R. (2009). Macroeconomía. Mexico: McGraw-Hill.

EcuRed. (2018). Provincia de Chimborazo (Ecuador). Obtenido de https: / / www.ecured.cu/Provincia_de_Chimborazo_(Ecuador)

El Riobambeño. (2018). Riobamba, Turismo. Obtenido de https: / www. riobamba.co/turismo-riobamba/

El Telegrafo . (21 de 0 de 2017). Obtenido de https: / / www.eltelegrafo. com.ec/noticias / 484/25/el-certamen-mejora-el-movimiento-dedivisas

El Universo. (29 de Diciembre de 2014). Obtenido de https:/ / www. eluniverso.com/noticias / 2014/12/29/ nota / 4385096/ formacionbruta-capital-sube-dice-bce

El Universo. (9 de Abril de 2009). Obtenido de shorturl.at/muVW0 
Encuesta nacional de empleo desempleo y subempleo. (2017). Obtenido de https:/ / www.ecuadorencifras.gob.ec/documentos/web-inec/ EMPLEO/2017/Diciembre/122017_M.Laboral.pdf

Entorno turístico. (2018). Entorno turístico. Obtenido de ¿Cuáles son los tipos de turismo que existen?: https: / / www.entornoturistico.com / cuales-son-los-tipos-de-turismo-que-existen/

Erazo,N.E.(Juliode2009).UniversidadTecnológicaEquinoccial.Obtenido de http:/ / suia.ambiente.gob.ec/documents/783967/891135/ Propuesta+de+Desarrollo+Eco-+Tur\%C3\%ADstico+Para+De+ La+Provincia+De+Chimborazo.pdf / 2b3e7f16-5c4a-476f-9ec89dab58924372

GAD Municipal de Riobamba . (2017). Obtenido de https://www. gadmriobamba.gob.ec/index.php/ noticias / boletines-deprensa / 50-boletines-de-prensa-octubre-2017 / 1489-mejorarla-asistencia-a-los-prestadores-de-servicios-turisticos-es-elcompromiso-del-municipio

GAD Municipal de Riobamba. (2018). Boletín Demanda Turística. Riobamba. Obtenido de Municipio de Riobamba: http://www. gadmriobamba.gob.ec/

GAD Municipal de Riobamba. (2019). Boletín Demanda Turística.

Gallegos, J. F. (2016). El turismo comunitario como una alternativa de la dinamización de la economía popular y solidaria. Obtenido de http:/ / repositorio.uasb.edu.ec/handle/10644/5124

Gallegos, J. F. (2016). Obtenido de http://repositorio.uasb.edu.ec/ bitstream/10644/5124/1/T2041-MGD-Dillon-El\%20turismo.pdf

Go Ecuador. (s.f.). Obtenido de https://goecuador.net/atractivosturisticos/ provincia/ chimborazo-ecuador?fbclid=IwAR0GDZ7m 
LWiSc5uAfv1H5jCU3-nMi418wzNXC811qdnXUYOAQ77uZAD9 $\mathrm{M} 7 \mathrm{M}$

Gobernación de Chimborazo. (s.f.). Obtenido de http://www. gobernacionchimborazo.gob.ec/lugares-turisticos-de-laprovincia/

Gobernación de Chimborazo. (s.f.). Obtenido de http://www. gobernacionchimborazo.gob.ec/lugares-turisticos-de-laprovincia/

Guía Virtual de Turismo Accesible. (2014). Obtenido de http:// turismoaccesible.ec/site/destination/region-sierra/chimborazo /

Herrera, R. . (2012). Turismo Chimborazo. Obtenido de https:/ / aecidecuador.ec/wp-content/uploads/2013/12/Turismo-chimborazo. pdf

Hoteles Ecuador. (2019). Obtenido de https://www. hotelesecuador.com.ec/disptxt2.php? menu=Tips\% 20 viajero\& tip $=$ tips\& idiom $=1 \&$ fbclid=IwAR38GVs $\mathrm{Zw}_{-}$ Bgusex0KrptorTrRDbSyFNC19k7XXQaYqptd4qwx3R9u3yiXc

Ibarra, C. A. (2016). Tipo de cambio real y crecimiento: una revisión de la literatura. Revista de Economía Mexicana(1), 39 - 86.

Iwanatrip. (2019). Obtenido de https://iwanatrip.com/detalle/ Provincia-de-Chimborazo-Ecuador/1335

Lara, M. (2016). Administración Hotelera. scielo, 7. Obtenido de http: / / scielo.sld.cu/pdf/eyd/v157n2/eyd02216.pdf

Larraín, F., \& Sachs, J. (2002). Macroeconomía en una economía global.

Maldonado,C. y. (2009).Análisisemvolventededatos(DEA) paraelsector 
hotelero de Cartagena. scielo, 13. Obtenido de http: / / repositorio. unicartagena.edu.co:8080/jspui/ bitstream/11227/798/1/269-\%20 TTG\%20-

Márquez, C. (14 de Diciembre de 2018). El Comercio. Obtenido de https: / / www.elcomercio.com / actualidad / alausi-inversioneshoteleras-turismo-chimborazo.html

Mayorista de Turismo. (2017). Hotelería y turismo en el Ecuador. Obtenido de https: / www.hdp.com.ec/tarde-temprano-ecuadorturismo-la-hoteleria-van-reemplazar-los-ingresos-petroleros / ?fb clid=IwAR0NMVhUFQlqggfpYxXAfMirSmWkCbdpqqgKjcqU_ GlcL5rFEGyGrPNKLi4

Ministerio de Turismo. (2019). Feriados Nacionales. Obtenido dehttps: / / servicios.turismo.gob.ec/index.php/turismocifras / 2018-09-18-21-11-17/ feriados-nacionales

Ministerio de Turismo . (2015). Ecuador Potencia Turística . Obtenido de https://www.turismo.gob.ec/wp-content/uploads/2015/04/ Documento-Proyecto-Ecuador-Potencia-Tur\%C3\%ADstica.pdf

Ministerio de Turismo . (25 de 04 de 2018). Obtenido de https: / / www. turismo.gob.ec/aventura-naturaleza-y-leyendas-te-esperan-enchimborazo-tungurahua-y-cotopaxi /

Ministerio de Turismo. (2012). Obtenido de Ecuador Ama la Vida: https: / / www.turismo.gob.ec/wp-content/ uploads / downloads /2012/07/Presentacion_Taller_Presidente_FINAL.pdf

Ministerio de Turismo. (18 de Septiembre de 2018). Turismo en Cifras. Obtenido de Turismo en Cifras: https: / / servicios.turismo.gob.ec/ index.php/turismo-cifras / 2018-09-18-21-11-17 / establecimientosregistrados 
Ministerio de Turismo. (2012). Obtenido de https: / / www.turismo.gob. ec/inicia-intervencion-en-los-refugios-del-nevado-chimborazo-2 /

Ministerio de Turismo. (2014). Obtenido de https://www.turismo. gob.ec/wp-content / uploads / 2015 / 03/Rendici\%C3\%B3nCuentas-2014.pdf

Ministerio de Turismo. (2014). Obtenido de https: / / www.turismo.gob. ec/wp-content/ uploads / 2015 / 04/Documento-Proyecto-EcuadorPotencia-Tur $\%$ C3\%ADstica.pdf

Ministerio de Turismo. (2014). REGLAMENTO DE TRANSPORTE TERRESTRE. Obtenido de https://www.turismo.gob.ec/wpcontent / uploads / 2015 / 04 / REGLAMENTO-TRANSPORTETERRESTRE-TURISTICO.pdf

Ministerio de Turismo. (Noviembre de 2014). Obtenido de https:// www.turismo.gob.ec/wpcontent/uploads/2015/05/program_ excelencia_institucional.pdf

Ministerio de Turismo. (2016). El Turismo dinamizó en 285.5 millones de dólares la economía el 2016.

Ministerio de Turismo. (2017). Obtenido de https: / / servicios.turismo. gob.ec/ descargas / Turismo-cifras / AnuarioEstadistico/BoletinEstadisticas-Turisticas-2012-2016.pdf

Ministerio de Turismo. (18 de Septiembre de 2018). Turismo en Cifras. Obtenido de Turismo en Cifras: https: / / servicios.turismo.gob.ec/ index.php / turismo-cifras / 2018-09-18-21-11-17 / establecimientosregistrados

Ministerio de Turismo. (2018). Establecimientos registrados de alimentos y bebidas. Obtenido de https://servicios.turismo.gob.ec/index. php / turismo-cifras / 2018-09-18-21-11-17 / establecimientosregistrados 
Ministerio de Turismo. (2018). establecimientos-registrado. Obtenido dehttps: / / servicios.turismo.gob.ec/index.php/turismocifras/2018-09-18-21-11-17/ establecimientos-registrados

Ministerio de Turismo. (2018). Informe de Rendición de Cuentas de 2018. Obtenido de https://www.turismo.gob.ec/wp-content/ uploads / 2019/ 02 / Informe-Rendici\% C3\%B3n-de-Cuentas-2018MINTUR.pdf

Ministerio de Turismo. (2018). Ingreso de divisas por turismo crece en $46 \%$ durante el primer trimestre de 2018. Obtenido de https:/ / www.turismo.gob.ec/ingreso-de-divisas-por-turismo-crece-en-46durante-el-primer-trimestre-de-2018/

Ministerio de Turismo. (2018). Obtenido de https: / / servicios.turismo. gob.ec/index.php/turismo-cifras / 2018-09-19-20-08-01 / cuentasatelite-de-turismo

Ministerio de Turismo. (2019). Plan Nacional de Turismo 2030. Obtenido de https://www.turismo.gob.ec/wp-content/uploads/2020/03/ PLAN-NACIONAL-DE-TURISMO-2030-v.-final-Registro-Oficialsumillado-comprimido_compressed.pdf

Ministerio de Turismo.(04 de02 de2019). MinisteriodeTurismo.Obtenido de https://www.turismo.gob.ec/el-turismo-ecuatoriano-crecioun-11-en-2018 / ?fbclid=IwAR0ZbBMdbCwiJVd-mNVP5-GLaawC swupAvrhJ11eVIS2fa3hQiw1ooQwmro

Ministerio de Turismo. (2019). Promedio de llegada de visitantes extranjeros a Ecuador creció 4\% en 2019. Obtenido de https: / / www. turismo.gob.ec/ promedio-de-llegada-de-visitantes-extranjeros-aecuador-crecio-4-en-2019/

Ministerio de Turismo. (2020). ESTABLECIMIENTOS DE INTERMEDIACIÓN TURÍSTICA REGISTRADOS. Obtenido 
Ministerio de Turismo. (2020). Obtenido de https: / / servicios.turismo. gob.ec/ descargas / Turismo-cifras / AnuarioEstadistico/Boletin-deEstadisticas-Turisticas-2012-2016.pdf

Ministerio de Turismo. (2020). Obtenido de https://servicios. turismo.gob.ec/index.php/turismo-cifras/2018-09-19-17-01-51/ movimientos-internos-geovit

MINTUR. (2019). Obtenido de https:/ / www.turismo.gob.ec/la-feriaecuador-ama-la-vida-convoco-a-3-000-visitantes /

Monge, J., Gaviño, N., Vaca, C., \& Salazar , J. (2018). Observatorio Económico y Social de Tugurahua. Obtenido de https: / / www.uta. edu.ec/v3.2/uta/observatorioeconomico/boletin17.pdf

Montúfar Guevara, S.P. (01 de 2017). Modelo de gestión para el desarrollo sustentable del turismo en la ciudad de Riobamba. Quito.

Neffa, J. C. (1999). Actividad, trabajo y empleo: algunas reflexiones sobre un. Obtenido de http:/ / www.memoria.fahce.unlp.edu.ar/ art_revistas/pr.2956/pr.2956.pdf

Observatorio Económico de la UNACH. (2019). Boletin Nº 1. Riobamba: UNACH.

Observatorio Económico de la UNACH. (2020). Boletin N³. Riobamba: UNACH.

Organización Mundial del Turismo. (2018). ¿Por qué el turismo? Obtenido de http://www2.unwto.org/es/content/por-que-elturismo

Pichincha Universal . (10 de 02 de 2019). Pinchinca Uuniveral. Obtenido de https://www.pichinchauniversal.com.ec/2018-conozca-lascifras-del-turismo-interno-en-ecuador/ 
Quinllín, W. (2018). Indicadores de rendimiento financiero para mejorar la gestión de los establecimientos de alojamiento turístico en la ciudad de Riobamba. scielo, 13-15.

Quiroz, G. (27 de Abril de 2016). El Comercio. Obtenido de https:// www.elcomercio.com/actualidad/turismo-manabi-terremotoeconomia-inversion.html

Radio Huancavilca. (07 de 02 de 2018). Radio Huancavilca. Obtenido de https: / / radiohuancavilca.com.ec/noticias / 2018/02 / 07 / turismointerno-crece-ecuador-nuevas-tendencias /

Recuperado el 10 de 03 de 2020, de Banco Central del Ecuador.: https: / / contenido.bce.fin.ec/documentos / PublicacionesNotas / Catalogo/ CuentasNacionales / Anuales/Dolares/FBKFvd.pdf

Riobamba. Obtenido de http: / / www.gadmriobamba.gob.ec/

Rivera, C. (2015). Técnicas econométricas en detalle. el análisis envolvente de datos . scielo, 20.

Romero, B. (2015). Sector Turístico, buscando una luz al final del tunel.

Romero, B. (2016). revistagestion. Obtenido de https: / revistagestion. ec/sites/default/files/import/legacy_pdfs/265_003.pdf

Ronquillo, S. S. (2015). Dialnet. Obtenido de https:/ / dialnet.unirioja. es/descarga/articulo/6419737.pdf

Ruiz , E., \& Solis , D. (2007). TURISMO COMUNITARIO EN EL ECUADOR: Desarrollo y sosteniblidad social. Quito: Abya-Yala.

Ruiz, A., \& Ortiz, M. (03 de 2006). Escuela Politécnica Nacional. Obtenido de https:/ / bibdigital.epn.edu.ec/bitstream/15000/116/1/CD0131.pdf 
Somarriba, N. (2015). Aproximación a la medición de la calidad de vida social e individual en la europa comunitaria . scielo, 3-5.

Tapia,J.(2010).TurismoenelEcuador,unamiradaglobaldesdelageografía turística. Obtenido de http: / repositorio.puce.edu.ec/bitstream/ handle $/ 22000 / 5475 /$ T-PUCE-5703.pdf? sequence=1\&isAllowed=y

Tene, D. (2018). Estrategias empresariales y competitividad del hotel marqués de rio de la ciudad de Riobamba, provincia de Chimborazo. scielo, 15 .

Toledo, M. (2015). Constitución de la República del Ecuador. Ecuador, 7-8.

Velasco, A. (2017). CIRCUITO TURÍSTICO DEL NÚCLEO HISTÓRICO DE LA CIUDAD DE RIOBAMBA PARA LA DIVERSIFICACIÓN DE LA OFERTA A PERSONAS DEFICIENTES AUDITIVAS. Obtenido

Zaldivar, M. (2016). La expansión internacional de la industria hotelera. Scielo, 40. Obtenido de http: / / scielo.sld.cu/ scielo.php?script=sci_ arttext\&pid=S0252-85842016000200002

Zambrano, M., Navas, Y., Olivero, F., Cabezas, G., \& Franco, A. (17 de 06 de 2019). Pacarina del Sur. Obtenido de http: / / pacarinadelsur. com/ home / mar-del-sur/1286-capacidades-del-turismo-en-lacosta-ecuatoriana 


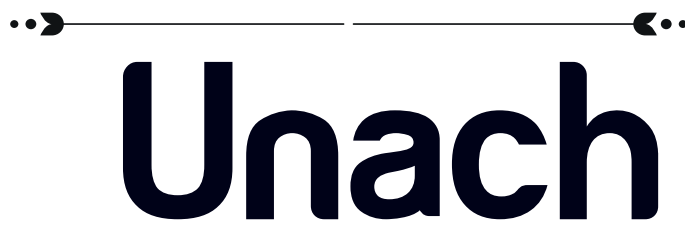

UNIVERSIDAD NACIONAL DE CHIMBORAZO

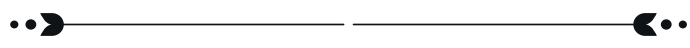

Gestión del Conocimiento y Propiedad Intelectual

SECTOR TURÍSTICO y su Impacto en la Economía Ecuatoriana; se publicó en el mes de abril de 2021 en la Universidad Nacional de Chimborazo. 


\section{SECTOR \\ TURÍSTICO \\ y su Impacto en la Economía Ecuatoriana}

El turismo hace referencia a los viajes que realizan las personas a distintos lugares de destino por un periodo consecutivo inferior a un año con fines de ocio, por negocios y otros (OMT, 1994). Ecuador paraíso turístico, en los últimos años ha sido un punto estratégico para turistas nacionales y extranjeros. A través de la difusión del patrimonio cultural e inmaterial único del país, que promueve la generación de ingresos.

El turismo en el Ecuador inició su desarrollo moderno en los años 50 del siglo pasado, pero principalmente en las tres últimas décadas empieza a consolidarse como actividad económica y socio-cultural de gran importancia (Ruiz \& Solis, 2007). Para este sector es importante crear normas o leyes, incluso incentivos que lo promuevan y al mismo tiempo salvaguarden los lugares visitados por los turistas.

En el Ecuador, durante el año 2017 se registraron 1'617.914 llegadas internacionales al país, lo que representa un crecimiento del $14 \%$ con relación al año 2016, que dejaron ingresos por $\$ 1,204.5$ millones. Con lo que se puede ver que el turismo cada vez tiene un crecimiento mayor, con lo que su impacto en la economía es cada vez más importante (Coordinación General de Estadística e Investigación del MINTUR, 2018).
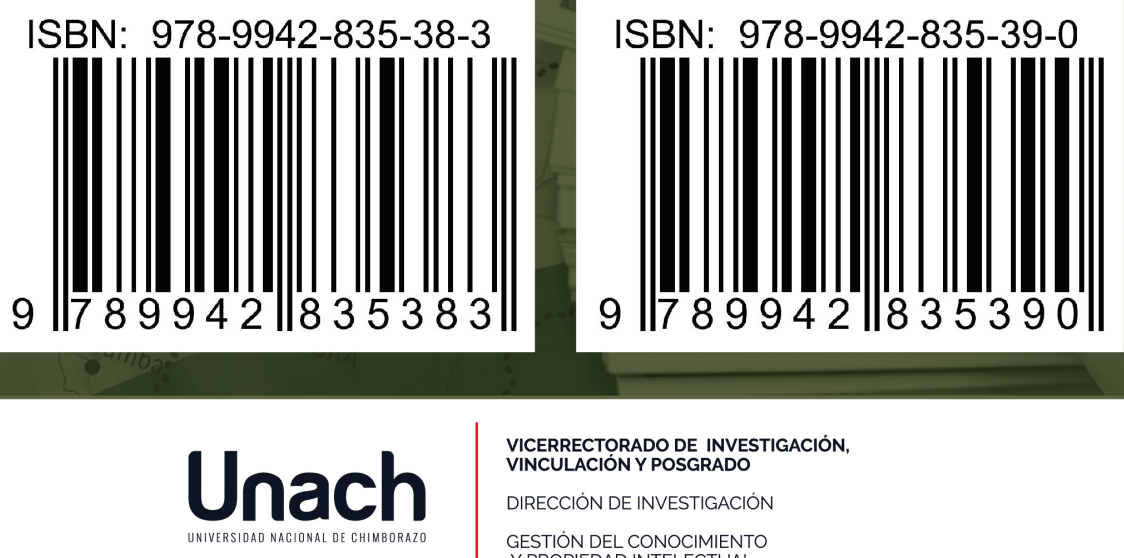